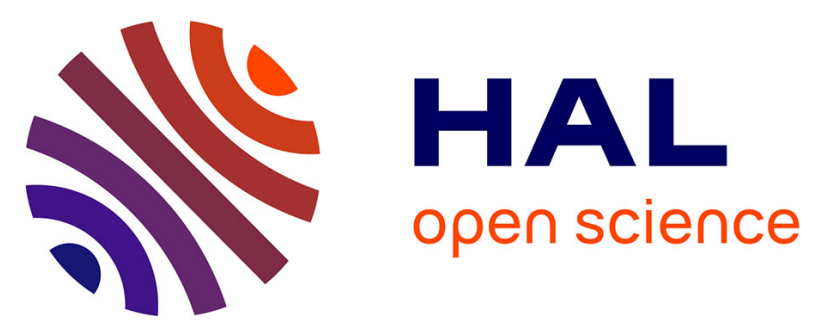

\title{
The water isotopic version of the land-surface model ORCHIDEE: implementation, evaluation, sensitivity to hydrological parameters
}

\author{
Camille Risi, Jérôme Ogée, Sandrine Bony, Thierry Bariac, Naama \\ Raz-Yaseef, Lisa Wingate, Jeffrey Welker, Alexander Knohl, Cathy \\ Kurz-Besson, Monique Leclerc, et al.
}

\section{To cite this version:}

Camille Risi, Jérôme Ogée, Sandrine Bony, Thierry Bariac, Naama Raz-Yaseef, et al.. The water isotopic version of the land-surface model ORCHIDEE: implementation, evaluation, sensitivity to hydrological parameters. Hydrology: Current Research, 2016, 7 (4), pp.100258. 10.4172/21577587.1000258. hal-03252151

\section{HAL Id: hal-03252151 \\ https://hal.science/hal-03252151}

Submitted on 10 Jun 2021

HAL is a multi-disciplinary open access archive for the deposit and dissemination of scientific research documents, whether they are published or not. The documents may come from teaching and research institutions in France or abroad, or from public or private research centers.
L'archive ouverte pluridisciplinaire $\mathbf{H A L}$, est destinée au dépôt et à la diffusion de documents scientifiques de niveau recherche, publiés ou non, émanant des établissements d'enseignement et de recherche français ou étrangers, des laboratoires publics ou privés. 


\title{
The water isotopic version of the land-surface model ORCHIDEE: implementation, evaluation, sensitivity to hydrological parameters
}

Camille Risi ${ }^{1}$, Jérôme Ogée ${ }^{2}$, Sandrine Bony ${ }^{1}$, Thierry Bariac ${ }^{3}$, Naama Raz-Yaseef ${ }^{4,5}$, Lisa Wingate ${ }^{2}$, Jeffrey Welker ${ }^{6}$, Alexander Knohl ${ }^{7}$, Cathy Kurz-Besson ${ }^{8}$, Monique Leclerc ${ }^{9}$, Gengsheng Zhang ${ }^{9}$, Nina Buchmann ${ }^{10}$, Jiri Santrucek ${ }^{11,12}$, Marie Hronkova ${ }^{11,12}$, Teresa David ${ }^{13}$, Philippe Peylin ${ }^{14}$, Francesca Guglielmo ${ }^{14}$

Preprint of paper published in Hydrol Current Res 2016, 7:4, DOI: 10.4172/2157-7587.1000258

${ }^{1}$ LMD/IPSL, CNRS, UPMC, Paris, France

2 INRA Ephyse, Villenave d'Ornon, France

${ }^{3}$ UMR 7618 Bioemco, CNRS-UPMC-AgroParisTech-ENS Ulm-INRA-IRD-PXII Campus AgroParisTech, Bâtiment EGER, Thiverval-Grignon, 78850 France

${ }^{4}$ Earth Sciences Division, Lawrence Berkeley National Laboratory, Berkeley, USA

${ }^{5}$ Department of Environmental Sciences and Energy Research, Weizmann Institute of Science, PO Box 26, Rehovot 76100, Israel

${ }^{6}$ Biology Department and Environment and Natural Resources Institute, University of Alaska, Anchorage, AK 99510, United States

${ }^{7}$ Bioclimatology, Faculty of Forest Sciences and Forest Ecology, Georg-August University of Göttingen, 37077 Göttingen, Germany

${ }^{8}$ Instituto Dom Luiz, Centro de Geofísica IDL-FCUL, Lisboa, Portugal

${ }^{9}$ University of Georgia, Griffin, GA 30223, United States

${ }^{10}$ Institute of Agricultural Sciences, ETH Zurich, Zurich, Switzerland

${ }^{11}$ Biology Centre ASCR, Branisovska 31, Ceske Budejovice, Czech Republic

${ }^{12}$ University of South Bohemia, Faculty of Science, Branisovska 31, Ceske Budejovice, Czech Republic

${ }^{13}$ Instituto Nacional de Investigação Agrária e Veterinária, Quinta do Marquês, Portugal

${ }^{14}$ LSCE/IPSL, CNRS, UVSQ, Orme des Merisiers, Gif-sur-Yvette, France

\begin{abstract}
Land-surface models (LSMs) exhibit large spread and uncertainties in the way they partition precipitation into surface runoff, drainage, transpiration and bare soil evaporation. To explore to what extent water isotope measurements could help evaluate the simulation of the soil water budget in LSMs, water stable isotopes have been implemented in the ORCHIDEE LSM. This article presents this implementation and the evaluation of simulations both in a stand-alone mode and coupled with an atmospheric general circulation model. ORCHIDEE simulates reasonably well the isotopic composition of soil, stem and leaf water compared to local observations at ten measurement sites. When coupled to LMDZ, it simulates well the isotopic composition of precipitation and river water compared to global observations. Sensitivity tests to LSM parameters are performed to identify processes whose representation by LSMs could be better evaluated using water isotopic measurements. We find that measured vertical variations in soil water isotopes could help evaluate the representation of infiltration pathways by multi-layer soil models. Measured water isotopes in rivers could help calibrate the partitioning of total runoff into surface runoff and drainage and the residence time scales in underground reservoirs. Finally, co-located isotope measurements in precipitation, vapor and soil water could help estimate the partitioning of infiltrating precipitation into bare soil evaporation.
\end{abstract}

\section{Introduction}

Land-surface models (LSMs) used in climate models exhibit a large spread in the way they partition radiative energy into sensible and latent heat ([Henderson-Sellers et al., 2003, Qu and Henderson-Sellers, 1998], precipitation into evapo-transpiration and runoff ([Koster and Milly, 1996, Polcher et al., 1996, Wetzel et al., 1996]), evapotranspiration into transpiration and bare soil evaporation ([Desborough et al., 1996, Mahfouf et al., 1996]), and 
runoff into surface runoff and drainage ([Ducharne et al., 1998, Boone and Coauthors, 2004, Boone et al., 2009]). This results in an large spread in the predicted response of surface temperature ([Crossley et al., 2000]) and hydrological cycle ([Gedney et al., 2000, Milly et al., 2005]) to climate change ([Crossley et al., 2000]) or land use change ([Lean and Rowntree, 1997, Pitman et al., 2009]). Therefore, evaluating the accuracy of the partitioning of precipitation into surface runoff, drainage, transpiration and bare soil evaporation (hereafter called the soil water budget) in LSMs is crucial to improve our ability to predict future hydrological and climatic changes.

The evaluation of LSMs is hampered by the difficulty to measure over large areas the different terms of the soil water budget, notably the evapo-transpiration terms and the soil moisture storage ([Moran et al., 2009, Seneviratne et al., 2010]). Single point measurements of evapo-transpiration fluxes ([Baldocchi et al., 2001]) and soil moisture ([Robock et al., 2000]) are routinely performed within international networks, but those measurements remain difficult to upscale to a climate model grid box due to the strong horizontal heterogeneity of the land surface ( [Vachaud et al., 1985, Rodriguez-Iturbe et al., 1995]). Spatially-integrated data such as river runoff observations are very valuable to evaluate soil water budgets at the regional scale ([Nijssen et al., 1997, Oki and Sud, 1998]), but are insufficient to constrain the different terms of the water budget. Additional observations are therefore needed.

In this context, water isotope measurements have been suggested to help constrain the soil water budget ([Gat, 1996, Henderson-Sellers et al., 2004]), its variations with climate or land use change ([Henderson-Sellers et al., 2001]), and its representation by large-scale models ([Henderson-Sellers, 2006, Wong, 2016]). For example, water stable isotope measurements in the different water pools of the soil-vegetation-atmosphere continuum have been used to quantify the relative contributions of transpiration and bare soil evaporation to evapo-transpiration ([Moreira et al., 1997, Yepez et al., 2003, Williams et al., 2004, Rothfuss et al., 2010]), to infer plant source water depth ([Brunel et al., 1997]), to assess the mass balance of lakes ([Krabbenhoft, 1990, Gibson, 2002, Gibson and Edwards, 2002]) or to investigate pathways from precipitation to river discharge ([Wels et al., 1991, Millet et al., 1997, Weiler et al., 2003, Ladouche et al., 2001]). These isotope-based techniques generally require high frequency isotope measurements and are best suitable for intensive field campaigns at the local scale. At larger spatial and temporal scales, some attempts have been made to use regional gradients in precipitation water isotopes for partitioning evapo-transpiration into bare soil-evaporation and transpiration ([Salati et al., 1979, Gat and Matsui, 1991, Jasechko et al., 2013]).

To explore to what extent water isotope measurements could be used to evaluate and improve land surface parameterizations, water isotopes were implemented in the LSM ORCHIDEE (ORganizing Carbon and Hydrology In Dynamic EcosystEms, [Ducoudré et al., 1993, Krinner et al., 2005]). This isotopic version of ORCHIDEE has already been used to explore how tree-ring cellulose records past climate variations ([Shi et al., 2011b]) and to investigate the continental recycling and its isotopic signature in Western Africa ([Risi et al., 2010a]) and at the global scale ([Risi et al., 2013].

The first goal of this article is to evaluate the isotopic version of the ORCHIDEE model against recently-madeavailable new datasets combining water isotopes in precipitation, vapor, soil water and rivers. The second goal is to evaluate the isotopic version of the ORCHIDEE model when coupled to the atmospheric general circulation model (GCM) LMDZ (Laboratoire de Météorologie Dynamique Zoom, [Hourdin et al., 2006]). The third goal is to perform sensitivity tests to LSM parameters to identify processes whose representation by LSMs could be better evaluated using water isotopic measurements.

After introducing notations and models in section 2, we present ORCHIDEE simulations in a stand-alone mode at measurement sites (section 3) and global ORCHIDEE-LMDZ coupled simulations (section 4).

\section{$2 \quad$ Notation and models}

\subsection{Notations}

Isotopic ratios $\left(\mathrm{HDO} / \mathrm{H}_{2}^{16} \mathrm{O}\right.$ or $\left.\mathrm{H}_{2}^{18} \mathrm{O} / \mathrm{H}_{2}^{16} \mathrm{O}\right)$ in the different water pools are expressed in \%o relative to a standard: $\delta=\left(\frac{R_{\text {sample }}}{R_{\text {SMOW }}}-1\right) \cdot 1000$, where $R_{\text {sample }}$ and $R_{S M O W}$ are the isotopic ratios of the sample and of the Vienna Standard Mean Ocean Water (V-SMOW) respectively ([Craig, 1961, Gonfiantini, 1978]). To first order, variations in $\delta D$ are similar to those in $\delta^{18} O$ but are 8 times larger. Deviation from this behavior can be associated with kinetic fractionation and is quantified by deuterium excess $\left(d=\delta D-8 \cdot \delta^{18} O\right.$, [Craig, 1961, Dansgaard, 1964]). Hereafter, we note $\delta^{18} O_{p}, \delta^{18} O_{v}, \delta^{18} O_{s}, \delta^{18} O_{\text {stem }}$ and $\delta^{18} O_{\text {river }}$ the $\delta^{18} O$ of the precipitation, atmospheric vapor, soil, stem, river water respectively. The same subscripts apply for $d$. 


\section{$2.2 \quad$ The LMDZ model}

LMDZ is the atmospheric GCM of the IPSL (Institut Pierre Simon Laplace) climate model ([Marti et al., 2005, Dufresne et al., 2012]). We use the LMDZ-version 4 model ([Hourdin et al., 2006]) which was used in the International Panel on CLimate Change's Fourth Assessment Report simulations ([Solomon, 2007, Meehl et al., 2007]). The resolution is $2.5^{\circ}$ in latitude, $3.75^{\circ}$ in longitude and 19 vertical levels. Each grid cell is divided into four subsurfaces: ocean, land ice, sea ice and land (treated by ORCHIDEE) (figure E.1a). All parameterizations, including ORCHIDEE, are called every $30 \mathrm{~min}$. The implementation of water stable isotopes is similar to that in other GCMs ([Joussaume et al., 1984, Hoffmann et al., 1998]) and has been described in [Bony et al., 2008, Risi et al., 2010b]. LMDZ captures reasonably well the spatial and seasonal variations of the isotopic composition in precipitation ([Risi et al., 2010b]) and water vapor ([Risi et al., 2012]).

\subsection{The ORCHIDEE model}

The ORCHIDEE model is the LSM component of the IPSL climate model. It merges three separate modules: (1) SECHIBA (Schématisation des EChanges Hydriques a l'Interface entre la Biosphère et l'Atmosphère, [Ducoudré et al., 1993, De Rosnay, 1999]) that simulates land-atmosphere water and energy exchanges, (2) STOMATE (Saclay-Toulouse-Orsay Model for the Analysis of Terrestrial Ecosystems, [Krinner et al., 2005]) that simulates vegetation phenology and biochemical transfers ; and (3) LPJ (Lund-Postdam-Jena, [Sitch, 2003]) that simulates the vegetation dynamics. Water stable isotopes were implemented in SECHIBA, and we use prescribed land cover maps so that the two other modules could be de-activated.

Each grid box is divided into up to 13 land cover types: bare soil, tropical broad-leaved ever-green, tropical broad-leaved rain-green, temperate needle-leaf ever-green, temperate broad-leaved ever-green, temperate broadleaved summer-green, boreal needle-leaf ever-green, boreal broad-leaved summer-green, boreal needle-leaf summergreen, C3 grass, C4 grass, C3 agriculture and C4 agriculture. Water and energy budgets are computed for each land cover type.

Figure E.1b illustrates how ORCHIDEE represents the surface water budget. Rainfall is partitioned into interception by the canopy and through-fall rain. Through-fall rain, snow melt, dew and frost fill the soil. The soil is represented by two water reservoirs: a superficial and a bottom one ([Choisnel, 1977, Choisnel et al., 1995]). Taken together, the two reservoirs have a water holding capacity of $300 \mathrm{~mm}$ and a depth of $2 \mathrm{~m}$. Soil water undergoes transpiration by vegetation, bare soil evaporation or runoff. Transpiration and evaporation rates depend on soil moisture to represent water stress in dry conditions. Runoff occurs when the soil water content exceeds the soil holding capacity and is partitioned into $95 \%$ drainage and $5 \%$ surface runoff ([Ngo-Duc, 2005]). Snowfall fills a single-layer snow reservoir, where snow undergoes sublimation or melt. By comparison, when not coupled to ORCHIDEE, the simple bucket-like LSM in LMDZ makes no distinction neither between bare soil evaporation and transpiration nor between surface runoff and drainage ([Manabe et al., 1965]).

Surface runoff and drainage are routed to the coastlines by a water routing model ([Polcher, 2003]). Surface runoff is stored in a fast ground water reservoir which feeds the stream reservoir with residence time of 3 days. Drainage is stored in a slow ground water reservoir which feeds the stream reservoir with residence time of 25 days. The water in the stream reservoir is routed to the coastlines with a residence time of 0.24 days.

\subsection{Implementation of water stable isotopes in ORCHIDEE}

We represent isotopic processes in a similar fashion as other isotope-enabled LSMs ([Riley et al., 2002, Cuntz et al., 2003, Aleinov and Schmidt, 2006, Yoshimura et al., 2006, Haese et al., 2013]). Some details of the isotopic implementation are described in [Risi, 2009]. In absence of fractionation, water stable isotopes $\left(\mathrm{H}_{2}^{16} \mathrm{O}, \mathrm{H}_{2}^{18} \mathrm{O}, \mathrm{HDO}, \mathrm{H}_{2}^{17} \mathrm{O}\right)$ are passively transferred between the different water reservoirs. We assume that surface runoff has the isotopic composition of the rainfall and snow melt that reach the soil surface. Drainage has the isotopic composition of soil water ([Gat, 1996]). We calculate the isotopic composition of bare soil evaporation or of evaporation of water intercepted by the canopy using the Craig and Gordon equation ([Craig and Gordon, 1965]) (appendix B.2). We neglect isotopic fractionation during snow sublimation (appendix B.1). We consider isotopic fractionation at the leaf surface (appendix B.4) but we assume that transpiration has the isotopic composition of the soil water extracted by the roots (appendix B.1).

In the control coupled simulation, we assume that the isotopic composition of soil water is homogeneous vertically and equals the weighted average of the two soil layers. However, transpiration, bare soil evaporation, surface runoff and drainage draw water from different soil water reservoirs whose isotopic composition is distinct 
([Brooks et al., 2010, Bowen, 2015, Good et al., 2015]). Therefore, we also implemented a representation of the vertical profile of the soil water isotopic composition (appendix $\mathrm{C}$ ).

\section{Stand-alone ORCHIDEE simulations at MIBA and Carbo-Europe measurement sites}

First, we performed simulations using ORCHIDEE as a stand-alone model at ten sites (section 3.2). Using isotopic measurements in soil, stem and leaf water (section 3.1), simulations are evaluated at each site at the monthly scale (section 3.4). Sensitivity tests to evapo-transpiration partitioning and soil infiltration processes are performed (section 3.5).

\subsection{Measurements used for evaluation}

To first order the composition of all land surface water pools is driven by that in the precipitation ([Kendall and Coplen, 2001]). Therefore, a rigorous evaluation of an isotope-enabled LSM requires to evaluate the difference between the composition in each water pool and that in the precipitation. Besides, to better isolate isotopic biases, we need a realistic atmospheric forcing. We tried to select sites where (1) isotope were measured in different water pools of the soil-plant-atmosphere continuum, during at least a full seasonal cycle and (2) meteorological variables were monitored at a frequency high enough (30 minutes) to ensure robust forcing for our model and (3) water vapor and precipitation were monitored to provide isotopic forcing for the LSM. Only two sites satisfy these conditions: Le Bray and Yatir. Relaxing some of these conditions, we got a more a representative set of ten sites representing diverse climate conditions (table 1, figure E.2, section 3.1.1).

\subsubsection{Description of the ten sites}

The ten sites belong to two kinds of observational networks: MIBA (Moisture Isotopes in the Biosphere and Atmosphere, [Twining et al., 2006, Knohl et al., 2007, Hemming et al., 2007]) or Carbo-Europe ([Valentini et al., 2000, Hemming et al., 2005]).

Le Bray site, in South-Eastern France, joined the MIBA and GNIP network in 2007. It is an even-aged Maritime pine forest with C3 grass understory that has been the subject of many eco-physiological studies since 1994, notably as part of the Carbo-Europe flux network ([Stella et al., 2009]). In 2007 and 2008, samples in precipitation, soil surface, needles, twigs and atmospheric vapor were collected every month and analyzed for $\delta^{18} O$ following the MIBA protocol ([Hemming et al., 2007, Wingate et al., 2010]). This site was also the subject of intensive campaigns where soil water isotope profiles were collected between 1993 and 1997, and in 2007 ([Wingate et al., 2009]).

The Yatir site, in Israel, is a semi-arid Aleppo pine forest. It is an afforestation growing on the edge of the desert, with mean-annual precipitation of $280 \mathrm{~mm}$ ([Grünzweig et al., 2009, Raz-Yaseef et al., 2009]). It has also been the subject of many eco-physiological studies as part of the Carbo-Europe flux network ([Raz-Yaseef et al., 2009]) and joined the MIBA network in 2004. It. In 2004-2005, samples of soil water at different depth, stems and needles were collected following the MIBA protocol. The water vapor isotopic composition has been monitored daily at the nearby Rehovot site $\left(31.9^{\circ} \mathrm{N}, 34.65 \mathrm{E}\right.$, [Angert et al., 2008]) and is used to construct the water vapor isotopic composition forcing (section 3.2). We must keep in mind however that although only $66 \mathrm{~km}$ from Yatir, Rehovot is much closer to the sea and is more humid than Yatir. The precipitation isotopic composition has been monitored monthly at the nearby GNIP station Beit Dagan $\left(32^{\circ} \mathrm{N}, 34.82^{\circ} \mathrm{E}\right)$ and is used to construct the precipitation isotopic composition forcing (section 3.2).

The Morgan-Monroe State Forest, Donaldson Forest and Anchorage sites are part of the MIBA-US (MIBAUnited States) network and are located in Indiana, in Florida and in Alaska respectively (table 1). Sampling took place in 2005 and 2006 according to the MIBA protocols. The Donaldson Forest site, which jointed the MIBA-US network in 2005, is located at the AmeriFlux Donaldson site near Gainesville, Florida, USA. The site is flat with an elevation of about $50 \mathrm{~m}$. It was covered by a forest of managed slash pine plantation, with an uneven understory composed mainly of saw palmetto, wax myrtle and Carolina jasmine ([Zhang et al., 2010]). The leaf area index was measured during a campaign in 2003 and estimated at 2.85. We use this value in our simulations.

The Mitra, Bily Kriz, Brloh, Hainich and Tharandt sites are part of the Carbo-Europe project. Hainich and Tharandt are located in Germany. The experimental site of Herdade da Mitra (230 m altitude, nearby Évora in southern Portugal) is characterized by a Mediterranean mesothermic humid climate with hot and dry summers. It is a managed agroforestry system characterized by an open evergreen woodland sparsely covered with Quercus suber 
L. and $Q$. ilex rotundifolia trees (30 trees/ha), with an understorey mainly composed of Cistus shrubs, and winterspring C3 annuals. The isotopic samplings of leaves, twigs, soil, precipitation and groundwater were performed on a seasonal to monthly basis. All samples where extracted and analyzed at the Paul Scherrer Institute (Switzerland).

Bily Kriz and Brloh are both located on the Czech Republic. Bily Kriz is an experimental site in Moravian-Silesian Beskydy Mountains (936 m a.s.l.) with detailed records of environmental conditions ([Kratochvilová et al., 1989]) It is dominated by Norway spruce forest. It joined the MIBA project in the season 2005. Brloh is a South Bohemian site in the Protected Landscape Area Blanskýles (630 m a.s.l.). It is dominated by deciduous beech forest and was used as MIBA sampling site from 2004 to 2010 ([Voelker et al., 2014]).

\subsubsection{Isotopic measurements}

Samples of soil water, stems and leaves were collected at the monthly scale. The MIBA and MIBA-US protocols recommend sampling the first 5-10 cm excluding litter and the Carbo-Europe protocol recommends sampling the first $5 \mathrm{~cm}$ ([Hemming et al., 2005]), but in practice the soil water sampling depth varies from site to site. At some sites, soil water was sampled down to $1 \mathrm{~m}$. For evaluating the seasonal evolution of soil water $\delta^{18} O$, we focus on soil samples collected in the first $15 \mathrm{~cm}$ only. Observed full soil water $\delta^{18} O$ profiles were used only at Le Bray and Yatir for evaluating the shape of simulated soil water $\delta^{18} O$ profiles (section 3.4.4).

Carbo-Europe samples were extracted and analyzed at the Department of Environmental Sciences and Energy Research, Weizmann Institute of Science, Israel. MIBA-US samples were extracted and analyzed at the Center for Stable Isotope Biogeochemistry of the University of California, Berkeley. Analytical errors for $\delta^{18} O$ in soil, stem and leaf water vary from $0.1 \%$ to $0.2 \%$ depending on the sites and involved stable isotope laboratory.

\subsubsection{Meteorological, turbulent fluxes and soil moisture measurements}

At most of the sites, meteorological parameters (radiation, air temperature and humidity, soil temperature and moisture) are continuously measured and are used to construct the meteorological forcing for ORCHIDEE.

Fluxes of latent and sensible energy are measured using the eddy co-variance technique and are used for evaluating the hydrological simulation (section 3.4.1). Gaps are filled using ERA-Interim reanalyses ([Dee et al., 2011]).

Soil moisture observations are available at most sites.

\subsection{Simulation set-up}

To evaluate in detail the isotope composition of different water pools, stand-alone ORCHIDEE simulations on the ten MIBA and Carbo-Europe sites (section 3.1.1) were performed. We prescribe the vegetation type and properties and the bare soil fraction based on local knowledge at each site (table 3).

ORCHIDEE offline simulations require as forcing several meteorological variables: near-surface temperature, humidity and winds, surface pressure, precipitation, downward longwave and shortwave radiation fluxes. At Le Bray and Yatir, we use local meteorological measurements available at hourly time scale. At other sites, we use local meteorological measurements when available and combine them with ERA-Interim reanalyses at 6-hourly time scale for missing variables. At other sites, no nearby meteorological measurements are available and only ERA-Interim reanalyses ([Dee et al., 2011]) are used (table 3).

At each site, we run the model three times over the first year of isotopic measurement (e.g. 2007 at Le Bray). These three years are discarded as spin-up. Then we run the model over the full period of isotopic measurements (e.g. 2007-2008 at Le Bray). We checked that at all sites, the seasonal distribution of $\delta^{18} O_{s}$, which is the slowest variable to spin-up, is identical between the last year of spin-up and the following year.

We force ORCHIDEE with monthly isotopic composition of precipitation and near-surface water vapor. Since we evaluate the results at the monthly time scale, we assume that monthly isotopic forcing is sufficient. At Le Bray and Yatir, monthly observations of isotopic composition of precipitation and near-surface water vapor are available to construct the forcing. Unfortunately, these observations are not available on the other sites. Therefore, we create isotopic forcing using isotopic measurements in the precipitation performed on nearby GNIP or USNIP stations (section 4.3.1). To interpolate between the nearby stations, we take into account spatial gradients and altitude effects by exploiting outputs from an LMDZ simulation (appendix D). 


\subsection{Model-data comparison methods}

\subsubsection{Simulated isotopic composition in soil, stem and leaf water}

The soil profile option is activated in all our stand-alone ORCHIDEE simulations (appendix C). We compare the soil water samples collected in the first $15 \mathrm{~cm}$ of the soil (in the first $5-10 \mathrm{~cm}$ at many sites) to the soil water composition simulated in the uppermost layer.

The observed composition of stem water is compared to the simulated composition of the transpiration flux.

When comparing observed and simulated composition of leaf water, the Peclet effect, which mixes stomatal water with xylem water (appendix B.7), is deactivated. Neglecting the Peclet effect may lead to overestimate of $\delta^{18} O_{\text {leaf }}$ values (section 3.4 .5$)$.

\subsubsection{Impact of the temporal sampling}

Over the ten sites, samples were collected during specific days and hours. This temporal sampling may induce artifacts when comparing observations to monthly-mean simulated ORCHIDEE values. For soil and stem water, the effect of temporal sampling can be neglected because simulated soil and stem water composition vary at a very low frequency. For leaf water however, there are large diurnal variations ([Lai et al., 2006a]). For example, if leaf water is sampled every day at noon when $\delta^{18} O_{\text {leaf }}$ is maximum, then observed $\delta^{18} O_{\text {leaf }}$ will be more enriched than monthly-mean $\delta^{18} O_{\text {leaf }}$. The exact sampling time is available for Le Bray site only, where we will estimate the effect of temporal sampling in section 3.4.5.

\subsubsection{Spatial heterogeneities}

We are aware of the scale mismatch between punctual in-situ measurements and an LSM designed for large scales (a typical GCM grid box is more than $100 \mathrm{~km}$ wide). However, for soil moisture it has been shown that local measurements represent a combination of small scale $(10-100 \mathrm{~m})$ variability ([Vachaud et al., 1985, Rodriguez-Iturbe et al., 1995]) and a large-scale (100-1000km) signal ([Vinnikov et al., 1996]) that a large-scale model should capture ([Robock et al., 1998]). The sampling protocol allows us to evaluate the spatial heterogeneities. For example at Le Bray, two samples were systematically taken a few meters apart, allowing us to calculate the difference between these two samples. On average over all months, the difference between the two samples is $3.5 \%$ for $\delta^{18} O_{s}, 4.8 \%$ for $\delta^{18} O_{\text {stem }}$ and $1.3 \%$ for $\delta^{18} O_{\text {leaf }}$. At Yatir, samples were taken several days every month, allowing us to calculate a standard deviation between the different samples for every month. On average of all months, the standard deviation is $0.9 \%$ for $\delta^{18} O_{s}$, $0.4 \%$ for $\delta^{18} O_{\text {stem }}$ and $1.2 \%$ for $\delta^{18} O_{\text {leaf }}$. These error bars need to be kept in mind when assessing model-data agreement.

\subsubsection{Soil moisture}

Soil moisture have a different physical meaning in observations and model. Soil moisture is measured as volumetric soil water content (SWC) and expressed in \%. In ORCHIDEE, the soil moisture is expressed in mm and cannot be easily converted to volumetric soil water content: the maximum soil water holding capacity of $300 \mathrm{~mm}$ and soil depth of $2 \mathrm{~m}$ are arbitrary choices and do not reflect realistic values at all sites. In LSMs, soil moisture is more an index than an actual soil moisture content ([Koster and Milly, 1996]). In this version of ORCHIDEE in particular, it is an index to compute soil water stress, but it was not meant to be compared with soil water content measurements. Therefore, to compare soil moisture between model and observations, we normalize values to ensure that they remains between 0 and 1 . The observed normalized $\mathrm{SWC}$ is calculated as $\frac{S W C-S W C_{\min }}{S W C_{\max }-S W C_{\min }}$ where $S W C_{\min }$ and $S W C_{\max }$ are the minimum and maximum observed values of monthly SWC at each site. Similarly, simulated normalized SWC is calculated as $\frac{S W C-S W C_{\min }}{S W C_{\max }-S W C_{\min }}$ where $S W C_{\min }$ and $S W C_{\max }$ are the minimum and maximum simulated values of monthly SWC at each site.

\subsection{Evaluation at measurement sites}

In this section, we evaluate the simulated isotopic composition in different water reservoirs of the soil-vegetationatmosphere continuum at the seasonal scale.

\subsubsection{Hydrological simulation}

Before evaluating the isotopic composition of the different water reservoirs, we check whether the simulations are reasonable from a hydrological point of view. ORCHIDEE captures reasonably well the magnitude and seasonality 
of the latent and sensible heat fluxes at most sites (figures E.3 and E.4, left column). At Le Bray for example, the correlation between monthly values of evapo-transpiration is 0.98 and simulated and observed annual mean evapo-transpiration rates are $2.4 \mathrm{~mm} / \mathrm{d}$ and $2.0 \mathrm{~mm} / \mathrm{d}$ respectively. However, the model tends to overestimate the latent heat flux at the expense of the sensible heat flux at several sites. This is especially the case at the dry sites Mitra and Yatir: the observed evapo-transpiration is at its maximum in spring and then declines in summer due to soil water stress. ORCHIDEE underestimates the effect of soil water stress on evapo-transpiration and maintains the evapo-transpiration too strong throughout the summer.

The soil moisture seasonality is very well simulated at all sites where data is available (figures E.3 and E.4, central column), except for a two-month offset at Yatir (figure E.3f).

\subsubsection{Water isotopes in the soil water}

The evaluation of the isotopic composition of soil water is crucial before using ORCHIDEE to investigate the sensitivity to the evapo-transpiration partitioning (section 3.5.1) or to infiltration processes (section 3.5.2), or in the future to simulate the isotopic composition of paleo-proxies such as speleothems ([McDermott, 2004]).

In observations, at all sites, $\delta^{18} O_{s}$ remains close to $\delta^{18} O_{p}$, within the relatively large month-to-month noise and spatial heterogeneities (figures E.3 and E.4, right column, brown). At most sites (Le Bray, Donaldson Forest, Anchorage, Bily Kriz and Hainich), observed $\delta^{18} O_{s}$ exhibits no clear seasonal variations distinguishable from monthto-month noise. At Morgan-Monroe and Mitra, and to a lesser extent at Brloh and Tharandt, $\delta^{18} O_{s}$ progressively increases throughout the spring, summer and early fall, by up to 5\% at Morgan-Monroe. The increase in $\delta^{18} O_{s}$ in spring can be due to the increase in $\delta^{18} O_{p}$. The increase in $\delta^{18} O_{s}$ in late summer and early fall, while $\delta^{18} O_{p}$ starts to decrease, is probably due to the enriching effect of bare soil evaporation. At Yatir, $\delta^{18} O_{s}$ increases by $10 \%$ from January to June, probably due to the strong evaporative enrichment on this dry site. Then, the $\delta^{18} O_{s}$ starts to decline again in July. This could be due to the diffusion of depleted atmospheric water vapor in the very dry soil.

ORCHIDEE captures the order of magnitude of annual-mean $\delta^{18} O_{s}$ on most sites, and captures the fact that it remains close to $\delta^{18} O_{p}$. ORCHIDEE captures the typical $\delta^{18} O_{s}$ seasonality, with an increase in $\delta^{18} O_{s}$ in springsummer at Morgan-Monroe, Donaldson Forest, Mitra and Bily Kriz. However, the sites with a spring-summer enrichment in ORCHIDEE are not necessarily those with a spring-summer enrichment in observations. This means that ORCHIDEE misses what controls the inter-site variations in the amplitude of the $\delta^{18} O_{s}$ seasonality. The seasonality is not well simulated at Yatir. This could be due to the missed seasonality in soil moisture and evapotranspiration (section 3.4.1). This could be due also to the fact that at Yatir ORCHIDEE underestimates the proportion of bare soil evaporation to total evapo-transpiration: less than $10 \%$ in ORCHIDEE versus $38 \%$ observed ([Raz-Yaseef et al., 2009]), which could explain why the spring enrichment is underestimated. Besides, ORCHIDEE does not represent the diffusion of water vapor in the soil, which could explain why the observed $\delta^{18} O_{s}$ decrease at Yatir in fall is missed.

When comparing the different sites, annual-mean $\delta^{18} O_{s}$ follows annual-mean $\delta^{18} O_{p}$, with an inter-site correlation of 0.99 in observations. Therefore, it is easy for ORCHIDEE to capture the inter-site variations in annual-mean $\delta^{18} O_{s}$. A more stringent test is whether ORCHIDEE is able to capture the inter-site variations in annual-mean $\delta^{18} O_{s}-\delta^{18} O_{p}$. This is the case, with a correlation of 0.85 (figure E.5a) between ORCHIDEE and observations. In ORCHIDEE (and probably in observations), spatial variations in $\delta^{18} O_{s}-\delta^{18} O_{p}$ are associated with the relative importance of bare soil evaporation (detailed in section 3.5.1).

\subsubsection{Water isotopes in the stem water}

In observations, observed $\delta^{18} O_{\text {stem }}$ exhibits no seasonal variations distinguishable from month-to-month noise (figures E.3 and E.4, right column, blue). At Le Bray, Yatir, Mitra, Brloh, Hainich, observed $\delta^{18} O_{\text {stem }}$ is more depleted than the surface soil water. It likely corresponds to the $\delta^{18} O$ values in deeper soil layers, suggesting that the rooting system is quite deep. For example, at Mitra, the root system reaches least $6 \mathrm{~m}$ deep, and could at some places reach as deep as $13 \mathrm{~m}$ where it could use depleted ground water. At Donaldson Forest, Morgan-Monroe, Anchorage and Tharandt, $\delta^{18} O_{\text {stem }}$ is very close to $\delta^{18} O_{s}$, maybe reflecting small vertical variations in isotopic composition within the soil or shallow root profiles.

At Bily Kriz, observed $\delta^{18} O_{\text {stem }}$ is surprisingly more enriched than surface soil water. Several hypotheses could explain this result: (1) the surface soil water could be depleted by dew or frost at this mountainous, foggy site; (2) spruce has shallow roots and therefore sample soil water that is not so depleted; (3) the twigs that were sampled were relatively young so that evaporation from their surface could have occurred when they were still at tree; (4) twigs were sampled in sun-exposed part of the spruce crowns during sunny conditions, which could favor some 
evaporative enrichment. Additional measurements show a lower Deuterium excess in the stem water compared to the soil water, supporting evaporative enrichment of stems.

ORCHIDEE captures the fact that $\delta^{18} O_{\text {stem }}$ is nearly uniform throughout the year. As for soil water, it is easy for ORCHIDEE to capture the inter-site variations in annual-mean $\delta^{18} O_{\text {stem }}$ (inter-site correlation between ORCHIDEE and observations of 0.90). ORCHIDEE is able to capture some of the inter-site variations in annualmean $\delta^{18} O_{\text {stem }}-\delta^{18} O_{p}$, with a inter-site correlation between ORCHIDEE and observations of 0.60. However, ORCHIDEE simulates $\delta^{18} O_{\text {stem }}$ values that are very close to $\delta^{18} O_{s}$ values (figure E.5b). It is not able to capture $\delta^{18} O_{\text {stem }}$ values that are either more enriched or more depleted than $\delta^{18} O_{s}$. This could be due to the fact that ORCHIDEE underestimates vertical variations in soil isotopic composition (section 3.4.4). Also, ORCHIDEE is not designed to represent deep ground water sources or photosynthesizing twigs.

\subsubsection{Vertical profiles of soil water isotope composition}

At Le Bray, we compare our offline simulation for 2007 with soil profiles collected from 1993 to 1997 and in 2007 (figure E.6a-b). The year mismatch adds a source of uncertainty to the comparison. In summer (profiles of August 1993 and September 1997), the data exhibits an isotopic enrichment at the soil surface of about 2.5\%o compared to the soil at $1 \mathrm{~m}$ depth (figure E.6a), likely due to surface evaporation ([Mathieu and Bariac, 1996]). Then, by the end of September 1994, the surface becomes depleted, likely due to the input of depleted rainfall. Previously enriched water remains between 20 and $60 \mathrm{~cm}$ below the ground, suggesting an infiltration through piston-flow ([Gazis and Geng, 2004]). ORCHIDEE predicts the summer isotopic enrichment at the surface, but slightly later in the season (maximum in September rather than August) and underestimates it compared to the data (1.5\% enrichment compared to $2.5 \%$ observed, figure E.6b). The model also captures the surface depletion observed after the summer, as well as the imprint of the previous summer enrichment at depth. However, ORCHIDEE simulates the surface depletion in December, whereas the surface depletion can be observed sooner in the data, at the end of September 1994.

At Yatir, observed profiles exhibit a strong isotopic enrichment from deep to shallow soil layers in May-June by up to $10 \%$ (figure E.6c). As for Le Bray, the model captures but underestimates this isotopic enrichment in spring and summer by about 3\% (figure E.6d). This discrepancy could be the result of underestimated bare soil evaporation. Observed profiles also feature a depletion at the surface in winter that the model does not reproduce. This depletion could be due to back-diffusion of depleted vapor in dry soils ([Barnes and Allison, 1983, Allison et al., 1983, Mathieu and Bariac, 1996, Braud et al., 2009b]), a process that is not represented in ORCHIDEE but likely to be significant in this region. Soil evaporation fluxes measured with a soil chamber at Yatir shows that when soils are dry, there is adsorption of vapor from the atmosphere to the dry soil pores before sunrise and after sunset ([Raz-Yaseef et al., 2012]).

\subsubsection{Water isotopes in leaf water}

It is important to evaluate the simulation of the isotopic composition of leaf water by ORCHIDEE if we want to use this model in the future for the simulation of paleo-climate proxies such tree-ring cellulose ([McCarroll and Loader, 2004, Shi et al., 2011a]), for the simulation of the isotopic composition of atmospheric $\mathrm{CO}_{2}$ which may be used to partition $\mathrm{CO}_{2}$ fluxes into respiration from vegetation and soil ([Yakir and Wang, 1996, Yakir and Sternberg, 2000]) or for the simulation of the isotopic composition of atmospheric $O_{2}$ which may be used to infer biological productivity ([Bender et al., 1994, Blunier et al., 2002]).

In the observations, $\delta^{18} O_{\text {leaf }}$ exhibits a large temporal variability reflecting a response to changes in environmental conditions (e.g. relative humidity and the isotopic composition of atmospheric water vapor). At all sites except at Yatir, $\delta^{18} O_{\text {leaf }}$ is most enriched in summer than in winter, by up to $15 \%$. (figures E.3 and E.4, right column, green). This is because the evaporative enrichment is maximum in summer due to drier and warmer conditions .

ORCHIDEE captures the maximum enrichment in summer. However, ORCHIDEE underestimates the annualmean $\delta^{18} O_{\text {leaf }}$ at most sites (figure E.5). This could be due to the fact that most leaf samples were collected during the day, when the evaporative enrichment is at its maximum, while for ORCHIDEE we plot the daily-mean $\delta^{18} O_{\text {leaf }}$. At Le Bray, if we sample the simulated $\delta^{18} O_{\text {leaf }}$ during the correct days and hours, simulated $\delta^{18} O_{\text {leaf }}$ increases by $4 \%$ in winter and by $10 \%$ in summer. Such an effect can thus quantitatively explain the model-data mismatch. After taking this effect into account, simulated $\delta^{18} O_{\text {leaf }}$ may even become more enriched than observed. This is the case at Le Bray, especially in summer. The overestimation of summer $\delta^{18} O_{\text {leaf }}$ could be due to neglecting diffusion in leaves or non-steady state effects (appendix B.4).

Again, Yatir is a particular case. Minimum $\delta^{18} O_{\text {leaf }}$ occurs in spring-summer while the soil evaporative enrichment is maximum. In arid regions and seasons, leaves may close stomata during the most stressful periods of the 
day, inhibiting transpiration, and thus retain the depleted isotopic signal associated with the moister conditions of the morning ([Yakir and Yechieli, 1995, Gat et al., 2007]). ORCHIDEE does not represent this process and thus simulates too enriched $\delta^{18} O_{\text {leaf }}$.

\subsubsection{Summary}

Overall, ORCHIDEE is able to reproduce the main features of the seasonal and vertical variations in soil water isotope content, and seasonal variations in stem and leaf water content. Discrepancies can be explained by some sampling protocols, by shortcomings in the hydrological simulation or by neglected processes in ORCHIDEE (e.g. fractionation in the vapor phase).

The strong spatial heterogeneity of the land surface at small scales does not prevent ORCHIDEE from performing reasonably well. This suggests that in spite of some small-scale spatial heterogeneities at each site, local isotope measurements contain large-scale information and are relevant for the evaluation of large-scale LSMs.

\subsection{Sensitivity analysis}

\subsubsection{Sensitivity to evapo-transpiration partitioning}

Several studies have attempted to partition evapo-transpiration into the transpiration and bare soil evaporation terms at the local scale ([Moreira et al., 1997, Yepez et al., 2003, Williams et al., 2004, Wang et al., 2010]). Estimating $E / E T$, where $E$ is the bare soil evaporation and $E T$ is the evapo-transpiration, requires measuring the isotopic composition of soil water, stem water and of the evapo-transpiration flux. The isotopic composition of the evapo-transpiration can be estimated through "Keeling plots" approach ([Keeling, 1961]), but this is costly ([Moreira et al., 1997]) and the assumptions underlying this approach are not always valid ([Noone et al., 2012]).

Considering a simple soil water budget at steady state and with vertically-uniform isotopic distribution (appendix $\mathrm{E})$, we show that although estimating $E / E T$ requires measuring the isotopic composition of the evapo-transpiration flux, estimating $E / I$ (where $I$ is the precipitation that infiltrates into the soil) requires measuring temperature, relative humidity $(h)$ and the isotopic composition of the soil water $\left(\delta^{18} O_{s}\right)$, water vapor $\left(\delta^{18} O_{v}\right)$ and precipitation $\left(\delta^{18} O_{p}\right)$ only. Such variables are available from several MIBA and Carbo-Europe sites. More specifically, $E / I$ is proportional to $\delta^{18} O_{p}-\delta^{18} O_{s}$ (appendix E):

$$
E / I=\frac{\alpha_{e q} \cdot \alpha_{K} \cdot(1-h) \cdot\left(\delta^{18} O_{p}-\delta^{18} O_{s}\right)}{\left(\delta^{18} O_{s}+10^{3}\right) \cdot\left(1-\alpha_{e q} \cdot \alpha_{K} \cdot(1-h)\right)-\alpha_{e q} \cdot h \cdot\left(\delta^{18} O_{v}+10^{3}\right)}
$$

where $\alpha_{e q}$ and $\alpha_{K}$ are the equilibrium and kinetic fractionation coefficients respectively.

Below, we show that this equation can apply to annual-mean quantities, neglecting effects associated with daily or monthly co-variations between different variables. We investigate to what extent this equation allows us to estimate the magnitude of $E / I$ at local sites.

At the Yatir site, all the necessary data for equation 3.1 is available. An independent study has estimated $E / I=38 \%$ ([Raz-Yaseef et al., 2009]). Using annually averaged observed values $\left(\delta^{18} O_{p}=-5.1 \%\right.$ and $\delta^{18} O_{s}=-3.7 \%$ in the the surface soil), we obtain $E / I=46 \%$. However, in ORCHIDEE, the annually averaged surface $\delta^{18} O_{s}$ is $0.8 \%$ lower when sampled at the same days as in the data. When correcting for this bias, we obtain $E / I=28 \%$. Observed $E / I$ lies between these two estimates. This shows the applicability of this estimation method, keeping in mind that estimating $E / I$ is the most accurate where $E / I$ is lower.

When we perform sensitivity tests to ORCHIDEE parameters at the various sites, the main factor controlling $\delta^{18} O_{s}$ is the $E / I$ fraction. This is illustrated as an example at Le Bray and Mitra sites (figure E.7). Sensitivity tests to parameters as diverse as the rooting depth or the stomatal resistance lead to changes in $\delta^{18} O_{s}-\delta^{18} O_{p}$ and in $E / I$ that are very well correlated, as qualitatively predicted by equation E.4. This means that whatever the reason for a change in $E / I$, the effect on $\delta^{18} O_{s}-\delta^{18} O_{p}$ is very robust.

Quantitatively, the slope of $\delta^{18} O_{s}-\delta^{18} O_{p}$ as a function of $E / I$ among the ORCHIDEE tests is of $0.78 \%_{0} / \%$ $(\mathrm{r}=0.94, \mathrm{n}=6)$ at Le Bray and of $0.25 \% / \%(\mathrm{r}=0.999, \mathrm{n}=5)$ at Mitra, compared to about $0.25-0.3 \% / \%$ predicted by equation E.4. The agreement is thus very good at Mitra. The better agreement at Mitra is because it is a dry site where $E / I$ varies greatly depending on sensitivity tests. In contrast, Le Bray is a moist site where $E / I$ values remains small for all the sensitivity tests, so numerous effects other than $E / I$ and neglected in equation E.4 can impact $\delta^{18} O_{s}-\delta^{18} O_{p}$.

To summarize, local observations of $\delta^{18} O_{s}-\delta^{18} O_{p}$ could help constrain the simulation of $E / I$ in models. This would be useful since the evapo-transpiration partitioning has a strong impact on how an LSMs represents landatmosphere interactions ([Lawrence et al., 2007]). 


\subsubsection{Sensitivity to soil infiltration processes}

Partitioning between evapo-transpiration, surface runoff and drainage depends critically on how precipitation water infiltrates the soil ([Wetzel et al., 1996, Ducharne et al., 1998, Boone et al., 2009]), which is a key uncertainty even in multi-layer soil models where infiltration processes are represented explicitly ([De Rosnay, 1999]). It has been suggested that observed isotopic profiles could help understand infiltration processes at the local scale ([Gazis and Geng, 2004]). The capacity of ORCHIDEE to simulate soil profiles (section 3.4.4) allows us to investigate whether measured isotope profiles in the soil could help evaluate the representation of these processes also in large-scale LSMs.

With this aim, we performed sensitivity tests at Le Bray. The simulated profiles are sensitive to vertical water fluxes in the soil. When the diffusivity of water in the soil column is decreased by a factor 10 from 0.1 to 0.01 compared to the control simulation, the deep soil layer becomes more depleted by about 0.7\% (figure E.8, blue) and the isotopic gradient from soil bottom to top becomes $30 \%$ steeper in summer, because the enriched soil water diffuses slower through the soil column.

Simulated profiles are also sensitive to the way precipitation infiltrates the soil. When precipitation is added only to the top layer (piston-flow infiltration) the summer enrichment is reduced by mixing of the surface soil water with rainfall, and it propagates more easily to lower layers during fall and winter. Conversely, when rainfall is evenly spread throughout the soil column (a crude representation of preferential pathway infiltration), the surface enrichment is slightly more pronounced and the deep soil water is more depleted by up to $0.8 \%$ in winter (figure E.8, green). However, the observed surface depletion occurs in February with preferential pathways, compared to December in the piston-like in infiltration. The quick surface depletion observed after the summer suggests that infiltration is dominated by the piston-like mechanisms.

To summarize, we show that vertical and seasonal variations of $\delta^{18} O_{s}$ are very sensitive to infiltration processes, and are a powerful tool to evaluate the representation of these processes in LSMs.

\section{Global-scale simulations using the coupled LMDZ-ORCHIDEE model}

\subsection{Simulation set-up}

To compare with global datasets, we performed LMDZ-ORCHIDEE coupled simulations. In all our experiments, LMDZ three-dimensional fields of horizontal winds are nudged towards ECMWF (European Center for Medium range Weather Forecast) reanalyses ([Uppala et al., 2005]). This ensures a realistic simulation of the large-scale atmospheric circulation and allows us to perform a day-to-day comparison with field campaign data ([Yoshimura et al., 2008, Risi et al., 2010b]). At each time step, the simulated horizontal wind field $\vec{u}$ is relaxed towards the reanalysis following this equation:

$$
\frac{\partial \vec{u}}{\partial t}=\vec{F}+\frac{u_{o b s}-\vec{u}}{\tau}
$$

where $u_{o b s}$ is the reanalysis horizontal wind field, $\vec{F}$ is the effect of all simulated dynamical and physical processes on $\vec{u}$, and $\tau$ is a time constant set to $1 \mathrm{~h}$ in our simulations ([Coindreau et al., 2007]).

To compare with global datasets (sections 4.3.2 and 4.4), LMDZ-ORCHIDEE simulations are performed for the year 2006, chosen arbitrarily. We are not interested in inter-annual variations and focus on signals that are much larger. To ensure that the water balance is closed at the annual scale, we performed iteratively 10 times the year 2006 as spin-up. In these simulations, the Peclet and non-steady state effects are de-activated.

To compare with field campaign observations in 2002 and 2005 (section 4.2), we use simulations performed for these specific years, initialized from the 2006 simulation. In these simulations, we test activating or de-activating the Peclet effect.

In all LMDZ-ORCHIDEE simulations, canopy-interception was de-activated (consistent with simulations that our modeling group performed for the Fourth Assessment Report).

\subsection{Evaluation of water isotopes in leaf water at the diel scale during campaign cases}

\subsubsection{Daily data from field campaigns}

Two field campaigns are used to evaluate the representation of $\delta^{18} O_{\text {leaf }}$ diurnal variability. The first campaign covers six diurnal cycles in May and July 2002 in a grassland prairie in Kansas $\left(39.20^{\circ} \mathrm{N} 96.58^{\circ} \mathrm{W}\right.$, [Lai et al., 2006b]). 
The second campaign covers four diurnal cycles in June 2005 in a pine plantation in Hartheim, Germany $\left(7.93^{\circ} \mathrm{N}\right.$, $7.60^{\circ} \mathrm{E}$, [Barnard et al., 2007]).

Because meteorological and isotopic forcing are not available for the entire year, we prefer to compare these measurements with LMDZ-ORCHIDEE simulations. At both sites, the simulated $\delta^{18} O_{v}$ and $\delta^{18} O_{\text {stem }}$ are consistent with those observed (model-data mean difference lower than 1.4\% in Kansas and 0.4\% at Hartheim), allowing us to focus on the evaluation of leaf processes.

\subsubsection{Evaluation results}

At the Kansas grassland site, $\delta^{18} O_{\text {leaf }}$ exhibits a diel cycle with an amplitude of about $10 \%$ ([Lai et al., 2006b]). LMDZ-ORCHIDEE captures this diel variability, both in terms of phasing and amplitude (figure E.9). The model systematically overestimates $\delta^{18} O_{\text {leaf }}$ by about $4 \%$, in spite of the underestimation of the stem water by $1.4 \%$ on average. This may be due to a bias in the simulated relative humidity (LMDZ is on average $13 \%$ too dry at the surface, which translates into an expected enrichment bias of 3.9\% on the leaf water assuming steady state based on equation B.6 of appendix B.4) or to uncertainties in the kinetic fractionation during leaf water evaporation.

At the Hartheim pine plantation, $\delta^{18} O_{\text {leaf }}$ is on average $8 \%$ more depleted for current-year needles than for 1-year-old needles. Also, the observed diel amplitude is weaker for current-year needles (5 to 8\%) than for 1-yearold needles (10 to $15 \%$ ). These observations are consistent with a longer diffusion length for current-year needles $(15 \mathrm{~cm})$ than for 1-year-old needles $(5 \mathrm{~cm})$ ([Barnard et al., 2007]) and with a larger transpiration rate, leading to a stronger Peclet effect. When neglecting Peclet and non-steady state effects, ORCHIDEE simulates an average $\delta^{18} O_{\text {leaf }}$ close to that of 1-year-old needles, consistent with the small diffusion length and evaporation rate of these leaves. ORCHIDEE captures the phasing of the diurnal cycle, but underestimates the diel amplitude by about $4 \%$. This is probably due to the underestimate of the simulated diel amplitude of relative humidity by $20 \%$. Accounting for Peclet and non-steady state effects strongly reduces both the average $\delta^{18} O_{\text {leaf }}$ and its diel amplitude (dashed brown on figure E.9a), in closer agreement with current-year needles.

To summarize, ORCHIDEE simulates well the leaf water isotopic composition. The leaf water isotope calculation based on [Craig and Gordon, 1965] simulates the right phasing and amplitude for leaves that have short diffusive lengths or low transpiration rates. Non-steady state and diffusion effects need to be considered in other cases. By activating or de-activating these effects, ORCHIDEE can simulate all cases.

\subsection{Evaluation of water isotopes in precipitation}

\subsubsection{Precipitation datasets}

To evaluate the spatial distribution of precipitation isotopic composition simulated by the LMDZ-ORCHIDEE coupled model, we use data from the Global Network for Isotopes in Precipitation (GNIP, [Rozanski et al., 1993]), further complemented by data from Antarctica ([Masson-Delmotte et al., 2008]) and Greenland ([Masson-Delmotte et al., 2005]). We also use this network to construct isotopic forcing at sites where the precipitation was not sampled (section 3.2, appendix D), complemented with the USNIP (United States Network for Isotopes in Precipitation, [Vachon et al., 2007]) network.

\subsubsection{Evaluation results}

At the global scale, the LMDZ-ORCHIDEE coupled model reproduces the annual mean distribution in $\delta^{18} O_{p}$ and $d_{p}$ observed by the GNIP network reasonably well (figure E.10), with correlations of 0.98 and 0.46 and root mean square errors (RMSE) of $3.3 \%$ and $3.5 \%$ respectively.

This good model-data agreement can be obtained even when we de-activate ORCHIDEE. When we use LMDZ in a stand-alone mode, in which the isotope fractionation at the land surface is neglected ([Risi et al., 2010b]), the model-data agreement is as good as when we use LMDZ-ORCHIDEE. Therefore, fractionating processes at the land surface have a second order effect on precipitation isotopic composition, consistent with [Yoshimura et al., 2006, Aleinov and Schmidt, 2006, Haese et al., 2013, Wong, 2016].

To quantify in more detail the effect of fractionation at the land surface, we performed additional coupled simulations with LMDZ-ORCHIDEE. We compare the control simulation described above (ctrl) to a simulation in which fractionation at the land surface was de-activated (nofrac) (figure E.11). In nofrac, the composition of bare soil evaporation equals that of soil water. Even when restricting the analysis to continental regions, the spatial correlations between the ctrl and nofrac simulations are 0.999 and 0.95 for $\delta^{18} O_{p}$ and $d_{p}$ respectively, and the root mean square differences are $0.27 \%$ and $1.1 \%$ for $\delta^{18} O_{p}$ and $d_{p}$ respectively. This confirms that fractionation at 
the land surface has a second-order effect on precipitation isotopic composition compared to the strong impact of atmospheric processes.

However, to second order, a detailed representation of fractionation at the land surface lead to a slight improvement in the simulation of $\delta^{18} O_{p}$ and to a significant improvement in that of $d_{p}$. In ctrl, $\delta^{18} O_{p}$ is lower by up to $1.5 \%$ and $d_{p}$ higher by up to $5 \%$ than in nofrac over boreal continental regions such as Siberia, Canada and central Asia, consistent with the expected effect of fractionation at surface evaporation ([Gat and Matsui, 1991]). Taking into account fractionation at the land surface leads to a better agreement with the GNIP data over these regions, where $\delta^{18} O_{p}$ is overestimated by about $4 \% 0$ and $d_{p}$ underestimated by 4 to $7 \%$ when neglecting fractionation at the land surface. The effect of fractionation is maximal over these boreal regions because (1) the fraction of bare soil evaporation is maximal, (2) a significant proportion of evaporatively-enriched soil water is lost by drainage and (3) a larger proportion of the moisture comes from land surface recycling ([Yoshimura et al., 2004, van der Ent et al., 2010, Risi et al., 2013]). Similar results were obtained with other models ([Kanner et al., 2013]).

To summarize, LMDZ-ORCHIDEE simulates well the spatial distribution of precipitation isotopic composition, but this distribution is not a very stringent test for the representation of land surface processes in ORCHIDEE. In the next section, we argue that the distribution of river isotopic composition is a more stringent test.

\subsection{Evaluation of water isotopes in river water}

Large rivers integrate a wide range of hydrological processes at the scale of GCM grid boxes ([Abdulla et al., 1996, Nijssen et al., 1997, Bosilovich et al., 1999, Oki and Sud, 1998, Ducharne et al., 2003]). Here we evaluate the isotopic composition of river water simulated by ORCHIDEE using data collected by the Global Network for isotopes in Rivers (GNIR, [Vitvar et al., 2006, Vitvar et al., 2007]).

Observed annual mean $\delta^{18} O_{\text {river }}$ follows to first order the isotopic composition of precipitation ([Kendall and Coplen, 2001]), and is thus also well simulated by LMDZ-ORCHIDEE (figure E.12a,b), with a spatial correlation between measured and simulated $\delta^{18} O_{\text {river }}$ of 0.80 and a RMSE of 3.2\% over the 149 LMDZ grid boxes containing data. Regionally however, the $\delta^{18} O$ difference between precipitation and river water $\left(\delta^{18} O_{\text {river }}-\delta^{18} O_{p}\right)$ can be substantial and provides a stronger constraint for the model. Over South America, Europe and some parts of the US, the river water is typically $1 \%$ to $4 \%$ more depleted than the precipitation (figure E.12a), because precipitation contributes more to rivers during seasons when it is the most depleted ([Dutton et al., 2005]). In contrast, over central Asia or northern America, river water is more enriched than precipitation, due to evaporative enrichment of soil water ([Kendall and Coplen, 2001, Gibson et al., 2005, Dutton et al., 2005]). This is further confirmed by a simulation where fractionation at the land surface was neglected (not shown), for which the river water is in global average $5.0 \%$ more depleted.

ORCHIDEE reproduces moderately well the magnitude and patterns of $\delta^{18} O_{\text {river }}-\delta^{18} O_{p}$, with a spatial correlation of 0.39 and a RMSE of $2.7 \%$ over the $22 \mathrm{LMDZ}$ grid boxes that contain $\delta^{18} O_{\text {river }}$ observations. It simulates the negative values over the western US, Europe and South America and the positive value over Mongolia. However, the model does not capture the positive $\delta^{18} O_{\text {river }}-\delta^{18} O_{p}$ in Eastern US, though positive values are simulated further North. This suggests that such a diagnostic may help identify biases in the representation of the soil water budget, as discussed in the following section.

\subsection{Sensitivity to the representation of pathways from precipitation to rivers}

At the local scale, water isotopes have already been used to partition river discharge peaks into the contributions from recent rainfall and soil water ([Wels et al., 1991, Millet et al., 1997, Weiler et al., 2003]). Given the property of rivers to integrate hydrological processes at the basin scales ([Abdulla et al., 1996, Nijssen et al., 1997, Bosilovich et al., 1999, Oki and Sud, 1998, Ducharne et al., 2003]), we now explore to what extent $\delta^{18} O_{\text {river }}$ could help evaluate pathways from precipitation to rivers in LSMs. We illustrate this using seasonal variations in $\delta^{18} O_{\text {river }}$ on two well established GNIR and GNIP stations in Vienna (Danube river) and Manaus (the Amazon) (figure E.13). The seasonal cycle in $\delta^{18} O_{\text {river }}$ is attenuated compared to that in $\delta^{18} O_{p}$, and $\delta^{18} O_{\text {river }}$ lags $\delta^{18} O_{p}$ (by 5 month at Vienna and 1-3 months at Manaus).

LMDZ-ORCHIDEE (control simulation) simulates qualitatively well the amplitude and the phasing observed in $\delta^{18} O_{p}$ and $\delta^{18} O_{\text {river }}$. To understand better what determines the attenuation and lag of the seasonality in $\delta^{18} O_{\text {river }}$ compared to that in $\delta^{18} O_{p}$, we perform sensitivity tests to ORCHIDEE parameters. Parameters tested include the partitioning of excess rainfall into surface runoff and drainage and the residence time scale of different reservoirs (slow, fast and stream) in the routing scheme. River discharge is extremely sensitive to these parameters ([Guimberteau et al., 2008]). 
If all the runoff occurs as surface runoff (figure E.13, blue), then the seasonal cycle of $\delta^{18} O_{\text {river }}$ is similar to that of $\delta^{18} O_{p}$. This shows that the attenuation and lag of the seasonality in $\delta^{18} O_{\text {river }}$ compared to that in $\delta^{18} O_{p}$ are caused by the storage of water into the slow reservoir, which accumulates drainage water.

When the residence time scale of the slow reservoir is multiplied by 2 (i.e. the water from the slow reservoir is poured twice faster into the streams, figure E.13, red), the simulated lag of $\delta^{18} O_{\text {river }}$ at Vienna increases from 4 to 5 months (in closer agreement with the data). In contrast, the seasonal cycle in $\delta^{18} O_{\text {river }}$ is not sensitive to residence time scales in the stream and fast reservoirs, which are too short to have any impact at the seasonal scale.

To summarize, ORCHIDEE performs well in simulating the seasonal variations in $\delta^{18} O_{\text {river }}$. In turn, $\delta^{18} O_{\text {river }}$ observations could help estimate the proportion of surface runoff versus drainage and calibrate empirical residence time constants in the routing scheme, offering a mean to enhance model performance.

\subsection{Evapo-transpiration partitioning}

In this section, we generalize at the global scale our results on evapo-transpiration partitioning estimates (section 3.5.1).

We apply equation 3.1 to annual-mean outputs from a LMDZ-ORCHIDEE simulation. We compare $E / I$ estimated from equation 3.1 to $E / I$ directly simulated by LMDZ-ORCHIDEE. The spatial pattern of $E / I$ is remarkably well estimated by equation 3.1 (figure E.14). The equation captures the maximum over the Sahara, Southern South America, Australia, central Asia, Siberia and Northern America. The isotope-derived spatial distribution of $E / I$ correlates well with the simulated distribution $(\mathrm{r}=0.91)$. Average errors are lower than $50 \%$ of the standard deviation at the global scale. This confirms that co-variation between the different variables at sub-annual time scales has a negligible effect, so that the equation can be applied to annual-mean quantities. Generally, $E / I$ estimates are best where $E / I$ is relatively small.

To test the effect of the assumption that the soil water isotopic composition is vertically constant, we applied equation 3.1 using $\delta^{18} O_{s}-\delta^{18} O_{p}$ from a simulation with soil profiles activated. This assumption is a significant source of uncertainty on estimating $E / I$ (table 4 ). We also analyzed the effect of potential measurement errors in $\delta^{18} O_{s}, \delta^{18} O_{p}, \delta^{18} O_{v}$, temperature or relative humidity on the $E / I$ reconstruction. Results are relatively insensitive to small errors in these measurements (table 4). However, results are sensitive to the choice of the $n$ exponent in the calculation of the kinetic fractionation $\alpha_{K}$ (table 4): knowing the $n$ exponent with an accuracy of 0.07 (e.g. estimated $n$ ranges from 0.63 to 0.70 ) is necessary to estimate $E / I$ with an absolute precision of $2 \%$.

Finally, estimating $E / I$ using equation 3.1 bears additional sources of uncertainty in that we cannot estimate using the ORCHIDEE model. These are related to all processes that ORCHIDEE does not simulate. For example, ORCHIDEE underestimates or mis-represents the vertical isotopic gradients in soil water at some sites (section 3.4.4, appendix C.2) and does not represent the effect of water vapor diffusion in the soil (appendix C.2). These effects may disturb the proportionality between $E / I$ and $\delta^{18} O_{s}-\delta^{18} O_{p}$ in practical applications.

To summarize, co-located isotope measurements in precipitation, vapor and soil water could provide an accurate constrain on the proportion of bare soil evaporation to precipitation infiltration.

\section{Conclusion and perspectives}

The ORCHIDEE LSM, in which we have implemented water stable isotopes, reproduces the isotopic compositions of the different water pools of the land surface reasonably well compared to local data from MIBA and CarboEurope and to global observations from the GNIP and GNIR networks. Despite the scale mismatch between local measurements and a GCM grid box, and despite the strong spatial heterogeneity in the land surface, the capacity of ORCHIDEE to reproduce the seasonal and vertical variations in the soil isotope composition suggests that even local measurements can yield relevant information to evaluate LSMs at the large scale.

We show that the simulated isotope soil profiles are sensitive to infiltration pathways and diffusion rates in the soil. The spatial and seasonal distribution of the isotope composition of rivers is sensitive to the partitioning of total runoff into surface runoff and drainage and to the residence time scales in underground reservoirs. The isotopic composition of soil water is strongly tied to the fraction of infiltrated water that evaporates through the bare soil. These sensitivity tests suggest that isotope measurements, combined with more conventional measurements, could help evaluate the parameterization of infiltration processes, runoff parameterizations and the representation of surface water budgets in LSMs.

Evaluating an isotopic LSM requires co-located observations of the isotope composition in precipitation, vapor and soil at least at the monthly scale. However, such co-located measurements are still very scarce, and most MIBA and Carbo-Europe sites are missing one of the components. Therefore, for LSM evaluation purpose, we advocate 
for the development of co-located isotope measurements in the different water pools at each site, together with meteorological variables. Our results suggest that isotope measurements are spatially relatively well representative and that even monthly values are already valuable to identify model bias or to estimate soil water budgets. Therefore, in the perspective of LSM evaluation, if a compromise should be made with sampling frequency and spatial coverage, we favor co-located measurements of all the different water pools at the monthly scale on a few sites representative of different climatic conditions, rather than multiplying sites where water pools are not all sampled. Additionally, at each observation site, collecting different soil samples a few meters apart is helpful to check that they are spatial representative. In the future, development in laser technology ([Lee et al., 2007, Gupta et al., 2009]) will allow the generalization of water vapor isotope monitoring at the different sampling sites, which has long been a very tedious activity ([Angert et al., 2008]).

From the modeling point of view, kinetic fractionation processes during bare soil evaporation are a source of uncertainty, and a better understanding and quantification of this fractionation is necessary ([Braud et al., 2009b, Nusbaumer, 2016]). In addition, the accuracy of isotopic simulations by LSM is expected to improve as the representation of hydrological processes improves. In particular, given the importance of vertical water exchanges for the isotopic simulation, implementing water isotopes in a multi-layer hydrological parameterization with sufficient vertical resolution ([Riley et al., 2002]) is crucial. In the future, we plan to implement water isotopes in the latest version of ORCHIDEE, which is multi-layer and more sophisticated ([de Rosnay et al., 2000, Zhu et al., 2015, Ryder et al., 2016]). Finally, latest findings largely based on water isotopic measurements suggest that different water pools co-exist within a soil column and that evaporation, transpiration, runoff and drainage tap from these different pools ([Botter et al., 2011, Bowen, 2015, Evaristo et al., 2015]). These effects are not yet represented explicitly in global LSMs. These effects were mainly evidenced based on isotope measurements, and in turn, their representation expected to significantly impact isotopic simulations. Such feedbacks between isotopic research and hydrological parameterization improvements should lead to LSM improvements in the future. With this in mind, LSM inter-comparison projects would strongly benefit from including water isotopes as part of their diagnostics, in the lines of iPILSP (isotope counterpart of the Project for Intercomparison of Land-surface Parameterization Schemes, [Henderson-Sellers, 2006]).

\section{A Lists of abbreviations and symbols}

\begin{tabular}{|c|c|}
\hline Abbreviation & Meaning \\
\hline \hline LMDZ & Laboratoire de Météorologie Dynamique-Zoom: the atmospheric model \\
\hline ORCHIDEE & ORganizing Carbon and Hydrology In Dynamic EcosystEms: the land-surface model \\
\hline GCM & General circulation model \\
\hline LSM & land-surface model \\
\hline LAI & Leaf Area Index \\
\hline MIBA & Moisture In Biosphere and Atmosphere: network for water isotopes in soil, stem and \\
& leaf water \\
\hline MIBA-US & MIBA in the United States \\
\hline GNIP & Global Network for Isotopes in Precipitation \\
\hline USNIP & Global Network for Isotopes in Precipitation \\
\hline GNIR & European Center for Medium range Weather Forecast \\
\hline ECMWF & Root Mean Square Error \\
\hline RMSE & isotope counterpart of the Project for Intercomparison of Land-surface \\
\hline iPILPS & Parameterization Schemes \\
&
\end{tabular}




\begin{tabular}{|c|c|}
\hline Symbol & Meaning \\
\hline$\delta^{18} \mathrm{O}$ & Anomaly of $\mathrm{H}_{2}^{18} \mathrm{O} / \mathrm{H}_{2} \mathrm{O}$ ratio relatively to the mean ocean water (section 2.1 ), in \%o \\
\hline$d$ & Deuterium excess (section 2.1) \\
\hline$\delta^{18} O_{s}$ & Soil water $\delta^{18} O$ in $\%$ \\
\hline$\delta^{18} O_{\text {stem }}$ & Stem or twig water $\delta^{18} \mathrm{Oin} \%$ \\
\hline$\delta^{18} O_{\text {leaf }}$ & Leaf water $\delta^{18} \mathrm{Oin} \%$ \\
\hline$\delta^{18} O_{\text {river }}$ & River or stream water $\delta^{18} \mathrm{Oin} \%$ \\
\hline$d_{p}$ & Deuterium excess in precipitation \\
\hline$R$ & $\mathrm{H}_{2}^{18} \mathrm{O} / \mathrm{H}_{2} \mathrm{O}$ ratio \\
\hline$R_{s}$ & Isotopic ratio in the soil water \\
\hline$R_{v}$ & Isotopic ratio in the near-surface atmospheric water vapor \\
\hline$P$ & precipitation flux in $\mathrm{mm} / \mathrm{d}$ \\
\hline$E$ & bare soil evaporation flux in $\mathrm{mm} / \mathrm{d}$ \\
\hline $\mathcal{R}$ & surface runoff flux in $\mathrm{mm} / \mathrm{d}$ \\
\hline$D$ & drainage flux in $\mathrm{mm} / \mathrm{d}$ \\
\hline$I$ & infiltration flux in $\mathrm{mm} / \mathrm{d}: I=P-\mathcal{R}$ \\
\hline$R_{p}, R_{E}, R_{T}$, etc... & Isotopic ratio in the precipitation, bare soil evaporation, transpiration, etc... \\
\hline$\alpha_{e q}, \alpha_{K}$ & Equilibrium and kinetic fractionation coefficients \\
\hline$h$ & relative humidity \\
\hline
\end{tabular}

\section{B Representation of isotope fractionation during evaporation from land surface water pools}

\section{B.1 Processes for which we neglect fractionation}

Snow sublimation is associated with a slight fractionation due to exchanges between snow and vapor in snow pores ([Sokratov and Golubev, 2009, Ekaykin et al., 2009, Noone et al., 2012]). However, we assume that these effects are small enough to be neglected, as in other GCMs ([Hoffmann et al., 1998]).

Water uptake by roots has been shown to be a non-fractionating process ([Washburn and Smith, 1934, Barnes and Allison, 198 but fractionation at the leaf surface during transpiration impacts the composition of transpired fluxes at scales shorter than daily ([Lai et al., 2006a, Lee et al., 2007]). As the application of ORCHIDEE in the context of our study focuses mainly on time scales of a month or longer, we assume here that the transpiration and stem water have the composition of soil water extracted by the roots.

\section{B.2 Evaporation from bare soils and canopy-intercepted water}

We represent isotope fractionation during evaporation of soil and canopy-intercepted water using the model of [Craig and Gordon, 1965]: at any time $t$, the isotopic composition of evaporation $R_{E}$ is given by:

$$
R_{E}(t)=\frac{R_{l}(t)-\alpha_{e q} \cdot h \cdot R_{v}(t)}{\alpha_{K} \cdot \alpha_{e q} \cdot(1-h)}
$$

where $R_{l}$ and $R_{v}$ are the isotopic compositions of liquid water at the evaporative site and of water vapor respectively, $h$ is the relative humidity normalized to surface temperature, $\alpha_{e q}$ is the isotopic fractionation during liquid-vapor equilibrium ([Majoube, 1971b]) and $\alpha_{K}$ is the kinetic fractionation during water vapor diffusion. The kinetic fractionation during soil evaporation is still very uncertain ([Braud et al., 2009b, Braud et al., 2009a]). We use the very widespread formulation of [Stewart, 1975, Mathieu and Bariac, 1996]:

$$
\alpha_{K}=\left(\frac{D}{D_{i}}\right)^{n}
$$

where $D$ and $D_{i}$ are the molecular diffusivities of light and heavy water vapor in air, respectively, and $n$ is an exponent that depends on the flow regime (0.5, 0.67 and 1 for turbulent, laminar and stagnant regimes respectively) but remains difficult to estimate ([Braud et al., 2009b, Braud et al., 2009a]). In this study, we take $n=0.67$ for both evaporation of soil and canopy-intercepted water, corresponding to moist conditions in the case of soils ([Mathieu and Bariac, 1996]). However, we also tried 0.5 and 1.0 to estimate the range of uncertainty related to this parameter. The isotopic composition of precipitation is only slightly sensitive to the formulation of the kinetic 
fractionation: when $n$ varies from 0.5 to 1 , significant changes in $\delta^{18} O_{p}$ and $d_{p}$ are restricted to areas where bare soil covers more than $70 \%$. Even in those case, changes in $\delta^{18} O_{p}$ and $d_{p}$ never exceed $2 \%$ and $7 \%$ respectively. The impact is slightly stronger on soils. Varying $n$ from 0.5 to 1 leads to $\delta^{18} O_{s}$ variations of $2 \%$ in offline simulations on the Bray site, of the order of the observed average difference between two samples collected on the same day $(2.2 \%)$. In coupled simulations, the impact on $\delta^{18} O_{s}$ and $d_{s}$ reaches $8 \%$ and $20 \%$ respectively on very arid regions such as the Sahara.

To calculate the temporal mean isotopic composition of evaporation over the time step $\Delta t, \overline{R_{E}}$, we assume $R_{v}$ and $h$ are constant throughout each time step. On the other hand, we allow the isotopic ratio of liquid water to vary over the simulation time step $\Delta t$ following [Stewart, 1975]. While assuming constant $R_{l}$ is a valid assumption for models with very short time steps ([Braud et al., 2005]), it is not the case in ORCHIDEE $(\Delta t=30 \mathrm{~min})$. We then calculate $\overline{R_{E}}$ as:

$$
\overline{R_{E}}=\frac{R_{l 0} \cdot\left(1-f^{\beta+1}\right)-\gamma \cdot R_{v} \cdot f \cdot\left(1-f^{\beta}\right)}{1-f}
$$

where $R_{l 0}$ is the initial isotopic ratio of liquid water, $f$ is the remaining liquid fraction in the water reservoir affected by isotopic enrichment, and $\beta$ and $\gamma$ are parameters defined by [Stewart, 1975]:

$$
\beta=\frac{1-\alpha_{e q} \cdot \alpha_{K} \cdot(1-h)}{\alpha_{e q} \cdot \alpha_{K} \cdot(1-h)}
$$

and

$$
\gamma=\frac{\alpha_{e q} \cdot h}{1-\alpha_{e q} \cdot \alpha_{K} \cdot(1-h)}
$$

For canopy-intercepted water, the water reservoir is sufficiently small to assume that the water reservoir affected by isotopic enrichment is the total canopy-intercepted water. For soil evaporation on the other hand, we assume that the depth of the water reservoir affected by isotopic enrichment equals the average distance traveled by water molecules in the soil:

$$
L=\sqrt{K_{D} \cdot \Delta t}
$$

where $K_{D}$ is the effective self-diffusivity of liquid water in the soil column. Neglecting the dispersion term, $K_{D}$ is given by ([Munnich et al., 1980, Barnes and Allison, 1983, Barnes and Allison, 1988, Melayah et al., 1996, Braud et al., 2005]):

$$
K_{D}=D_{m} \cdot \tau \cdot \theta_{l}
$$

where $D_{m}=2.5 \cdot 10^{-9} \mathrm{~m}^{2} / \mathrm{s}$ is the molecular liquid water self-diffusivity ([Mills, 1973, Harris and Woolf, 1980]), $\tau$ is the soil tortuosity and $\theta_{l}$ is the volumetric soil water content. In the control simulation, we assume $\theta_{l} \cdot \tau=0.1$ leading to $L=0.67 \mathrm{~mm}$. This choice is consistent with a $\tau$ of 0.67 ([Braud et al., 2005]) and an average $\theta_{l}$ of about $15 \%$. At the Bray, measurements along profiles show $\theta_{l}$ varying from about 5 to $30 \%$. Since these values are difficult to constrain observationally and very variable spatially and temporally, sensitivity tests to $\theta_{l} \cdot \tau$ are performed and described in section 3.5.2. We neglect the vapor phase in the soil and associated fractionation and diffusion processes ([Melayah et al., 1996]).

\section{B.3 Dew formation}

We assume fractionation during dew and frost formation following a Rayleigh distillation of the vapor in the lowest $10 \mathrm{hPa}(\sim 80 \mathrm{~m})$ of the atmosphere. Since the atmospheric water vapor condenses in small proportion during frost and dew, this choice of the depth of atmosphere involved in the condensation has almost no impact on the composition of the dew and frost formed. Following common practice, we use equilibrium fractionation coefficient from [Merlivat and Nief, 1967], [Majoube, 1971a] and [Majoube, 1971b] and the kinetic fractionation formation of [Jouzel and Merlivat, 1984] with $\lambda=0.004$, whose choice has very little impact on the results.

\section{B.4 Leaf water evaporation}

\section{B.4.1 Steady-state}

At isotopic steady state, the composition of water transpired by the vegetation is equal to that of the soil water extracted by the roots. In default simulations, we assume that isotopic steady state for plant water is established 
at any time and we diagnose the composition of the leaf water at the evaporation site, $R_{e}^{S S}$, by inverting the Craig and Gordon equation ([Craig and Gordon, 1965]):

$$
R_{e}^{S S}=\alpha_{e q} \cdot\left(\alpha_{K} \cdot(1-h) \cdot R_{s}+h \cdot R_{v}\right)
$$

where $R_{s}$ and $R_{v}$ are the isotopic ratio in soil water and water vapor respectively, $h$ is the relative humidity normalized to surface temperature, $\alpha_{e q}$ is the isotopic fractionation during liquid-vapor equilibrium ([Majoube, 1971b]) and $\alpha_{K}$ is the kinetic fractionation during water vapor diffusion. We take the same kinetic fractionation formulation as for the soil evaporation (appendix B.2, [Stewart, 1975]), with $n=0.67$ ([Riley et al., 2002, Williams et al., 2004]). Leaf water compositions are significantly sensitive to parameter $n$, with variations of the order of $10 \%$ as $n$ varies from 0.5 to 1 . We assume that the leaf temperature used to calculate $\alpha_{e q}$ is equal to the soil temperature, but results are very little sensitive to this assumption.

\section{B.4.2 Non-stationary and diffusive effects}

The isotopic composition of leaf water has been the subject of many observational and numerical modeling studies ([Farquhar and Cernusak, 2005, Cuntz et al., 2007, Ogée et al., 2007, Wingate et al., 2010]). Several studies have shown that the composition of the leaves is affected by mixing with xylem water and by non-stationary effects ([Ogée et al., 2007, Cuntz et al., 2007, Dubbert et al., 2014]). Non-steady state effects are also incorporated in ORCHIDEE following [Farquhar and Cernusak, 2005]. The isotopic ratio in the leaf mesophyll $R_{L}^{S S}$ is the result of the mixing between leaf water at the evaporative site and xylem water (Peclet effect):

$$
R_{L}^{S S}=R_{e}^{S S} \cdot f+R_{s}(1-f)
$$

where $f$ is a coefficient decreasing as the Peclet effect increases:

$$
f=\frac{1-e^{-P}}{P}
$$

and $P$ is the Peclet parameter ([Cuntz et al., 2007, Barnard et al., 2007]):

$$
P=\frac{E \cdot L_{e f f}}{W \cdot D_{m}}
$$

$E$ is the transpiration rate per leaf area, $L_{e f f}$ is the effective diffusion length and $W$ is the leaf water content per leaf volume (assumed equal to $10^{3} \mathrm{~kg} / \mathrm{m}^{3}$, order of magnitude in [Barnard et al., 2007]). The Peclet number $P$ can be tuned by changing $L_{\text {eff }}$, that depends on leaf geometry and drought intensity (e.g. 7 to 12 mm in [Cuntz et al., 2007], 50 to $150 \mathrm{~mm}$ in [Barnard et al., 2007]). We take $L_{e f f}=8 \mathrm{~mm}$ to optimize our simulation on Hartheim (section 3).

For some simulations, we account for the effect of water storage in leaves (leading to some memory in the leaf water isotopic composition) following [Dongmann et al., 1974]). Assuming that $W$ is constant, we calculate the leaf lamina composition $R_{L}$ as ([Farquhar and Cernusak, 2005]):

$$
R_{L}(t)=R_{L}(t-d t) \cdot e^{-d t / \tau}+R_{L}^{S S}(t) \cdot\left(1-e^{-d t / \tau}\right)
$$

where

$$
\tau=\frac{W \cdot \alpha_{K} \cdot \alpha_{e q} \cdot f}{g}
$$

and $g$ is the sum of the total (stomatic and boundary layer) conductances. The isotopic composition of transpiration is then calculated so as to conserve isotope mass.

\section{Representation of the vertical distribution of soil water isotopic com- position}

\section{C.1 Principle}

In control simulations, we assume that the isotopic composition of soil water is homogeneous vertically and equals the weighted average of the two soil layers. In addition, to test this assumption, we implemented a representation of the vertical distribution of the soil water isotopic composition: the soil water is spread vertically between several 
layers. The first layer contains a water height $L=\sqrt{K_{D} \cdot \Delta t}$, where $K_{D}$ is the diffusivity of water molecules in water and $\Delta t$ is the time step of the simulation, and the other layers contain a water height resol $\cdot L$. The parameter resol can be tuned to find a compromise between vertical resolution and computational time. Layers are created from the top to bottom until all layers are full with water except the deepest one that contains the remaining soil water. For example, with $L=0.67 \mathrm{~mm}$, up to 16 layers can thus be created if the soil is saturated. Bare soil evaporation is extracted from the first layer. Transpiration is extracted from the different layers following a root extraction profile that reflects the sensitivity of transpiration to soil moisture ([Rosnay and Polcher, 1998]). Drainage takes water from the deepest layer. In the control simulation, rain and snow melt are added to the first layer (piston-like flow). In a sensitivity test, that can also be homogeneously distributed in the different layers, to crudely represent preferential pathways through fractures or pores in the soil.

At each time step, the soil water isotopic composition in each layer is re-calculated by taking into account the sources and sinks for each layer and ensuring that each layer remains full except the deepest one. Isotopic diffusion between adjacent layers is applied at each time step (equation B.5). The water budget of the total soil remains exactly the same as without vertical discretization.

\section{C.2 Evaluation for an idealized case}

The module representing vertical distribution of water isotopes in the soil is first evaluated for an idealized case when it is not yet embedded into ORCHIDEE.

First, we use a case in which the soil column evaporates at its top and is permanently refilled at the bottom by a water with $\delta^{18} \mathrm{O}$ of $-8 \%$ ([Braud et al., 2005]). The soil remains saturated, and we focus on the steady state reached after a few hundreds of days ([Braud et al., 2005]). An analytical solution is available for this case ([Zimmermann et al., 1967, Barnes and Allison, 1983]). The analytical solution and a much more sophisticated model of soil water isotopes (MuSICA, [Ogée et al., 2003]) yield very similar results (figure E.15a): the bottom of the soil is at $-8 \%$ while the top of the soil is enriched up to $15 \%$. The soil module of ORCHIDEE is able to reproduce these results when the value of $\theta_{l} \cdot \tau$ is set to be very low (0.001) and when the vertical resolution is sufficiently high (layers of $0.75 \mathrm{~mm}$ ). Whatever the value for $\theta_{l} \cdot \tau$, ORCHIDEE results become less sensitive to the vertical discretization when layers are thinner than about $2 \mathrm{~mm}$.

Second, we use a case in which the soil column, initially with a soil water of $-8 \%$, evaporates at its top until the soil water content is only 20\% ([Mathieu and Bariac, 1996, Braud et al., 2005]). The atmosphere has a relative humidity of $20 \%$ and a vapor $\delta^{18} O$ of $-15 \%$. The sophisticated models MuSICA and SiSPAT ([Braud et al., 2005]) feature a typical evaporative enrichment profile, with $\delta^{18} O$ increasing from its initial value of $-8 \%$ at the bottom to a maximum $\delta^{18} \mathrm{O}$ of $13 \%$ about $10 \mathrm{~mm}$ below the surface (figure E.15b). In the uppermost $10 \mathrm{~mm}$, there is a slight depletion due to diffusion of water vapor into the soil column ([Barnes and Allison, 1983]). ORCHIDEE is not able to reproduce this vertical profile. First, since diffusion of water vapor in the soil is neglected, it is not able to simulate the depletion near the surface. Second, since $\theta_{l} \cdot \tau$ is temporally and vertically constant in ORCHIDEE, it is not able to adapt to the drying of the soil. In the sophisticated model, as the soil dries, the soil water content $\theta_{l}$ decrease, thus inhibiting vertical mixing of soil water and favoring strong isotopic gradients. In contrast in ORCHIDEE, $\theta_{l} \cdot \tau$ remains constant at a value representative of a moister soil, thus favoring vertical mixing of soil water and leading to a nearly uniform enrichment with depth.

To summarize, our representation of isotopic vertical profiles in ORCHIDEE is probably most suited when soil moisture remains high and does not vary too strongly.

\section{Calculation of isotopic forcing from LMDZ outputs and nearby GNIP or USNIP stations}

When precipitation and water vapor isotopic observations are not available at a given site, we create isotopic forcing using isotopic measurements in the precipitation performed on nearby GNIP (Global Network for Isotopes in Precipitation, [Rozanski et al., 1993]) or USNIP (United States Network for Isotopes in Precipitation, [Vachon et al., 2007]) precipitation stations. To interpolate between the nearby stations, taking into account spatial gradients and altitude effects, we use outputs from an LMDZ simulation.

Let's assume there are $n$ GNIP or USNIP stations around the site of interest (MIBA or Carbo-Europe). The isotopic composition of precipitation at the site of interest and for a given month, $\delta_{p, s i t e}$, is calculated as:

$$
\delta_{p, s i t e}=\delta_{p, l m d z}(s)+a_{s} \cdot\left(z_{s i t e}-z_{l m d z}(s)\right)+\sum_{i=1}^{n} r_{i} \cdot\left(\delta_{p, N I P}(i)-\delta_{p, l m d z}(i)\right)
$$


where

$$
r_{i}=\frac{1 / d_{i}}{\sum_{j=1}^{n} 1 / d_{j}}
$$

and where $d_{i}$ is the geographical distance between the site of interest and the GNIP or USNIP station, $\delta_{p, l m d z}(s)$ is the precipitation isotopic composition simulated by LMDZ in the grid box containing the site $s, \delta_{p, l m d z}(i)$ is the precipitation isotopic composition simulated by LMDZ in the grid box containing the GNIP or USNIP station, $\delta_{p, N I P}(i)$ is the precipitation isotopic composition observed at the GNIP or USNIP station, $z_{\text {site }}$ is the altitude of the site of interest, $z_{l m d z}(s)$ is the altitude of the LMDZ grid box containing the site of interest and $a_{s}$ is the slope of the isotopic composition as a function of altitude simulated by LMDZ in the grid boxes containing and surrounding the site of interest. The first term on the right hand side corresponds to the raw LMDZ output for the site of interest. The second term allows us to correct for the altitude effect. Since LMDZ is run at a $2.5^{\circ}$ latitude $\times 3.75^{\circ}$ longitude resolution, we cannot expect the average grid box size to be representative of the local altitude at the site. The third term allows us to correct for possible biases in LMDZ compared to GNIP and USNIP observations. Table 3 lists the GNIP and USNIP stations used to construct the forcing at each site of interest.

To calculate the isotopic composition of the water vapor, we assume that although LMDZ might have biases for simulating the absolute values of precipitation and water vapor composition, it simulates properly the precipitationvapor difference ([Risi et al., 2010b, Risi et al., 2010a]). Therefore, the isotopic composition of water vapor at the site of interest, $\delta_{v, \text { site }}$, is calculated as:

$$
\delta_{v, \text { site }}=\delta_{p, \text { site }}+\delta_{v, l m d z}(s)-\delta_{p, l m d z}(s)
$$

where $\delta_{v, l m d z}(s)$ is the isotopic composition of water vapor simulated by LMDZ in the grid box containing the site of interest.

\section{E A simple equation to relate the soil water isotopic composition to the surface soil water budget}

To explore how the isotopic composition of soil water can help estimate terms of the soil water budget, we derive here a very simple theoretical framework.

We assume that the water mass balance is:

$$
P=E+T+D+\mathcal{R}
$$

where $P$ is the precipitation, $\mathcal{R}$ the surface runoff, $E$ is the bare soil evaporation, $T$ the transpiration and $D$ the drainage. Similarly, the isotopic mass balance is:

$$
P \cdot R_{p}=E \cdot R_{E}+T \cdot R_{T}+D \cdot R_{D}+\mathcal{R} \cdot R_{R}
$$

where $R_{p}, R_{E}, R_{T}, R_{D}$ and $R_{\mathcal{R}}$ are the isotopic ratios of incoming water at the soil surface, bare soil evaporation, transpiration, drainage and surface runoff respectively.

We assume that the bare soil evaporation isotope ratio depends on that of the soil $\left(R_{s}\right)$ following the [Craig and Gordon, 1965] relationship (equation B.1) and that the transpiration composition is equal to that of the soil $\left(R_{T}=R_{s}\right)$, implying little vertical variations in soil water isotope ratios. We assume that the isotopic composition of surface runoff is that of the incoming water $\left(R_{\mathcal{R}}=R_{p}\right)$ and that the isotopic composition of drainage is that of the soil water $\left(R_{D}=R_{s}\right)$. In doing so, we neglect again vertical isotope variations in the soil and the temporal co-variation between $R_{s}, D$ and $T$. Combining equations for the mass balance of water (equation E.2) and of water isotopes (equation E.1) then yields:

$$
R_{p}=E / I \cdot R_{E}+(1-E / I) \cdot R_{s}
$$

where $I=P-\mathcal{R}$ represents the incoming water that infiltrates into the soil. $E / I$ represents the proportion of the infiltrated water which is evaporated at the soil surface.

The composition of the bare soil evaporation flux, $R_{E}$, is a function of $R_{s}$ following the [Craig and Gordon, 1965] formulation (equation B.1). Replacing $R_{E}$ by its function of $R_{s}$ in equation E.3 allows us to deduce $E / I$ :

$$
E / I=\frac{\alpha_{e q} \cdot \alpha_{K} \cdot(1-h) \cdot\left(R_{p}-R_{s}\right)}{R_{s} \cdot\left(1-\alpha_{e q} \cdot \alpha_{K} \cdot(1-h)\right)-\alpha_{e q} \cdot h \cdot R_{v}}
$$


Therefore, $E / I$ is a function of the isotopic difference between the soil water and the precipitation water, which is easy to observe on instrumented sites such as MIBA or Carbo-Europe sites.

\section{Acknowledgments}

We thank a reviewer for his thorough review and detailed comments. LMDZ and ORCHIDEE simulations were performed on IDRIS machines to which access was granted by GENCI under project 0292. We thank Katia Laval for fruitful discussion and comments on an earlier version of this manuscript. We thank Matthias Cuntz for discussions. We thank Arthur Gessler and Romain Barnard for providing their data from Hartheim, and thank Chun-Ta Lai for providing his data from the Kansas prairie. We thank Danilo Dragoni, Kim Novick and Rich Phillips for providing information and data on the Morgan-Monroe site. We thank Marion Devaux, Cathy Lambrot (Inra-Ephyse, France), Rolf Siegwolf (Paul Scherrer Institute, Switzerland), Glyn Jones and Howard Griffiths (University of Cambridge, UK) for sampling and analysis of the isotopic data on the Bray and Mitra sites. We thank Eyal Rotenberg and Jean-Marc Bonnefond for providing the meteorological forcing over Yatir and the Bray respectively. We thank Dan Yakir for the isotopic and meteorological data collection in Yatir, his role in the MIBA initiative and comments on the manuscript. Part of the work was done while Camille Risi was a post-doc advised by David Noone, who I thank as well. This work benefited from financial support of the LEFE project MISSTERRE. Cathy Kurz-Besson was supported by the Fundação para a Ciência e Tecnologia (PTDC/AAG-REC/7046/2014). Lisa Wingate was supported by a Marie Curie Career Development Fellowship, thus some of the research leading to these results has received funding from the [European Community's] Seventh Framework Programme ([FP7/2007-2013] under grant agreement $n^{\circ}[237582]$. The research was supported partly by the Czech Science Foundation project to JS (14-12262S) and by the Czech research infrastructure for systems biology C4SYS project (LM2015055).

\section{References}

[Abdulla et al., 1996] Abdulla, F. A., Lettenmaier, D. P., Wood, E. F., and Smith, J. A. (1996). Application of a macroscale hydrological model to estimate the water balance of the Arkansas-Red River Basin. J. Geophys. Res., 101:7449-7459.

[Aleinov and Schmidt, 2006] Aleinov, I. and Schmidt, G. A. (2006). Water isotopes in the GISS ModelE land surface scheme. Global and Planet. Change, 51:108-120.

[Allison et al., 1983] Allison, G. B., Barnes, C. J., and Hughes, M. W. (1983). The distribution of deuterium and oxygen 18 in dry soils: II. Experimental. J. Hydrol., 64:377-397.

[Angert et al., 2008] Angert, A., Lee, J.-E., and Yakir, D. (2008). Seasonal variations in the isotopic composition of near-surface water vapour in the eastern Mediterranean. Tellus, 60 (4):674-684.

[Baldocchi et al., 2001] Baldocchi, D., Falge, E., Gu, L., Olson, R., Hollinger, D., and co authors (2001). FLUXNET: A New Tool to Study the Temporal and Spatial Variability of Ecosystem-Scale Carbon Dioxide, Water Vapor, and Energy Flux Densities. Bull. Am. Meteor. Soc., 82 (11):2415-24-34.

[Barnard et al., 2007] Barnard, R. L., Salmon, Y., Kodama, N., Sörgel, K., Holst, J., Rennenberg, H., Gessler, A., and Buchmann, N. (2007). Evaporative enrichment and time lags between d18O of leaf water and organic pools in a pine stand. Plant, Cell and Environment, 30:539-550.

[Barnes and Allison, 1988] Barnes, C. and Allison, G. (1988). Tracing of water movement in the unsaturated zone using stable isotopes of hydrogen and oxygen. J. Hydrol, 100:143-176.

[Barnes and Allison, 1983] Barnes, C. J. and Allison, G. B. (1983). The distribution of deuterium and oxygen 18 in dry soils: I. Theory. J. Hydrol., 60:141-156.

[Bender et al., 1994] Bender, M., Sowers, T., and Labeyrie, L. (1994). The Dole Effect and Its Variations During the Last 130,000 Years as Measured in the Vostok Ice Core. Glob. Biogeochem. Cycles, 8 (3):363?376.

[Blunier et al., 2002] Blunier, T., Barnett, B., Bender, M. L., , and Hendricks, M. B. (2002). Biological oxygen productivity during the last 60,000 years from triple oxygen isotope measurements. Glob. Biogeochem. Cycles, 16 (3):DOI 10.1029/2001GB001460. 
[Bony et al., 2008] Bony, S., Risi, C., and Vimeux, F. (2008). Influence of convective processes on the isotopic composition (deltaO18 and deltaD) of precipitation and water vapor in the Tropics. Part 1: Radiative-convective equilibrium and TOGA-COARE simulations. J. Geophys. Res., 113:D19305, doi:10.1029/2008JD009942.

[Boone and Coauthors, 2004] Boone, A. and Coauthors (2004). The Rhône-Aggregation Land Surface Scheme Intercomparison Project: An Overview. J. Clim., 17:187-208.

[Boone et al., 2009] Boone, A., de Rosnay, P., Balsamo, G., Beljaars, A., Chopin, F., Decharme, B., Delire, C., Ducharne, A., Gascoin, S., Grippa, M., Guichard, F., Gusev, Y., Harris, P., Jarlan, L., Kergoat, L., Mougin, E., Olga Nasonova, Anette Norgaard, T. O., Ottlé, C., Poccard-Leclercq, I., Polcher, J., Sandholt, I., Saux-Picart, S., Taylor, C., and Xue, Y. (2009). The AMMA Land Surface Model intercomparison Project (ALMIP). Bull. Am. Meteor. Soc., 90 (12):1865-1880, DOI:10.1175/2009BAMS2786.1.

[Bosilovich et al., 1999] Bosilovich, M. G., Yang, R., and Houser, P. R. (1999). River basin hydroloy in a global offline land-surface model. J. Geophys. Res., 104:19661-19673.

[Botter et al., 2011] Botter, G., Bertuzzo, E., and Rinaldo, A. (2011). Catchment residence and travel time distributions: The master equation. Geophysical Research Letters, 38(11).

[Bowen, 2015] Bowen, G. (2015). Hydrology: The diversified economics of soil water. Nature, 525(7567):43-44.

[Braud et al., 2009a] Braud, I., Bariac, T., Biron, P., and Vauclin, M. (2009a). Isotopic composition of bare soil evaporated water vapor. Part II: Modeling of RUBIC IV experimental results. J. Hydrol., 369:17-29.

[Braud et al., 2005] Braud, I., Bariac, T., Gaudet, J.-P., and Vauclin, M. (2005). SiSPAT-Isotope, a coupled heat, water and stable isotope (HDO and $\mathrm{H} 218 \mathrm{O}$ ) transport model for bare soil. Part I. Model description and first verifications. J. Hydrol., 309:301-320.

[Braud et al., 2009b] Braud, I., Biron, P., Bariac, T., Richard, P., Canale, L., Gaudet, J., and Vauclin, M. (2009b). Isotopic composition of bare soil evaporated water vapor. Part I: RUBIC IV experimental setup and results. $J$. Hydrol., 369:1-16.

[Brooks et al., 2010] Brooks, J. R., Barnard, H. R., Coulombe, R., and McDonnell, J. J. (2010). Ecohydrologic separation of water between trees and streams in a mediterranean climate. Nature Geoscience, 3(2):100-104.

[Brunel et al., 1997] Brunel, J., Walker, G., Dighton, J., and Montenya, B. (1997). Use of stable isotopes of water to determine the origin of water used by the vegetation and to partition evapotranspiration. A case study from HAPEX-Sahel. J. Hydrol, 188-189:466-481.

[Choisnel, 1977] Choisnel, E. (1977). Le bilan d'énergie et hydrique du sol. La Météorologie, 6 (11):103-133.

[Choisnel et al., 1995] Choisnel, E., Jourdain, S. V., and Jaquart, C. J. (1995). Climatological evaluation of some fluxes of the surface energy and soil water balances over France. Annales Geophysicae, 13:666-674.

[Coindreau et al., 2007] Coindreau, O., Hourdin, F., Haeffelin, M., Mathieu, A., and Rio, C. (2007). Assessment of physical parameterizations using a global climate model with stretchable grid and nudging. Mon. Wea. Rev., $135: 1474$.

[Craig, 1961] Craig, H. (1961). Isotopic variations in meteoric waters. Science, 133:1702-1703.

[Craig and Gordon, 1965] Craig, H. and Gordon, L. I. (1965). Deuterium and oxygen-18 variations in the ocean and marine atmosphere. Stable Isotope in Oceanographic Studies and Paleotemperatures, Laboratorio di Geologia Nucleate, Pisa, Italy:9-130.

[Crossley et al., 2000] Crossley, J. F., Polcher, J., Cox, P. M., Gedney, N., and Planton, S. (2000). Uncertainties linked to land-surface processes in climate change simulations. Clim. Dyn., 16:949-961.

[Cuntz et al., 2003] Cuntz, M., Ciais, Pand Hoffmann, G., and Knorr, W. (2003). A comprehensive global three-dimensional model of $\mathrm{D} 18 \mathrm{O}$ in atmospheric CO2: 1. Validation of surface processes. J. Geophys. Res., 108:doi:10.1029/2002JD003153.

[Cuntz et al., 2007] Cuntz, M., Ogee, J., Farquhar, G., Peylin, P., and Cernuzak, L. (2007). Modelling advection and diffusion of water isotopologues in leaves. Plant, cell and environment, 30:892-909. 
[Dansgaard, 1964] Dansgaard (1964). Stable isotopes in precipitation. Tellus, 16:436-468.

[De Rosnay, 1999] De Rosnay, P. (1999). Représentation de l'interaction sol-végétation-atmosphère dans le Modèle de Circulation Générale du Laboratoire de Météorologie Dynamique. PhD thesis, Université de Paris 06.

[de Rosnay et al., 2000] de Rosnay, P., Bruen, M., and Polcher, J. (2000). Sensitivity of the surface fluxes to the number of layers in the soil model used in GCMs. Geophys. Res. Let., 27 (20):3329-3332.

[Dee et al., 2011] Dee, D., Uppala, S., Simmons, A., Berrisford, P., Poli, P., Kobayashi, S., Andrae, U., Balmaseda, M., Balsamo, G., Bauer, P., et al. (2011). The era-interim reanalysis: Configuration and performance of the data assimilation system. Quarterly Journal of the royal meteorological society, 137(656):553-597.

[Desborough et al., 1996] Desborough, C., Pitman, A., and Irannejad, P. (1996). Analysis of the relationship between bare soil evaporation and soil moisture simulated by 13 land surface schemes for a simple non-vegetated site. Glob. Planet. Change, 13:47-56.

[Dongmann et al., 1974] Dongmann, G., Nurnberg, H., Forstel, H., and Wagener, K. (1974). On the enrichment of H2018 in the leaves of transpiring plants. Rad. and Environm. Biophys., 11:41-52.

[Dragoni et al., 2011] Dragoni, D., Schmid, H. P., Wayson, C. A., Potter, H., Grimmond, C. S. B., and Randolph, J. (2011). Evidence of increased net ecosystem productivity associated with a longer vegetated season in a deciduous forest in south?central Indiana, USA. Global Change Biology, 17(2):886-897.

[Dubbert et al., 2014] Dubbert, M., Cuntz, M., Piayda, A., and Werner, C. (2014). Oxygen isotope signatures of transpired water vapor: the role of isotopic non-steady-state transpiration under natural conditions. New Phytologist, 203:1242-1252.

[Ducharne et al., 2003] Ducharne, A., Golazb, C., Leblois, E., Lavala, K., Polcher, J., Ledoux, E., and de Marsily, G. (2003). Development of a high resolution runoff routing model, calibration and application to assess runoff from the LMD GCM. J. Hydrol., 280:207-228.

[Ducharne et al., 1998] Ducharne, A., Laval, K., and Polcher, J. (1998). Sensitivity of the hydrological cycle to the parametrization of soil hydrology in a gcm. Clim. Dyn., 14:307-327.

[Ducoudré et al., 1993] Ducoudré, N., Laval, K., and Perrier, A. (1993). SECHIBA, a new set of parametrizations of the hydrological exchanges at the land-atmosphere interface within the LMD atmospheric general circulation model. J. Clim., 6:248-273.

[Dufresne et al., 2012] Dufresne, J.-L., Foujols, M.-A., Denvil, S., Caubel, A., Marti, O., Aumont, O., alkanski, Y., Bekki, S., Bellenger, H., Benshila, R., Bony, S., Bopp, L., Braconnot, P., Brockmann, P., Cadule, P., Cheruy, F., Codron, F., Cozic, A., Cugnet, D., de Noblet, N., Duvel, J.-P., Ethé, C., Fairhead, L., Fichefet, T., Flavoni, S., Friedlingstein, P., Grandpeix, J.-Y., Guez, L., Guilyardi, E., Hauglustaine, D., Hourdin, F., Idelkadi, A., Ghattas, J., Joussaume, S., Kageyama, M., Krinner, G., Labetoulle, S., Lahellec, A., Lefebvre, M.-P., Lefevre, F., Levy, C., Li, Z. X., Lloyd, J., Lott, F., Madec, G., Mancip, M., Marchand, M., Masson, S., Meurdesoif, Y., Mignot, J., Musat, I., Parouty, S., Polcher, J., Rio, C., Schulz, M., Swingedouw, D., Szopa, S., Talandier, C., Terray, P., and Viovy, N. (2012). Climate change projections using the IPSL-CM5 Earth System Model: from CMIP3 to CMIP5. Clim. Dyn, 40 (9-10):1-43, DOI 10.1007/s00382-012-1636-1.

[Dutton et al., 2005] Dutton, A. L., Wilkinson, B., Welker, J. M., and Lohmann, K. C. (2005). Comparison of river water and precipitation delta18O across the 48 contiguous United States. Hydrol. Processes, 19:3551-3572.

[Ekaykin et al., 2009] Ekaykin, A. A., Hondoh, T., Lipenkov, V. Y., and Miyamoto, A. (2009). Post-depositional changes in snow isotope content: preliminary results of laboratory experiments. Clim. Past Discuss., 5:2239-2267.

[Evaristo et al., 2015] Evaristo, J., Jasechko, S., and McDonnell, J. J. (2015). Global separation of plant transpiration from groundwater and streamflow. Nature, 525(7567):91-94.

[Farquhar and Cernusak, 2005] Farquhar, G. and Cernusak, L. (2005). On the isotopic composition of leaf water in the non-steady state. Functional Plant Biology, 32:293-303.

[Gat, 1996] Gat, J. R. (1996). Oxygen and hydrogen isotopes in the hydrologic cycle. Annual Review of Earth and Planetary Sciences, 24:225-262. 
[Gat and Matsui, 1991] Gat, J. R. and Matsui, E. (1991). Atmospheric water balance in the Amazon basin: An isotopic evapotranspiration model. J. Geophys. Res., 96:13179-13188.

[Gat et al., 2007] Gat, J. R., Yakir, D., Goodfriend, G., Fritz, P., Trimborn, P., Lipp, J., Gev, I., Adar, E., and Waisel, Y. (2007). Stable isotope composition of water in desert plants. Plant Soil, 298:31-45, doi:10.1007/s11104007-9321-6.

[Gazis and Geng, 2004] Gazis, C. and Geng, X. (2004). A stable isotope study of soil water: evidence for mixing and preferential flow paths. Geoderma, 119:97-111.

[Gedney et al., 2000] Gedney, N., Cox, P. M., Douville, H., Polcher, J., and Valdes, P. (2000). Characterizing gcm land surface schemes to understand their responses to climate change. J. Clim., 13:3066-3079.

[Gholz and Clark, 2002] Gholz, H. L. and Clark, K. L. (2002). Energy exchange across a chronosequence of slash pine forests in Florida. Agricultural and Forest Meteorology, 112 (2):87-102.

[Gibson, 2002] Gibson, J. (2002). Short-term evaporation and water budget comparisons in shallow Arctic lakes using non-steady isotope mass balance. J. Hydrol., 264:242-261.

[Gibson and Edwards, 2002] Gibson, J. J. and Edwards, T. W. D. (2002). Regional water balance trends and evaporation-transpiration partitioning from a stable isotope survey of lakes in northern Canada. Glob. Biogeochem. Cycles, 16:1026, 10.1029/2001GB001839.

[Gibson et al., 2005] Gibson, J. J., Edwards, T. W. D., Birks, S. J., Amour, N. A. S., Buhay, W. M., McEachern, P., Wolfe, B. B., and Peters1, D. L. (2005). Progress in isotope tracer hydrology in Canada. Hydrol. Processes, $19: 303-327$.

[Gonfiantini, 1978] Gonfiantini, R. (1978). Standards for stable isotope measurements in natural compounds. Nature, 271:534-536.

[Good et al., 2015] Good, S. P., Noone, D., and Bowen, G. (2015). Hydrologic connectivity constrains partitioning of global terrestrial water fluxes. Science, 349(6244):175-177.

[Grünzweig et al., 2009] Grünzweig, J. M., Hemming, D., Maseyk, K., Lin, T., Rotenberg, E., Raz-Yaseef, N., Falloon, P. D., and Yakir, D. (2009). Water limitation to soil co2 efflux in a pine forest at the semiarid ?timberline? Journal of Geophysical Research: Biogeosciences, 114(G3).

[Guimberteau et al., 2008] Guimberteau, M., Laval, K., Perrier, A., and Polcher, J. (2008). Streamflow Simulations by the Land Surface Model ORCHIDEE Over the Mississippi River Basin: Impact of Resolution and Data Source on the Model. In American Geophysical Union, Fall Meeting.

[Gupta et al., 2009] Gupta, P., Noone, D., Galewsky, J., Sweeney, C., , and Vaughn, B. H. (2009). Demonstration of high-precision continuous measurements of water vapor isotopologues in laboratory and remote field deployments using wavelength-scanned cavity ring-down spectroscopy (WS-CRDS) technology. Rapid Commun. Mass Spectrom., 23:2534-2542.

[Haese et al., 2013] Haese, B., Werner, M., and Lohmann, G. (2013). Stable water isotopes in the coupled atmosphere-land surface model ECHAM5-JSBACH. Geoscientific Model Development, 6:1463-1480, doi: 10.5194/gmd-6-1463-2013.

[Harris and Woolf, 1980] Harris, K. A. and Woolf, L. A. (1980). Pressure and temperature dependence of the self diffusion coefficient of water and oxygen-18 water. J. Chem. Soc. Faraday Trans., 76 (1):377-385.

[Hemming et al., 2007] Hemming, D., Griffiths, H., Loader, A., Robertson, I., Wingate, L., and Yakir, D. (2007). The Moisture Isotopes in Biosphere and Atmosphere network (MIBA): initial results from the UK. Eos Trans. $A G U, 88$ (52).

[Hemming et al., 2005] Hemming, D., Yakir, D., Ambus, P., Aurela, M., Besson, C., Black, K., Buchmann, N., Burlett, R., Cescatti, A., Clement, R., et al. (2005). Pan-european $\delta 13 \mathrm{c}$ values of air and organic matter from forest ecosystems. Global Change Biology, 11(7):1065-1093.

[Henderson-Sellers, 2006] Henderson-Sellers, A. (2006). Improving land-surface parameterization schemes using stable water isotopes: Introducing the 'iPILPS' initiative. Glob. Planet. Change, 51:3-24. 
[Henderson-Sellers et al., 2003] Henderson-Sellers, A., Irannejad, P., McGuffie, K., , and Pitman, A. J. (2003). Predicting land-surface climates-better skill or moving targets? Geophy. Res. Lett., 30 (14):1777-1780, doi:10.1029/2003GL017387.

[Henderson-Sellers et al., 2004] Henderson-Sellers, A., McGuffie, K., Noone, D., and Irannejad, P. (2004). Using Stable Water Isotopes to Evaluate Basin-Scale Simulations of Surface Water Budgets. J. Hydromet., 5:805-822.

[Henderson-Sellers et al., 2001] Henderson-Sellers, A., McGuffie, K., and Zhang, H. (2001). Stable Isotopes as Validation Tools for Global Climate Model Predictions of the Impact of Amazonian Deforestation. J. Clim, 15:2664-2677.

[Hoffmann et al., 1998] Hoffmann, G., Werner, M., and Heimann, M. (1998). Water isotope module of the ECHAM atmospheric general circulation model: A study on timescales from days to several years. J. Geophys. Res., 103:16871-16896.

[Hourdin et al., 2006] Hourdin, F., Musat, I., Bony, S., Braconnot, P., Codron, F., Dufresne, J.-L., Fairhead, L., Filiberti, M.-A., Friedlingstein, P., Grandpeix, J.-Y., Krinner, G., Levan, P., Li, Z.-X., and Lott, F. (2006). The LMDZ4 general circulation model: climate performance and sensitivity to parametrized physics with emphasis on tropical convection. Clim. Dyn., 27:787-813.

[Jasechko et al., 2013] Jasechko, S., Sharp, W. D., Sharp, J. J., Birks, S. J., Yi, Y., and Fawcett, P. J. (2013). Terrestrial water fluxes dominated by transpiration. Nature, 496:347-350, doi:10.1038/nature11983.

[Joussaume et al., 1984] Joussaume, S., Jouzel, J., and Sadourny, R. (1984). A general circulation model of water isotope cycles in the atmosphere. Nature, 311:24-29.

[Jouzel and Merlivat, 1984] Jouzel, J. and Merlivat, L. (1984). Deuterium and oxygen 18 in precipitation: modeling of the isotopic effects during snow formation. J. Geophys. Res., 89:11:749.

[Kanner et al., 2013] Kanner, L. C., Buenning, N. H., Stott, L. D., and Timmermann, A. (2013). The role of soil evaporation in delao18 terrestrial climate proxies. Glob. Biogeochem. Cycles.

[Keeling, 1961] Keeling, C. (1961). The concentration and isotopic abundances of carbon dioxide and marine air. Geochim. Cosmochim. Acta, 24:277-298.

[Kendall and Coplen, 2001] Kendall, C. and Coplen, T. B. (2001). Distribution of oxygen-18 and deuterium in river waters across the United States. Hydrol. Processes, 15:1363-1393.

[Knohl et al., 2003] Knohl, A., Schulze, E.-D., Kolle, O., and Buchmann, N. (2003). Large carbon uptake by an unmanaged 250-year-old deciduous forest in Central Germany. Agricultural and Forest Meteorology, 118:151-167.

[Knohl et al., 2007] Knohl, A., Tu, K. P., Boukili, V., Brooks, P. D., Mambelli, S., Riley, W. J., and Dawson, T. E. (2007). MIBA-US: Temporal and Spatial Variation of Water Isotopes in Terrestrial Ecosystems Across the United States. Eos Trans. AGU, 88 (52).

[Koster and Milly, 1996] Koster, R. D. and Milly, P. C. D. (1996). The Interplay between Transpiration and Runoff Formulations in Land Surface Schemes Used with Atmospheric Models. J. Clim., 10:1578-1591.

[Krabbenhoft, 1990] Krabbenhoft, D. P. (1990). Estimating groundwater exchange with lakes 1. the stable isotope mass balance method. Water Resour. Res., 26 (10):2445-2453.

[Kratochvilová et al., 1989] Kratochvilová, I., Janous, D., Marek, M., Barták, M., and Ríha, L. (1989). Production activity of mountain cultivated norway spruce stands under the impact of air pollution. i. general description of problems. EKOLOGIA(CSSR)/ECOLOGY(CSSR)., 8(4):407-419.

[Krinner et al., 2005] Krinner, G., Viovy, N., de Noblet-Ducoudre, N., Ogee, J., Polcher, J., Friedlingstein, P., Ciais, P., Sitch, S., and Prentice, I. C. (2005). A dynamic global vegetation model for studies of the coupled atmosphere-biosphere system. Glob. Biogeochem. Cycles, 19.

[Kurz-Besson et al., 2006] Kurz-Besson, C., Otieno, D., Lobo do Vale, R., Siegwolf, R., Schmidt, M., Herd, A., Nogueira, C., David, T. S., David, J. S., John Tenhunen, Pareiro, J. S., and Chaves, M. (2006). Hydraulic Lift in Cork Oak Trees in a Savannah-Type Mediterranean Ecosystem and its Contribution to the Local Water Balance . Plant and Soil, 282 (1-2):361-378, DOI: 10.1007/s11104-006-0005-4. 
[Ladouche et al., 2001] Ladouche, B., Probst, A., Viville, D., Idir, S., Baqué, D., Loubet, M., Probst, J.-L., and Bariac, T. (2001). Hydrograph separation using isotopic, chemical and hydrological approaches (strengbach catchment, france). Journal of hydrology, 242(3):255-274.

[Lai et al., 2006a] Lai, C.-T., Ehleringer, J., Bond, B., and U, K. P. (2006a). Contributions of evaporation, isotopic non-steady state transpiration, and atmospheric mixing on the deltaO18 of water vapor in Pacific Northwest coniferous forests. Plant, Cell and Environment, 29(1):77-94.

[Lai et al., 2006b] Lai, C.-T., Riley, W., Owensby, C., Ham, J., Schauer, A., and Ehleringer, J. R. (2006b). Seasonal and interannual variations of carbon and oxygen isotopes of respired $\mathrm{CO} 2$ in a tallgrass prairie: Measurements and modeling results from 3 years with contrasting water availability. J. Geophys. Res., 111:D08S06,doi:10.1029/2005JD006436.

[Lawrence et al., 2007] Lawrence, D. M., Thornton, P. E., Oleson, K. W., and Bonan, G. B. (2007). The partitioning of evapotranspiration into transpiration, soil evaporation, and canopy evaporation in a gcm: Impacts on land?atmosphere interaction. J. Hydrometeor, 8:862?880.

[Lean and Rowntree, 1997] Lean and Rowntree, P. (1997). Understanding the sensitivity of a GCM simulation of Amazonian deforestation to the specification of vegetation and soil characteristics. J. Clim., 10:1216-1235.

[Lee et al., 2007] Lee, X., Kim, K., and Smith, R. (2007). Temporal variations of the 18O/16O signal of the wholecanopy transpiration in a temperate forest. Global Biogeochem. Cycles, 21:GB3013, doi:10.1029/2006GB002871.

[Mahfouf et al., 1996] Mahfouf, J.-F., Ciret, C., Ducharne, A., Irannejad, P., Noilhan, J., Shao, Y., PThornton, Xue, Y., and Yang, Z.-L. (1996). Analysis of transpiration results from the RICE and PILPS Workshop. Glob. Planet. Change, 13:73-88.

[Majoube, 1971a] Majoube, M. (1971a). Fractionnement en O18 entre la glace et la vapeur d'eau. Journal de Chimie Physique, 68:625-636.

[Majoube, 1971b] Majoube, M. (1971b). Fractionnement en Oxygène 18 et en Deutérium entre l'eau et sa vapeur. Journal de Chimie Physique, 10:1423-1436.

[Manabe et al., 1965] Manabe, S., Smagorinsky, J., and Strickler, R. (1965). Simulated climatology of a general circulation model with a hydrologic cycle. Mon. Weath. Rev., 93:769-798.

[Marti et al., 2005] Marti, O., Braconnot, P., Bellier, J., Benshila, R., Bony, S., Brockmann, P., Cdule, P., Caubel, A., Denvil, S., Dufresne, J.-L., Fairhead, L., Filiberti, M.-A., Foujols, M.-A., Fichefer, T., Friedlingstein, P., Grandpeix, J.-Y., Hourdin, F., Krinner, G., Lévy, C., Madec, G., Musat, I., de Noblet, N., Polcher, J., and Tanlandier, C. (2005). The new IPSL climate system model: IPSL-CM4. Technical report, IPSL, Note du pôle de modélisation de l'IPSL, 26: 1-86.

[Masson-Delmotte et al., 2008] Masson-Delmotte, V., Hou, S., Ekaykin, A., Jouzel, J., Aristarain, A., Bernardo, R. T., Bromwhich, D., Cattani, O., Delmotte, M., Falourd, S., Frezzotti, M., Gallée, H., Genoni, L., Isaksson, E., Landais, A., Helsen, M., Hoffmann, G., Lopez, J., Morgan, V., Motoyama, H., Noone, D., Oerter, H., Petit, J., Royer, A., Uemura, R., Schmidt, G., Schlosser, E., Simoes, J., Steig, E., Stenni, B., Stievenard, M., van den Broeke, M., van de Wal, R., van den Berg, W.-J., Vimeux, F., and White, J. (2008). A review of Antarctic surface snow isotopic composition: observations, atmospheric circulation and isotopic modelling. J. Climate, 21:3359-3387.

[Masson-Delmotte et al., 2005] Masson-Delmotte, V., Landais, A., Stievenard, M., Cattani, O., Falourd, S., Jouzel, J., Johnsen, S. J., Dahl-Jensen, D., Sveinsbjornsdottir, A., White, J. W. C., Popp, T., and Fischer, H. (2005). Holocene climatic changes in Greenland: Different deuterium excess signals at Greenland Ice Core Project (GRIP) and NorthGRIP. J. Geophys. Res., 110.

[Mathieu and Bariac, 1996] Mathieu, R. and Bariac, T. (1996). A numerical model for the simulation of stable isotope profiles in drying soils. J. Geophys. Res., 101 (D7):12685-12696.

[McCarroll and Loader, 2004] McCarroll, D. and Loader, N. (2004). Stable isotopes in tree rings. Quat. Sci. Rev., 23:771-801. 
[McDermott, 2004] McDermott, F. (2004). Palaeo-climate reconstruction from stable isotope variations in speleothems: a review. Quaternary Science Reviews, 23 (7-8):901-918.

[Meehl et al., 2007] Meehl, G. A., Covey, K., Delworth, T., Latif, M., McAvaney, B., Mitchell, J. F. B., Stouffer, R. J., and Taylor, K. (2007). The WCRP CMIP3 multimodel dataset: A new era in climate change research. Bull. Am. Meteor. Soc., 7:1383-1394.

[Melayah et al., 1996] Melayah, A., Bruckler, L., and Bariac, T. (1996). Modeling the transport of water stable isotopes in unsaturated soils under natural conditions 1. theory. water resources res., 32:2047-2054.

[Merlivat and Nief, 1967] Merlivat, L. and Nief, G. (1967). Fractionnement isotopique lors des changements d'états solide-vapeur et liquide-vapeur de l'eau à des températures inférieures à 0C. Tellus, 19:122-127.

[Millet et al., 1997] Millet, A., Bariac, T., Ladouche, B., Mathieu, R., Grimaldi, C., Grimaldi, M., Hubert, P., Molicova, H., Bruckler, L., Valles, V., Bertuzzi, P., Brunet, Y., and Boulègue, J. (1997). Influence of deforestation on the hydrological behavior of small tropical watersheds. Revue des Sciences de l'eau, 1:61-84.

[Mills, 1973] Mills, R. (1973). Self diffusion in normal and heavy water in the range 1-45C. J. Phys. Chem., $77: 685-688$.

[Milly et al., 2005] Milly, P. C. D., Dunne, K. A., and Vecchia, A. V. (2005). Global pattern of trends in streamflow and water availability in a changing climate. Nature, 17.

[Moran et al., 2009] Moran, M., , Scotta, R., Keefera, T., Emmericha, W., Hernandeza, M., Nearing, G., Paige, G., Cosh, M., , and O?Neille, P. (2009). Partitioning evapotranspiration in semiarid grassland and shrubland ecosystems using time series of soil surface temperature. Agric. and For. Meteorol., 149 (1):59-72.

[Moreira et al., 1997] Moreira, M., Sternberg, L., Martinelli, L., Victoria, R., Barbosa, E., Bonates, C., and Nepstad, D. (1997). Contribution of transpiration to forest ambient vapor based on isotopic measurements. Global Change Biol., 3:439-450.

[Munnich et al., 1980] Munnich, K. O., Sonntag, C., Christmann, D., and Thoma, G. (1980). Isotope fractionation due to evaporation from sand dunes. Z. Mitt. Zentralinst. Isot. Stralenforsch., 29:319-332.

[Ngo-Duc, 2005] Ngo-Duc, T. (2005). Modélisation des bilans hydrologiques continentaux : variabilité interannuelle et tendances. Comparaison aux observations. PhD thesis, Université Pierre et Marie Curie.

[Nijssen et al., 1997] Nijssen, B., Lettenmaier, D. P., Xu Liang, S., Wetzel, W., and Wood, E. F. (1997). Streamflow simulation for continental-scale river basins. Water Resour. Res., 33:711-724.

[Noone et al., 2012] Noone, D., Risi, C., Bailey, A., Brown, D., Buenning, N., Gregory, S., Nusbaumer, J., Sykes, J., Schneider, D., Vanderwende, B., Wong, J., Meillier, Y., and Wolf, D. (2012). Factors controlling moisture in the boundary layer derived from tall tower profiles of water vapor isotopic composition following a snowstorm in colorado. Atmos. Chem. Phys. Discuss., 12:16327-16375, doi:10.5194/acpd-12-16327-2012.

[Nusbaumer, 2016] Nusbaumer, J. (2016). An examination of atmospheric river moisture transport and hydrology using isotope-enabled CAM5. PhD thesis, University of Colorado at Boulder.

[Ogée et al., 2003] Ogée, J., Brunet, Y., Loustau, D., Berbigier, P., and Delzon, S. (2003). MuSICA, a CO2, water and energy multilayer, multileaf pine forest model: evaluation from hourly to yearly time scales and sensitivity analysis. Global Change Biology, 9 (5):697-717, DOI: 10.1046/j.1365-2486.2003.00628.x.

[Ogée et al., 2007] Ogée, J., Cuntz, M., Peylin, P., and Bariac, T. (2007). Non-steady-state, non-uniform transpiration rate and leaf anatomy effects on the progressive stable isotope enrichment of leaf water along monocot leaves. Plant, Cell and Environment, 30:367-387.

[Oki and Sud, 1998] Oki, T. and Sud, Y. C. (1998). Design of Total Runoff Integrating Pathways (TRIP) - A Global River Channel Network. Earth Interactions, 2:1-36.

[Pitman et al., 2009] Pitman, A. J., de Noblet-Ducoudre, N., Cruz, F. T., Davin, E. L., Bonan, G. B., Brovkin, V., Claussen, M., Delire, C., Ganzeveld, L., Gayler, V., van den Hurk, B. J. J. M., Lawrence, P. J., van der Molen, M. K., Muller, C., Reick, C. H., Seneviratne, S. I., Strengers, B. J., , and Voldoire, A. (2009). Uncertainties in climate responses to past land cover change: First results from the LUCID intercomparison study. Geophy. Res. Lett., 36:L14814, doi:10.1029/2009GL039076. 
[Polcher, 2003] Polcher, J. (2003). Les processus de surface à l'échelle globale et leurs interactions avec l'atmosphère. In Thèse d'habilitation à diriger des recherches, Université Paris 6.

[Polcher et al., 1996] Polcher, J., Laval, K., Dfimenil, L., Lean, J., and Rowntree, P. (1996). Comparing three land surface schemes used in general circulation models. J. Hydrol., 180:373-394.

[Qu and Henderson-Sellers, 1998] Qu, W. and Henderson-Sellers, A. (1998). Comparing the scatter in pilps off-line experiments with that in amip i coupled experiments. Global and Planetary Change, 19:209-223.

[Raz-Yaseef et al., 2009] Raz-Yaseef, N., Yakir, D., Rotenberg, E., Schiller, G., and Cohen, S. (2009). Ecohydrology of a semi-arid forest: partitionning among water balance components and its implications for predicted precipitation changes. Ecohydrolohy, page 10.1002/eco.65.

[Raz-Yaseef et al., 2012] Raz-Yaseef, N., Yakir, D., Schill, and Cohen, S. (2012). Dynamics of evapotranspiration partitioning in a semi-arid forest as affected by temporal rainfall patterns. Agr. Forest Meteorol, 157:77-85.

[Riley et al., 2002] Riley, W. J., Still, J., Torn, M. S., and Berry, J. A. (2002). A mechanistic model of H218O and $\mathrm{C} 18 \mathrm{OO}$ fluxes between ecosystems and the atmosphere: Model description and sensitivity analyses. Global Biogeochem. Cycles, 16 (4):1095, doi:10.1029/2002GB001878.

[Risi, 2009] Risi, C. (2009). Les isotopes stables de l'eau: applications à l'étude du cycle de l'eau et des variations du climat. $\mathrm{PhD}$ thesis, Université Pierre et Marie Curie.

[Risi et al., 2010a] Risi, C., Bony, S., Vimeux, F., Frankenberg, C., and Noone, D. (2010a). Understanding the Sahelian water budget through the isotopic composition of water vapor and precipitation. J. Geophys. Res, 115, D24110:doi:10.1029/2010JD014690.

[Risi et al., 2010b] Risi, C., Bony, S., Vimeux, F., and Jouzel, J. (2010b). Water stable isotopes in the LMDZ4 General Circulation Model: model evaluation for present day and past climates and applications to climatic interpretation of tropical isotopic records. J. Geophys. Res., 115, D12118:doi:10.1029/2009JD013255.

[Risi et al., 2013] Risi, C., Noone, D., Frankenberg, C., and Worden, J. (2013). Role of continental recycling in intraseasonal variations of continental moisture as deduced from model simulations and water vapor isotopic measurements. Water Resour. Res., 49:4136-4156, doi: 10.1002/wrcr.20312.

[Risi et al., 2012] Risi, C., Noone, D., Worden, J., Frankenberg, C., Stiller, G., Kiefer, M., Funke, B., Walker, K., Bernath, P., Schneider, M., Wunch, D., Sherlock, V., Deutscher, N., Griffith, D., Wernberg, P., Bony, S., Jeonghoon Lee, D. B., Uemura, R., and Sturm, C. (2012). Process-evaluation of tropical and subtropical tropospheric humidity simulated by general circulation models using water vapor isotopic observations. Part 1: model-data intercomparison. J. Geophy. Res., 117:D05303.

[Robock et al., 1998] Robock, A., Schlossera, C. A., Vinnikova, K. Y., Speranskayad, N. A., Entina, J. K., and Qiua, S. (1998). Evaluation of the AMIP soil moisture simulations . Glob. Planet. Change, 19 (1-4):181-208.

[Robock et al., 2000] Robock, A., Vinnikov, K. Y., Srinivasan, G., Entin, J. K., Hollinger, S. E., Speranskaya, N. A., Liu, S., and Namkhai, A. (2000). The global soil moisture data bank. Bull. Am. Meteor. Soc., 81:1281-1299.

[Rodriguez-Iturbe et al., 1995] Rodriguez-Iturbe, I., Vogel, G., Rigon, R., Entekhabi, D., Castelli, F., and Rinaldo, A. (1995). On the spatial organization of soil moisture fields. Geophys. Res. Lett., 22:2757-2760.

[Rosnay and Polcher, 1998] Rosnay, P. D. and Polcher, J. (1998). Modelling root water uptake in a complex land surface scheme coupled to a GCM. Hydrol. Earth Sci., 2:239-255.

[Rothfuss et al., 2010] Rothfuss, Y., Biron, P., Braud, I., Canale, L., Durand, J.-L., Gaudet, J.-P., Richard, P., Vauclin, M., and Bariac, T. (2010). Partitioning evapotranspiration fluxes into soil evaporation and plant transpiration using water stable isotopes under controlled conditions. Hydrological processes, 24(22):3177-3194.

[Rozanski et al., 1993] Rozanski, K., Araguas-Araguas, L., and Gonfiantini, R. (1993). Isotopic patterns in modern global precipitation. Geophys. Monogr. Seri., AGU, Climate Change in Continental Isotopic records.

[Ryder et al., 2016] Ryder, J., Polcher, J., Peylin, P., Ottlé, C., Chen, Y., Gorsel, E. v., Haverd, V., McGrath, M., Naudts, K., Otto, J., et al. (2016). A multi-layer land surface energy budget model for implicit coupling with global atmospheric simulations. Geoscientific Model Development, 9(1):223-245. 
[Salati et al., 1979] Salati, E., Dall'Olio, A., Matsui, E., and Gat, J. (1979). Recycling of water in the Amazon basin: An isotopic study. Water Resources Research, 15:1250-1258.

[Schmid et al., 2000] Schmid, H. P., Grimmond, C. S. B., Cropley, F., Offerle, B., and Su, H. B. (2000). Measurements of co2 and energy fluxes over a mixed hardwood forest in the mid-western united states. Agricultural and Forest Meteorology, 103 (4):357-374.

[Seneviratne et al., 2010] Seneviratne, S. I., Corti, T., Davin, E. L., Hirschi, M., Jaeger, E. B., Lehner, I., Orlowsky, B., and Teuling, A. J. (2010). Investigating soil moisture-climate interactions in a changing climate: a review. Earth-Sci Rev., 99 (3-4):125-161, doi.org/10.1016/j.earscirev.2010.02.004.

[Shi et al., 2011a] Shi, C., Daux, V., Risi, C., Hou, S.-G., Stievenard, M., Pierre, M., Li, Z., and Masson-Delmotte, V. (2011a). Reconstruction of southeast Tibetan Plateau summer cloud cover over the past two centuries using tree ring delta18O. Clim. Past, pages doi:10.5194/cpd-7-1825-2011.

[Shi et al., 2011b] Shi, C., Masson-Delmotte, V., Risi, C., Eglin, T., Stievenard, M., Pierre, M., bin Zhang, Q., and Daux, V. (2011b). Sampling Strategy and Climatic Implications of Tree-Ring Stable isotopes in Southeast Tibetan Plateau. Earth Planet. Sci. Lett., 301 (1?2):307-316, doi:10.1016/j.epsl.2010.11.014.

[Sitch, 2003] Sitch, S. e. a. (2003). Evaluation of ecosystem dynamics, plant geography and terrestrial carbon cycling in the LPJ dynamic vegetation model. Global Change Biol., 9:161-185.

[Sokratov and Golubev, 2009] Sokratov, S. A. and Golubev, V. N. (2009). Snow isotopic content change by sublimation. Journal of Glaciology, 55 (193):823-828.

[Solomon, 2007] Solomon, S. (2007). Climate change 2007-the physical science basis: Working group I contribution to the fourth assessment report of the IPCC, volume 4. Cambridge University Press.

[Stella et al., 2009] Stella, P., Lamaud, E., Brunet, Y., Bonnefond, J.-M., Loustau, D., , and Irvine, M. (2009). Simultaneous measurements of $\mathrm{CO} 2$ and water exchanges over three agroecosystems in South-West France. Biogeosciences Discuss., 6:2489-2522.

[Stewart, 1975] Stewart, M. K. (1975). Stable isotope fractionation due to evaporation and isotopic exchange of falling waterdrops: Applications to atmospheric processes and evaporation of lakes. J. Geophys. Res., 80:11331146.

[Twining et al., 2006] Twining, J., Stone, D., Tadros, C., Henderson-Sellers, A., and A, W. (2006). Moisture Isotopes in the Biosphere and Atmosphere (MIBA) in Australia: A priori estimates and preliminary observations of stable water isotopes in soil, plant and vapour for the Tumbarumba Field Campaign. Global and Planetary Change, 51:59-72.

[Uppala et al., 2005] Uppala, S., Kallberg, P., Simmons, A., Andrae, U., da Costa Bechtold, V., Fiorino, M., Gibson, J., Haseler, J., Hernandez, A., Kelly, G., Li, X., Onogi, K., Saarinen, S., Sokka, N., Allan, R., Andersson, E., Arpe, K., Balmaseda, M., Beljaars, A., van de Berg, L., Bidlot, J., Bormann, N., Caires, S., Chevallier, F., Dethof, A., Dragosavac, M., Fisher, M., Fuentes, M., Hagemann, S., Holm, E., Hoskins, B., Isaksen, L., Janssen, P., Jenne, R., McNally, A., Mahfouf, J.-F., Morcrette, J.-J., Rayner, N., Saunders, R., Simon, P., Sterl, A., Trenberth, K., Untch, A., Vasiljevic, D., Viterbo, P., and Woollen, J. (2005). The ERA-40 re-analysis. Quart. J. Roy. Meteor. Soc., 131:2961-3012.

[Vachaud et al., 1985] Vachaud, G., Passerat de Silans, A., Balabanis, P., and Vauclin, M. (1985). Temporal stability of spatially measured soil water probability density function. Soil Sci. Soc. Am., 49:822-828.

[Vachon et al., 2007] Vachon, R. W., White, J. W. C., Gutmann, E., and Welker, J. M. (2007). Amount-weighted annual isotopic (d18O) values are affected by the seasonality of precipitation: A sensitivity study. Geophy. Res. Lett., 34:L21707, doi:10.1029/2007GL030547.

[Valentini et al., 2000] Valentini, R., Matteucci, G., Dolman, A., Schulze, E.-D., Rebmann, C., Moors, E., Granier, A., Gross, P., Jensen, N., Pilegaard, K., et al. (2000). Respiration as the main determinant of carbon balance in european forests. Nature, 404(6780):861-865.

[van der Ent et al., 2010] van der Ent, R. J., Savenje, H. H. G., Schaefli, B., and Steele-Dunne, S. C. (2010). Origin and fate of atmopheric moisture over continents. Water Resour. Res., 46:W09525. 
[Vinnikov et al., 1996] Vinnikov, K., Robock, A., Speranskaya, N., and Schlosser, C. A. (1996). Scales of temporal and spatial variability of midlatitude soil moisture. J. Geophys. Res., 101:7163?7174.

[Vitvar et al., 2006] Vitvar, T., Aggarwal, P., and Herczeg, A. (2006). Towards a global network for monitoring isotopes in rivers. Geophys. Res. Abstracts, EGU, 8.

[Vitvar et al., 2007] Vitvar, T., Aggarwal, P. K., and Herczeg, A. L. (2007). Global network is launched to monitor isotopes in rivers. Eos Trans. AGU, 88 (33):doi:10.1029/2007EO330001.

[Voelker et al., 2014] Voelker, S., Brooks, J., Meinzer, F., Roden, J., Pazdur, A., Pawelczyk, S., Hartsough, P., Snyder, K., L., P., and J., S. (2014). Isolating relative humidity: dual isotopes delta18o and deltad as deuterium deviations from the global meteoric water line. Ecological Applications, 24:960-975.

[Wang et al., 2010] Wang, L., Caylor, K. K., Villegas, J. C., Barron-Gafford, G. A., Breshears, D. D., and Huxman, T. E. (2010). Partitioning evapotranspiration across gradients of woody plant cover: Assessment of a stable isotope technique. Geophy. Res. Lett., 37:L09401, doi:10.1029/2010GL043228.

[Washburn and Smith, 1934] Washburn, E. and Smith, E. (1934). The isotopie fractionation of water by physiological processes. Science, 79:188-189.

[Weiler et al., 2003] Weiler, M., McGlynn, B. L., McGuire, K. J., and McDonnell, J. J. (2003). How does rainfall become runoff? A combined tracer and runoff transfer function approach. Water Resources Research, 39.

[Wels et al., 1991] Wels, C., Cornett, J., and Lazerte, B. D. (1991). Hydrograph separation: a comparison of geochmical and isotopic tracers. J. Hydrol., 122:253-274.

[Wetzel et al., 1996] Wetzel, P. J., Liang, X., Irannejad, P., Boone, A., Noilhane, J., Shao, Y., Skelly, C., Xue, Y., , and Yang, Z. L. (1996). Modeling vadose zone liquid water fluxes: Infiltration, runoff, drainage, interflow. Global and Planetary Change, 13 (1-4):57-71.

[Williams et al., 2004] Williams, D. G., Cable, W., Hultine, K., and co authorso (2004). Evapotranspiration components determined by stable isotope, sap flow and eddy covariance techniques. Agricult. Forest. Meteor., 125:241258.

[Wingate et al., 2010] Wingate, L., Ogée, J., Burlett, R., and Bosc, A. (2010). Strong seasonal disequilibrium measured between the oxygen isotope signals of leaf and soil CO2 exchange. Glob. Change Biology, pages doi: 10.1111/j.1365-2486.2010.02186.x.

[Wingate et al., 2009] Wingate, L., Ogée, J., Cuntz, M., Genty, B., andUlli Seibtf, I. R., Yakir, D., Maseyk, K., Pendallh, E. G., Barbouri, M. M., Mortazavij, B., Burlett, R., Peylin, P., Miller, J., Mencuccini, M., Shimn, J. H., Hunti, J., , and Gracea, J. (2009). The impact of soil microorganisms on the global budget of deltaO18 in atmospheric CO2. PNAS, page doi: 10.1073/pnas.0905210106.

[Wong, 2016] Wong, T. (2016). The Impact of Stable Water Isotopic Information on Parameter Calibration in a Land Surface Model. PhD thesis, University of Colorado at Boulder.

[Yakir and Sternberg, 2000] Yakir, D. and Sternberg, L. d. S. L. (2000). The use of stable isotopes to study ecosystem gas exchange. Oecologia, 123:297-311.

[Yakir and Wang, 1996] Yakir, D. and Wang, X.-F. (1996). Fluxe of CO2 and water between terrestrial vegetation and the atmosphere estimated from isotope measurements. Nature, 380:515-517.

[Yakir and Yechieli, 1995] Yakir, D. and Yechieli, Y. (1995). Plant invasion of newly exposed hypersaline Dead Sea shore. Nature, 374:803-805.

[Yepez et al., 2003] Yepez, E., Williams, S., Scott, R., and Lin, G. (2003). Partitioning overstory and understory evapotranspiration in a semiarid savanna woodland from the isotopic composition of water vapor. Agricultural and Forest Meteorology, 119:53-68.

[Yoshimura et al., 2008] Yoshimura, K., Kanamitsu, M., Noone, D., and Oki, T. (2008). Historical isotope simulation using reanalysis atmospheric data. J. Geophys. Res., 113:D19108, doi:10.1029/2008JD010074. 
[Yoshimura et al., 2006] Yoshimura, K., Miyazaki, S., Kanae, S., and Oki, T. (2006). Iso-MATSIRO, a land surface model that incorporates stable water isotopes. Glob. Planet. Change, 51:90-107.

[Yoshimura et al., 2004] Yoshimura, K., Oki, T., Ohte, N., and Kanae, S. (2004). Colored moisture analysis estimates of variations in 1998 asian monsoon water sources. J. Meteor. Soc. Japan, 82:1315-1329.

[Zhang et al., 2010] Zhang, G., Leclerc1, M. Y., and Karipot, A. (2010). Local flux-profile relationships of wind speed and temperature in a canopy layer in atmospheric stable conditions. Biogeosciences, 7:3625?3636, doi:10.5194/bg-7-3625-2010.

[Zhu et al., 2015] Zhu, D., Peng, S., Ciais, P., Viovy, N., Druel, A., Kageyama, M., Krinner, G., Peylin, P., Ottlé, C., Piao, S., et al. (2015). Improving the dynamics of northern hemisphere high-latitude vegetation in the orchidee ecosystem model. Geoscientific Model Development, 8(7):2263-2283.

[Zimmermann et al., 1967] Zimmermann, U., Ehhalt, E., and Munnich, K. (1967). Soil-water movement and evapotranspiration: changes in the isotopic composition of the water. Proceedings of the symposium on isotopes in hydrology, 14-18 November, IAEA, Vienna:567-585. 


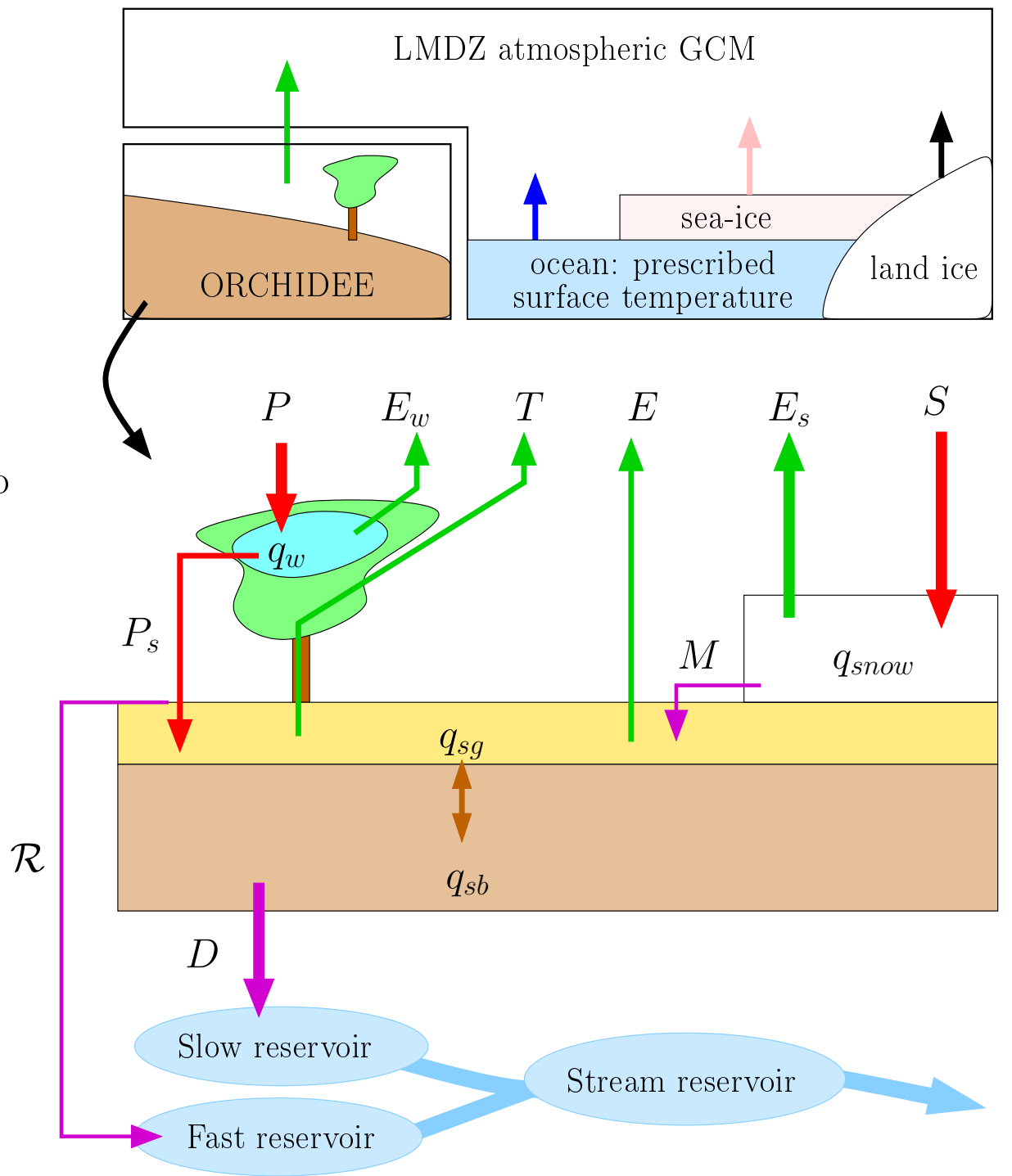

Figure E.1: a) The four sub-surfaces in the LMDZ GCM: land, ocean, sea ice and land ice. Their relative fraction in each grid box is prescribed. The sea surface temperature of the ocean is prescribed, and interactively calculated for sea-ice and land-ice. Over land, the land-surface model (LSM) ORCHIDEE calculates interactively the surface temperature and outgoing water fluxes. b) Water fluxes and pools represented in the ORCHIDEE LSM. Water pools are the soil water in the superficial $\left(q_{s g}\right)$ and bottom $\left(q_{s b}\right)$ layers, the water intercepted by the canopy $\left(q_{w}\right)$ and the snow pack $\left(q_{\text {snow }}\right)$. Fluxes onto the land surface are the total rain $(P)$ and snow $(S)$, and possibly dew or frost. As some rain is intercepted by the canopy, only throughfall rain $\left(P_{s}\right)$ arrives at the soil surface. Evaporation fluxes are the evaporation of intercepted water $\left(E_{w}\right)$, transpiration by the vegetation $(T)$, bare soil evaporation $(E)$ and snow sublimation $\left(E_{s}\right)$. Snow melt may be transferred from the snow pack to the soil $(M)$. Water from rainfall, melt (and possibly dew) exceeding the soil capacity is converted to surface runoff $(\mathcal{R})$ and drainage $(D)$. The routing model then transfers surface runoff and drainage to streams. 


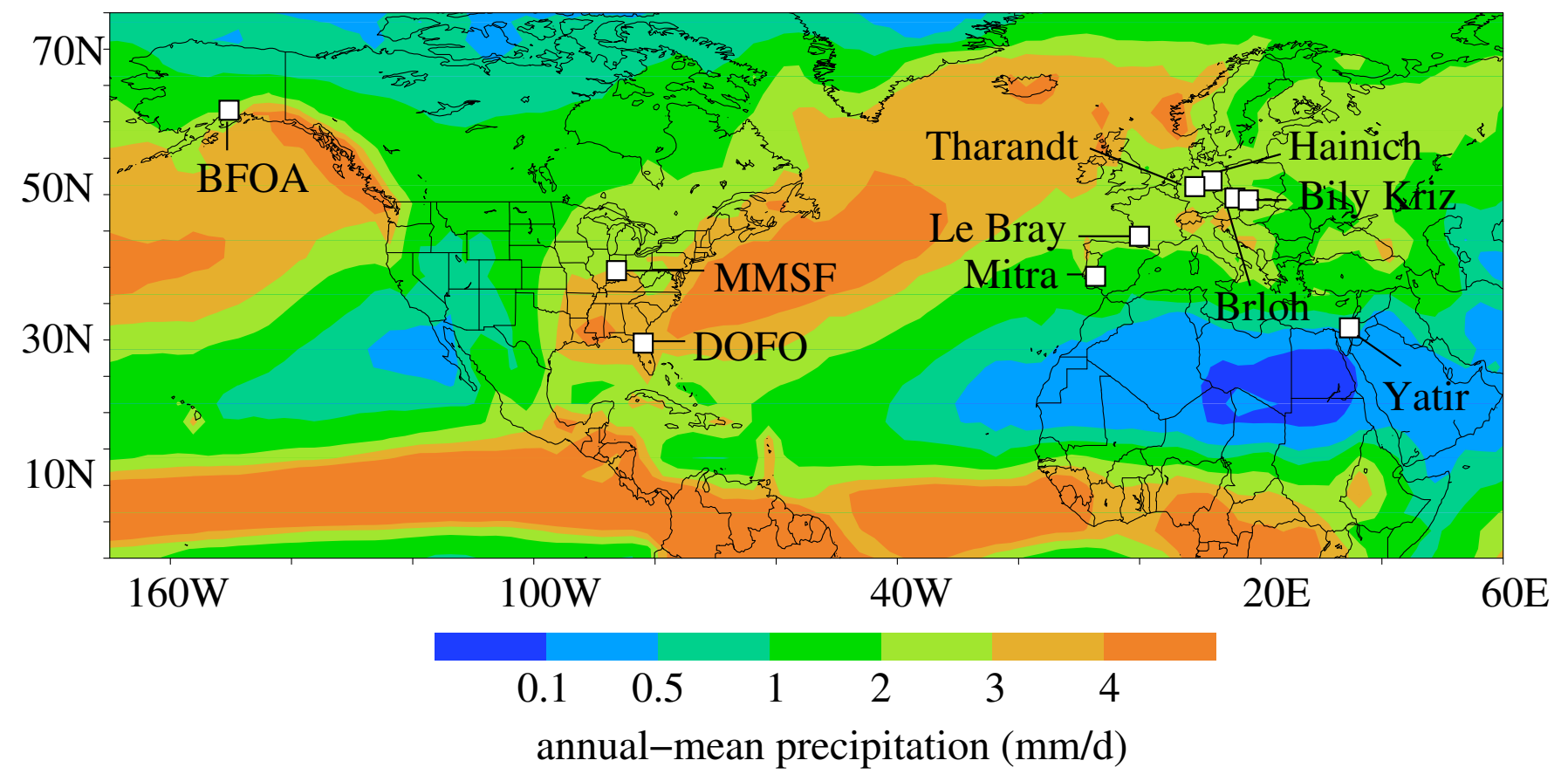

Figure E.2: Location of the ten stations used in this study for single-point model-data comparison. The background represents the annual-mean precipitation from GPCP (Global Precipitation Climatology Project) to illustrate the diversity of climate regimes covered by the ten stations. Each station is described in more detail in table 1. 

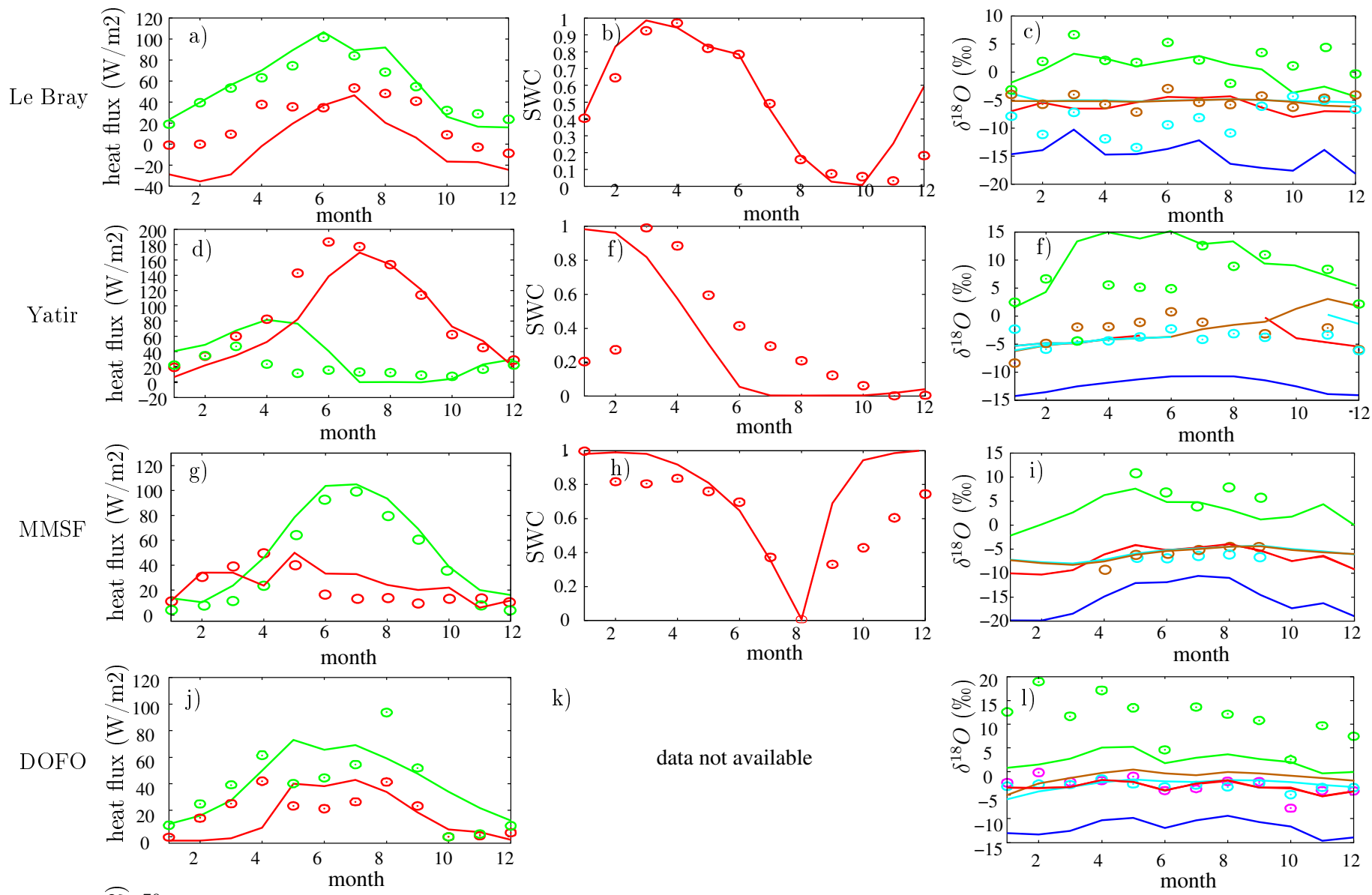

k)
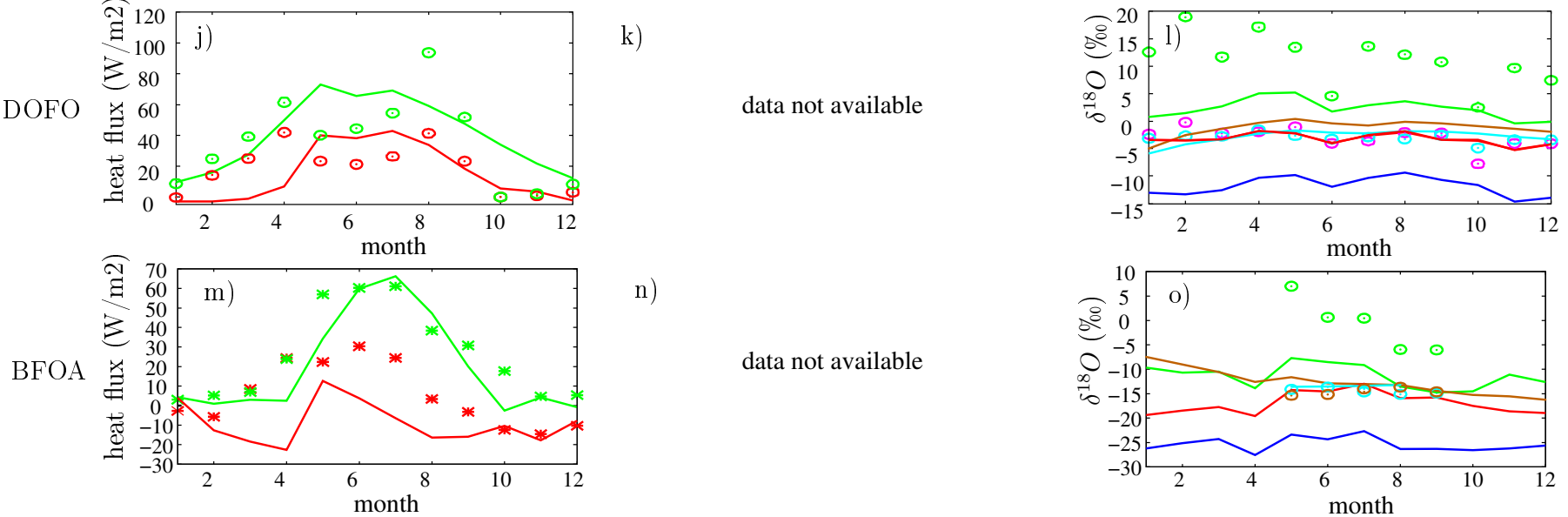

n)

data not available

data not available

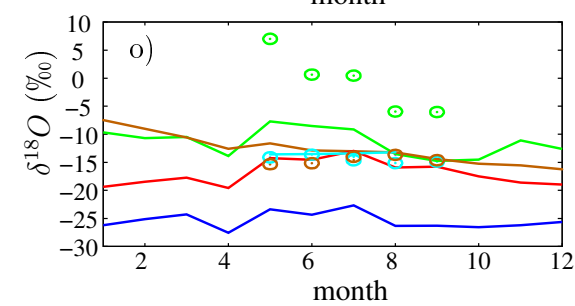

$$
\begin{aligned}
& \text { O ORCHIDEE simulation } \\
& \text { observations } \\
& \text { ERA-Interim }
\end{aligned}
$$

Key for latent flux plots

— sensible

- latent
Key for $\delta^{18} O$ plots

— precip forcing

— vapor forcing

- soil water

— stem water

- leaf water

Figure E.3: Evaluation of hydrological and isotopic variables simulated by ORCHIDEE on different MIBA or CarboEurope sites. a, d, g, j, m: latent (green) and sensible (red) heat fluxes observed locally when available (circles), simulated in the ERA-Interim reanalyses (stars) and simulated by ORCHIDEE (lines). b, e, h, k, n: normalized soil moisture content (SWC, without unit) observed locally (circles) and simulated by ORCHIDEE (lines). c, f, i, l, o: $\delta^{18} O$ of the surface soil (brown) and stems (green) simulated by ORCHIDEE in the control offline simulations (thin curves) and observed (circles). Observed $\delta^{18} O$ in precipitation (thick dashed red) and vapor (thick dashed blue) used as forcing are also shown. a-c: Le Bray, d-f: Yatir, g-i: Morgan-Monroe, j-l: Donaldson Forest, m-o: Anchorage. The normalized SWC (soil water content) is calculated as explained in section 3.1.1. 

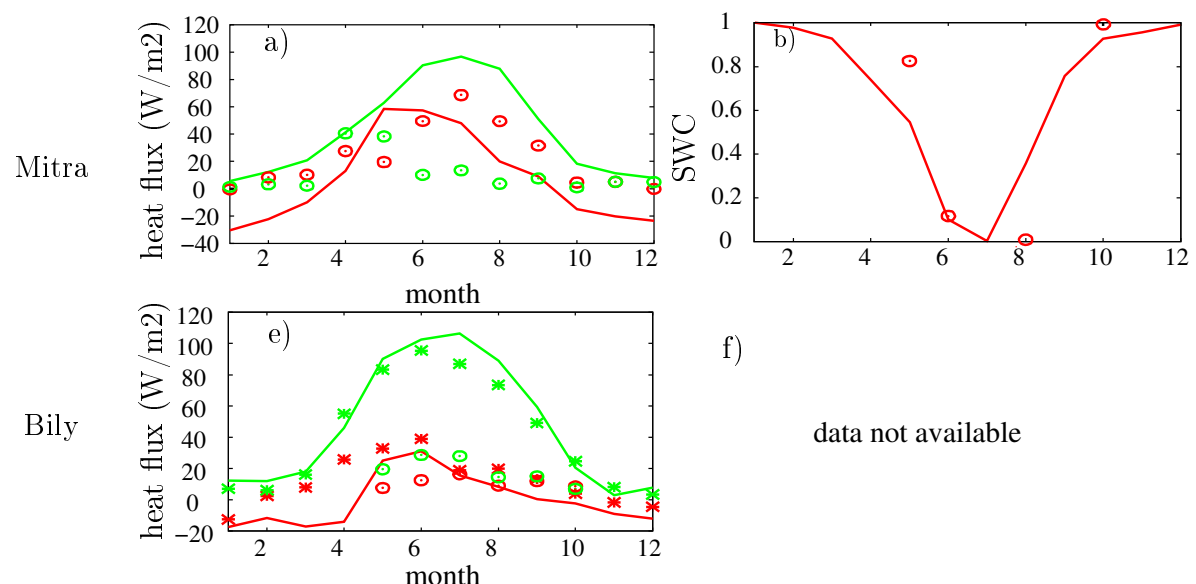

f)

data not available

Bily

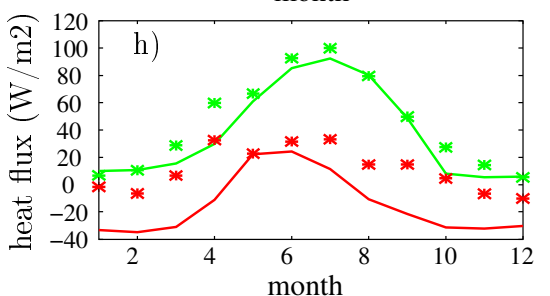

i)

data not available
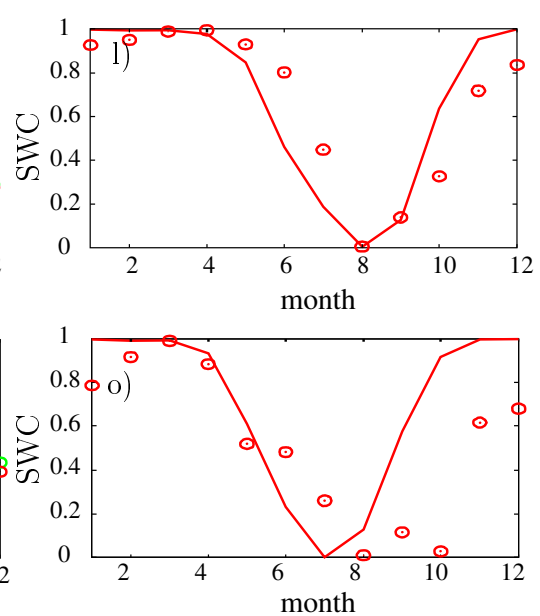

Key for latent flux plots - sensible
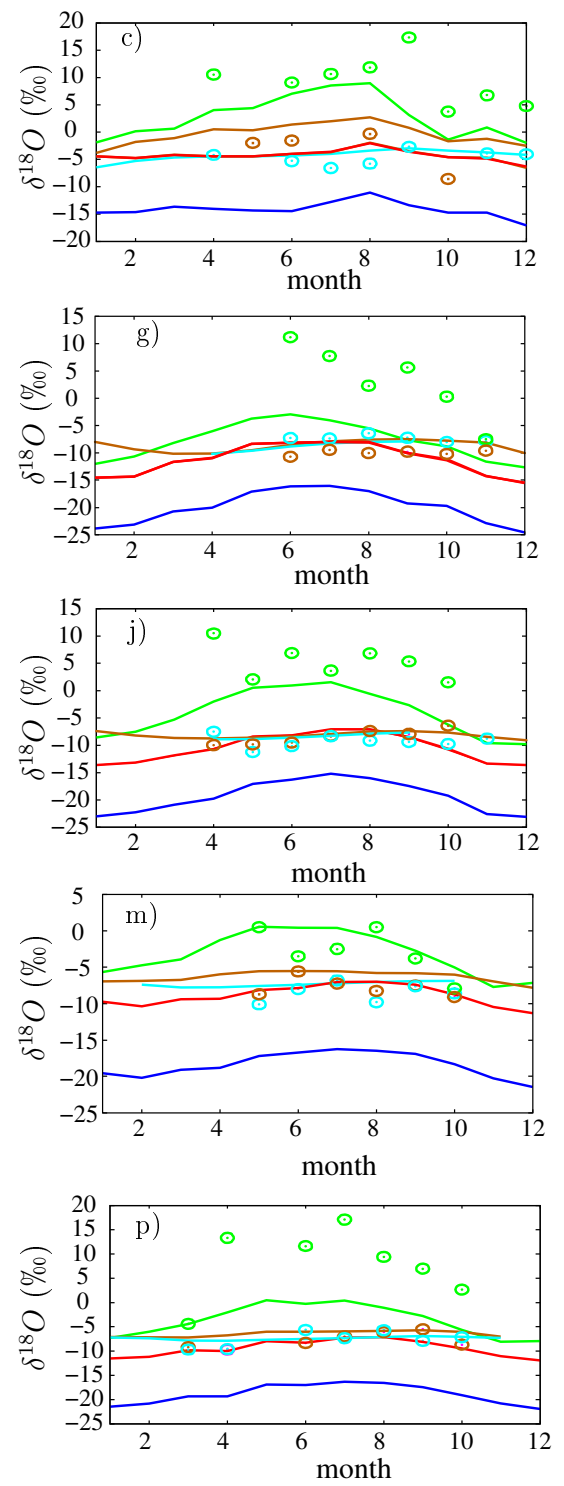

Key for $\delta^{18} O$ plots

- precip forcing

- vapor forcing

- soil water - leaf water

Figure E.4: Same as figure E.3 but for Mitra (a-c), Bily Kriz (d-f), Brloh (g-i), Hainich (j-l: Donaldson Forest), and Tharandt (m-o) 

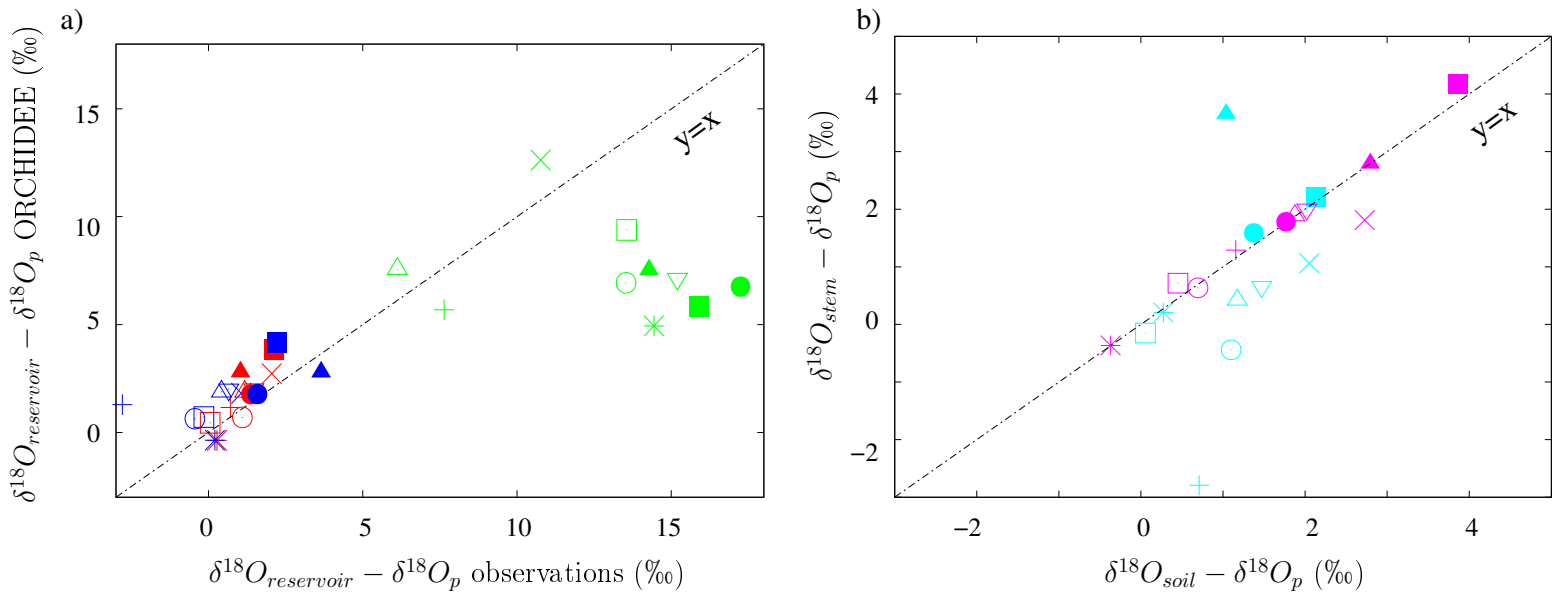

\begin{tabular}{|c|c|c|c|}
\hline \multicolumn{4}{|l|}{ Sites: } \\
\hline + LeBray & $\bigcirc$ Mitra & Water reservoir: & ORCHIDEE or observations: \\
\hline$X$ Yatir & $\Delta$ Bily & - Soil water & ORCHIDEE \\
\hline * DOFO & $\nabla$ Brloh & - Stem water & observations \\
\hline $\begin{array}{l}\square \text { MMSF } \\
\text { BFOA }\end{array}$ & $\begin{array}{l}\triangle \text { Hainich } \\
\text { - Tharandt }\end{array}$ & Leaf water & \\
\hline
\end{tabular}

Figure E.5: a) Relationship between simulated and observed annual-mean $\delta^{18} O$ in the soil water (red), stem water (blue) and leaf water (green), to which the precipitation-weighted annual-mean precipitation $\delta^{18} O$ is subtracted. In the case of perfect model-data agreement, markers should fall on the $\mathrm{y}=\mathrm{x}$ line. $\mathrm{b}$ ) Relationship between the annualmean $\delta^{18} O$ in the soil water and in stem water, to which the precipitation-weighted annual-mean precipitation $\delta^{18} O$ is subtracted, for both ORCHIDEE (magenta) and observations (cyan). When soil and stem water share the same $\delta^{18} O$, they fall on the $\mathrm{y}=\mathrm{x}$ line. 
Soil profiles on Le Bray, France

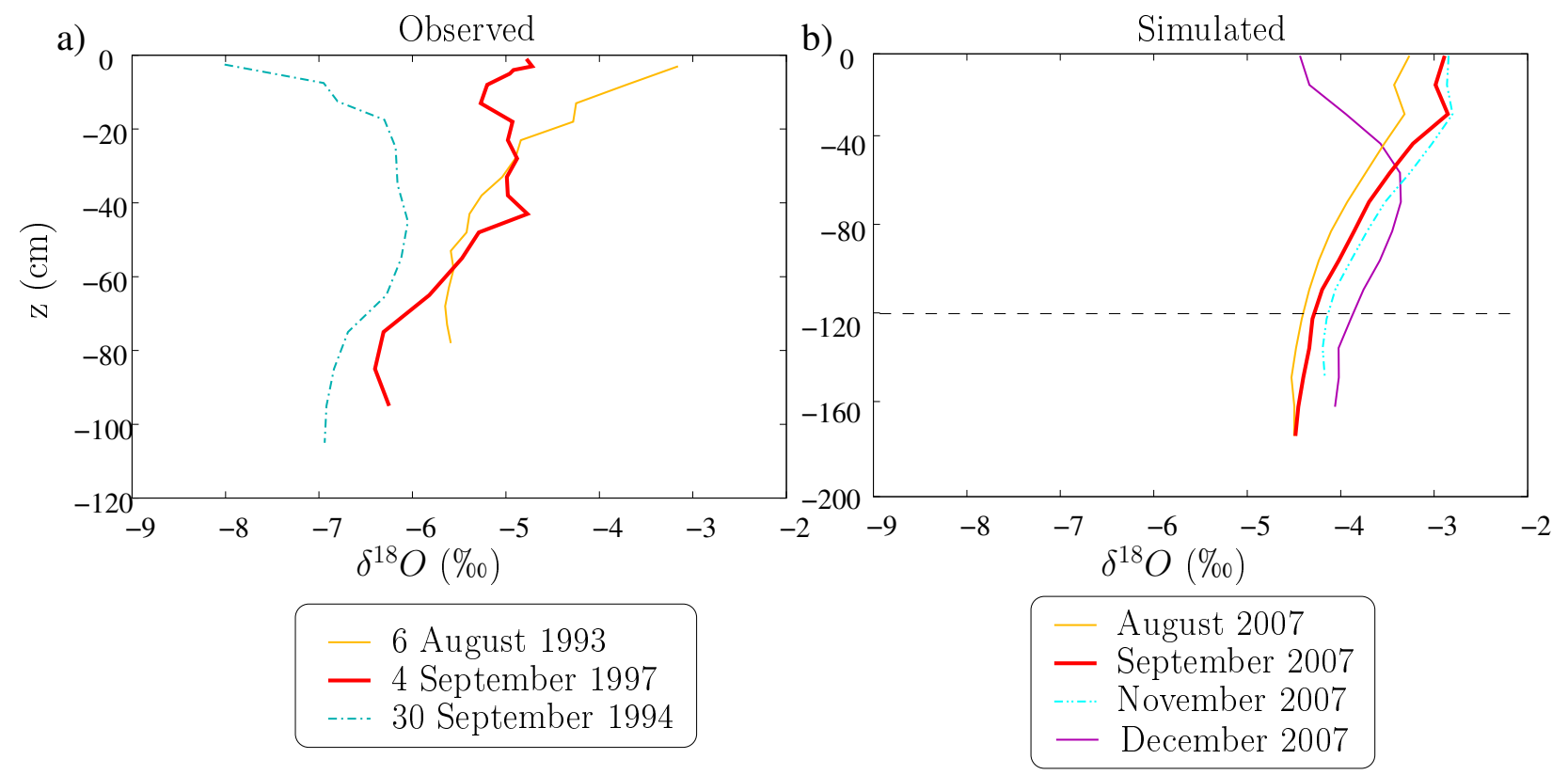

Soil profiles on Yatir, Israel
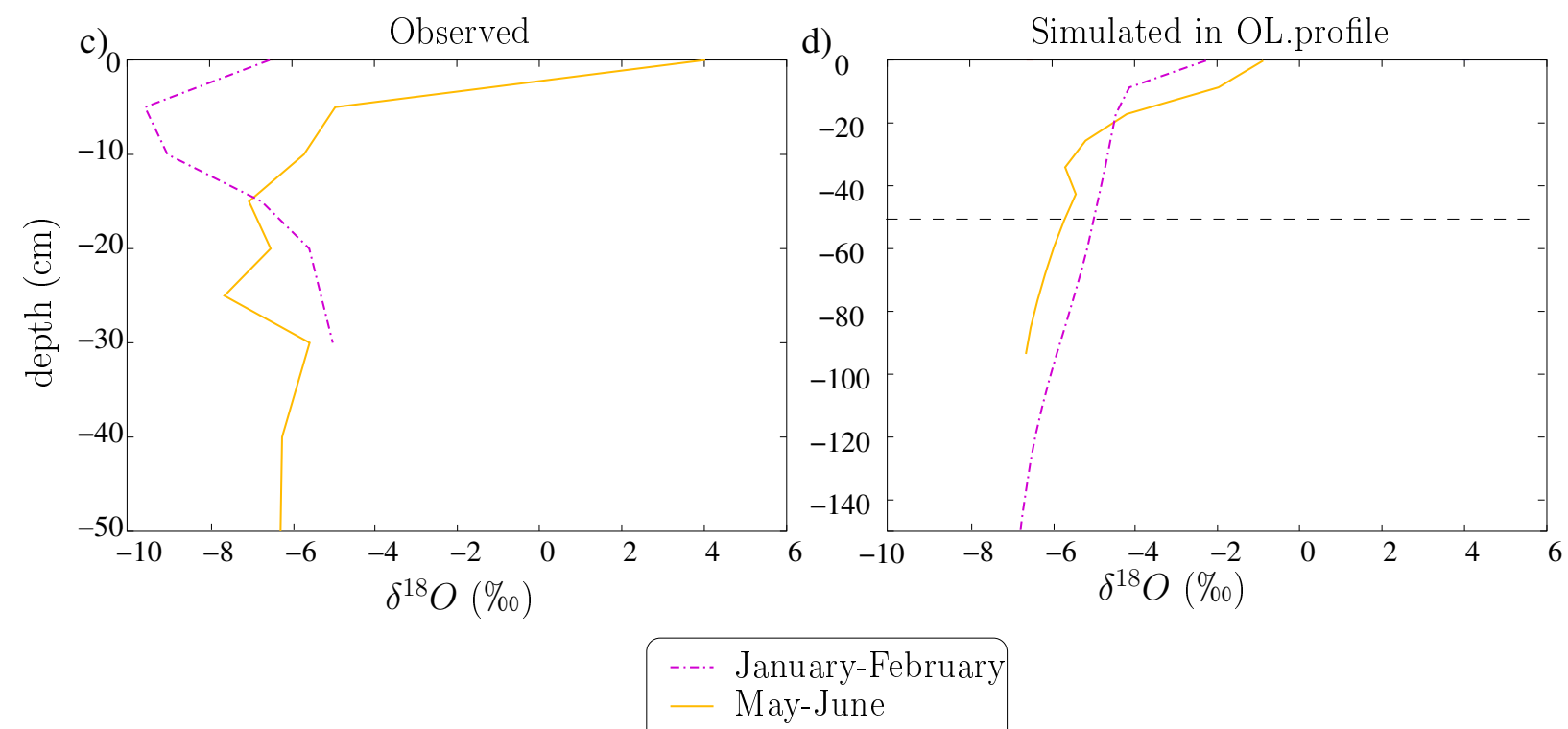

Figure E.6: Vertical profiles of soil $\delta^{18} O$ measured (a,c) and simulated by ORCHIDEE for the control offline simulations $(\mathrm{b}, \mathrm{d})$ on the Bray site $(\mathrm{a}, \mathrm{b})$ and the Yatir sites $(\mathrm{b}, \mathrm{d})$. Beware that the $\mathrm{y}$-scales for observations and simulations are different. This is because the representation of the soil water content is very rudimentary in the ORCHIDEE model, preventing any quantitative comparison of measured and simulated soil depth. The horizontal black dashed line represents the bottom of the observed profiles. Model outputs are sampled at the same time as the data. For the Yatir sites, frequent soil sampling for the same year allowed us plot representative bi-monthly averages for both measured and simulated profiles. This could not be the case for Le Bray. Some soil profiles were observed at Le Bray in 2007, but we do not show them because they are limited to the top $24 \mathrm{~cm}$ of the soil only. 


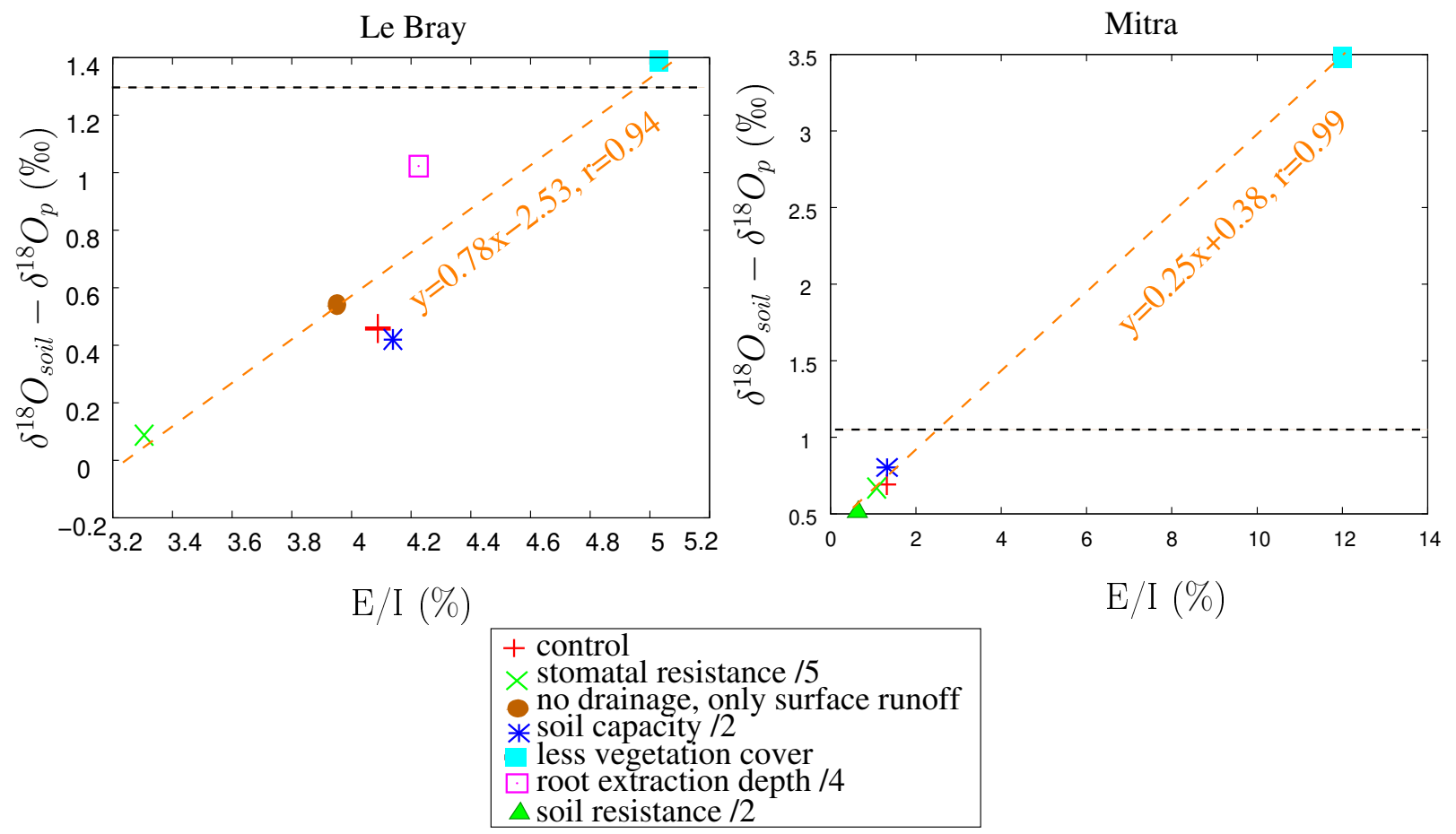

Figure E.7: Isotopic difference between soil water and precipitation $\left(\delta^{18} O_{s}-\delta^{18} O_{p}\right)$, as a function of $E / I$ (fraction of the infiltrated water that evaporates at the bare soil surface), for different sensitivity tests in ORCHIDEE. a) at Le Bray and b) at Mitra. All values are annual means. The horizontal dashed line represents the observed values for $\delta^{18} O_{s}-\delta^{18} O_{p}$. The orange dashed line shows the best linear fit between the different sensitivity tests.
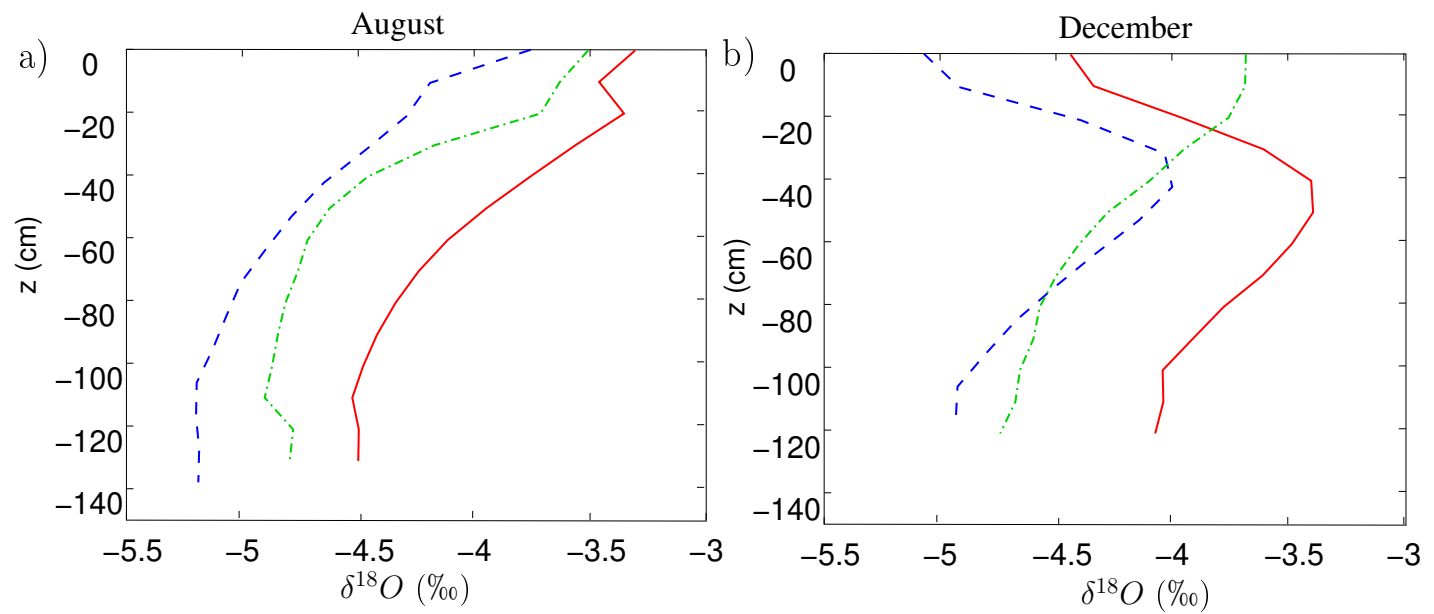

$$
\begin{array}{ll}
- & \theta_{l} \cdot \tau=0.1, \text { piston-like infiltration } \\
-\cdots \cdot & \theta_{l} \cdot \tau=0.01, \text { piston-like infiltration } \\
\cdots & \theta_{l} \cdot \tau=0.1, \text { preferential pathways infiltration }
\end{array}
$$

Figure E.8: Sensitivity of simulated $\delta^{18} O_{s}$ profiles to the parameterization of infiltration processes in the soil at Le Bray. July (a) and December (b) are shown for three different parameterizations in offline simulations: control simulation (solid red), a simulation in which the soil water diffusivity was divided by 10 (dashed blue) and a simulation is which the water infiltrates the soil uniformly in the vertical (crude representation of preferential pathways, dash-dotted green) rather than in a piston-like way as is the case for other simulations. 

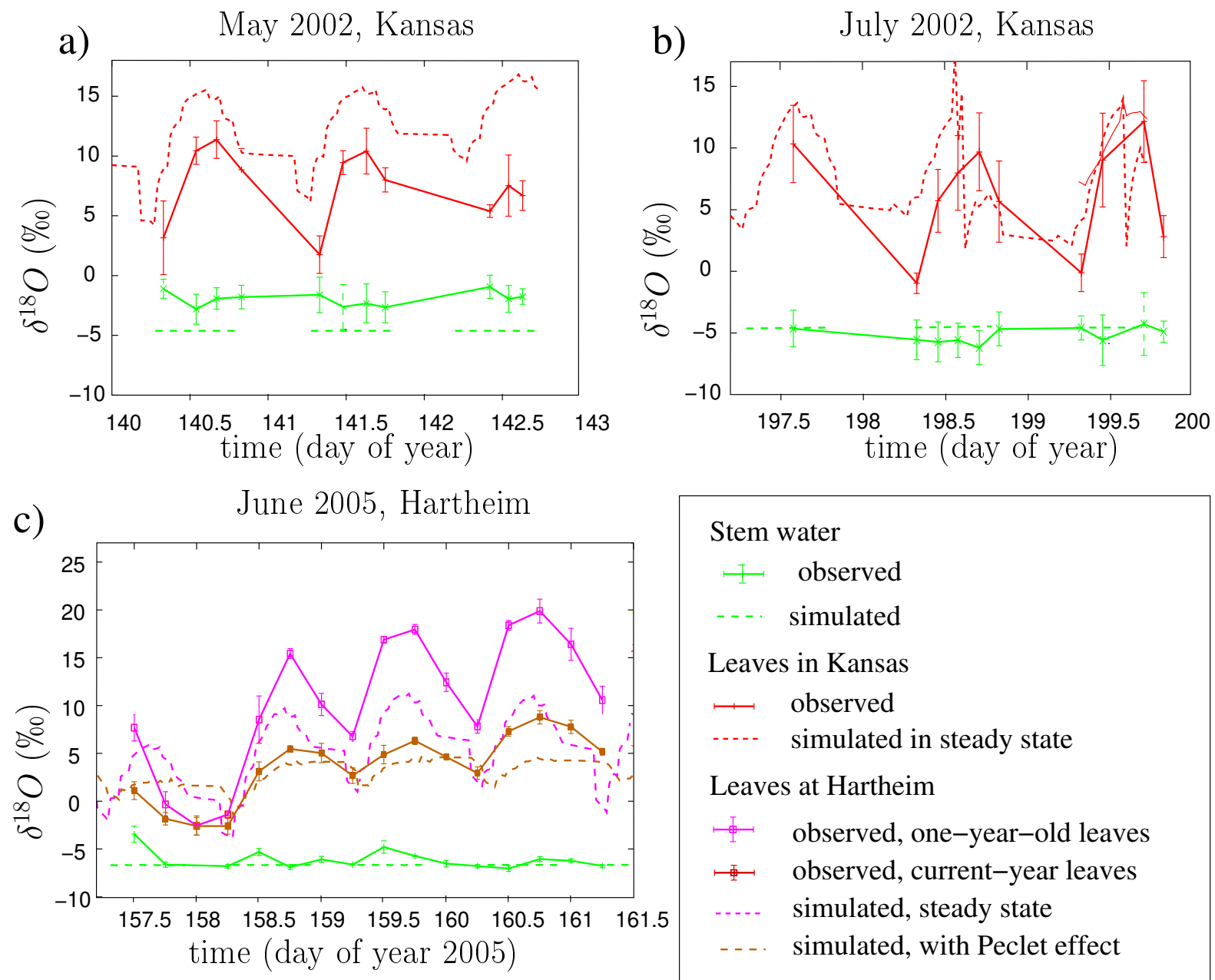

\section{Stem water \\ 1 observed \\ - . . simulated \\ Leaves in Kansas \\ — observed \\ -..-- simulated in steady state}

Leaves at Hartheim

I observed, one-year-old leaves

observed, current-year leaves

.... simulated, steady state

. . . simulated, with Peclet effect

Figure E.9: a-b) $\delta^{18} O$ of stem and grass leaves measured during two series of 3 diurnal cycles in May and July 2002 over the plains of Kansas ([Lai et al., 2006b]) and simulated by LMDZ-ORCHIDEE for the same year in the grid box containing the observation site. c) a) $\delta^{18} O$ of vapor (blue), pine leaves (pink and red) and stems (green) measured during four diurnal cycles in June 2005 in Hartheim, Germany ([Barnard et al., 2007]) and simulated by LMDZ-ORCHIDEE for the same year in the grid box containing the observation site. Simulated values are dashed, observed values solid. Two kinds of leaves were sampled during this campaign: one-year-old leaves (solid pink) and current-year leaves (solid brown). Two leaf water diagnostics were computed for in LMDZ-ORCHIDEE: stationary state at the evaporative site (dashed red, equation B.6) or non-stationary state in the lamina, taking into account the Peclet effect (dashed brown, equation B.8, using an effective length scale of $25 \mathrm{~mm}$ ). 

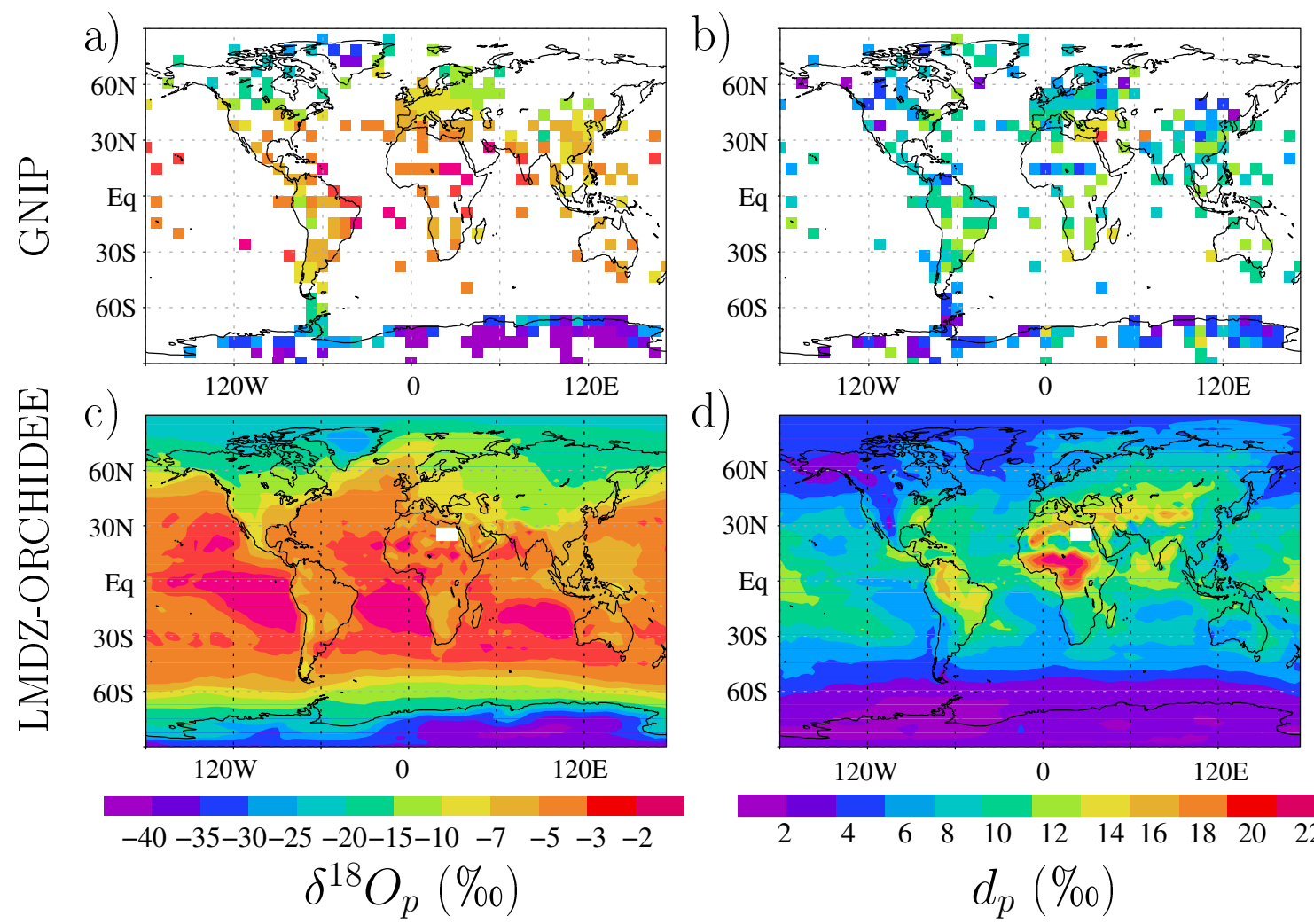

d)

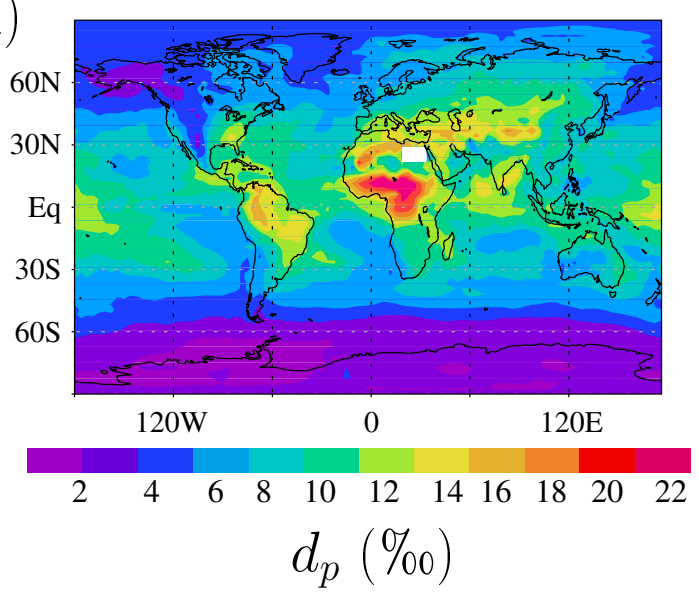

Figure E.10: a) Annual mean $\delta^{18} O_{p}$ from GNIP ([Rozanski et al., 1993]), Antarctica ([Masson-Delmotte et al., 2008]) and Greenland ([Masson-Delmotte et al., 2005]) data. The data is gridded over a coarse $7.5 \times 6.5^{\circ}$ grid for visualization purposes. b) Same as a) but for annual mean $d_{p}$. c) Annual mean $\delta^{18} O_{p}$ simulated by coupled LMDZ-ORCHIDEE model for the control simulation. d) same as c) but for annual mean $d_{p}$.

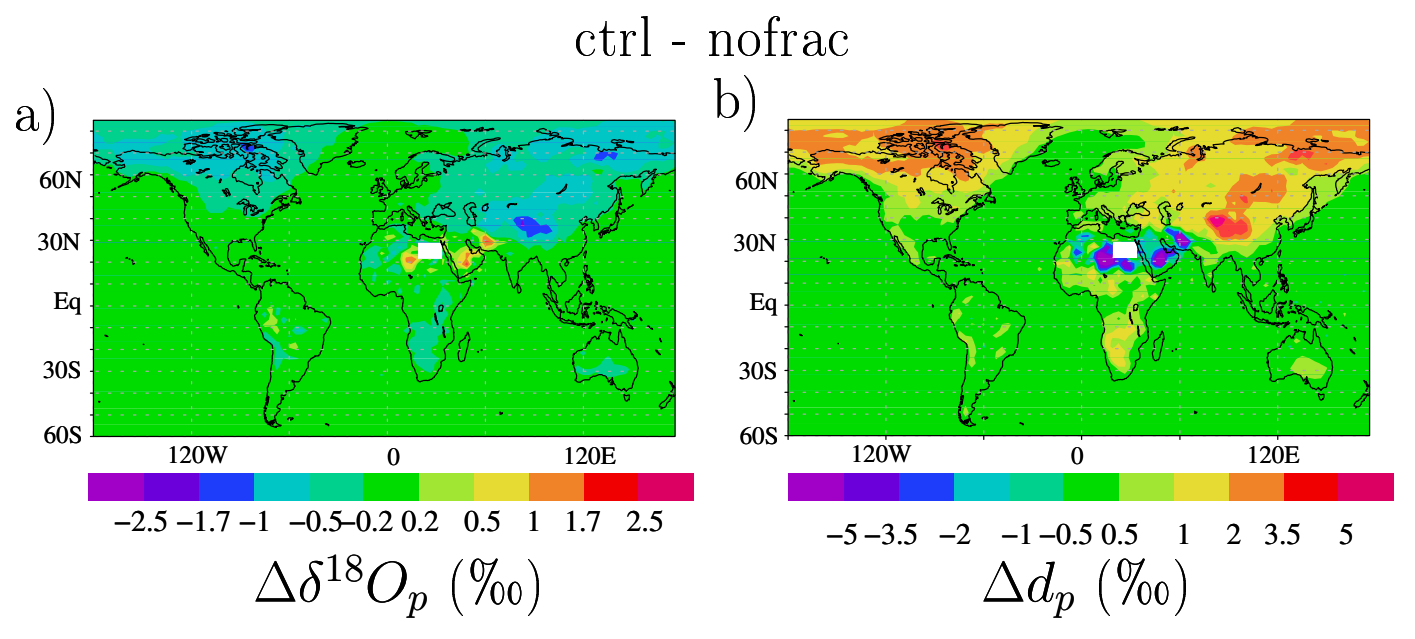

Figure E.11: a) Annual-mean $\delta^{18} O_{p}$ in the ctrl simulation (LMDZ-ORCHIDEE) minus annual mean $\delta^{18} O_{p}$ in the nofrac simulation (LMDZ-ORCHIDEE in which the isotopic fractionation was de-activated during bare soil evaporation). This shows the effect of isotopic fractionation at the soil surface on $\delta^{18} O_{p}$. b) Same as a) but for $d_{p}$. 

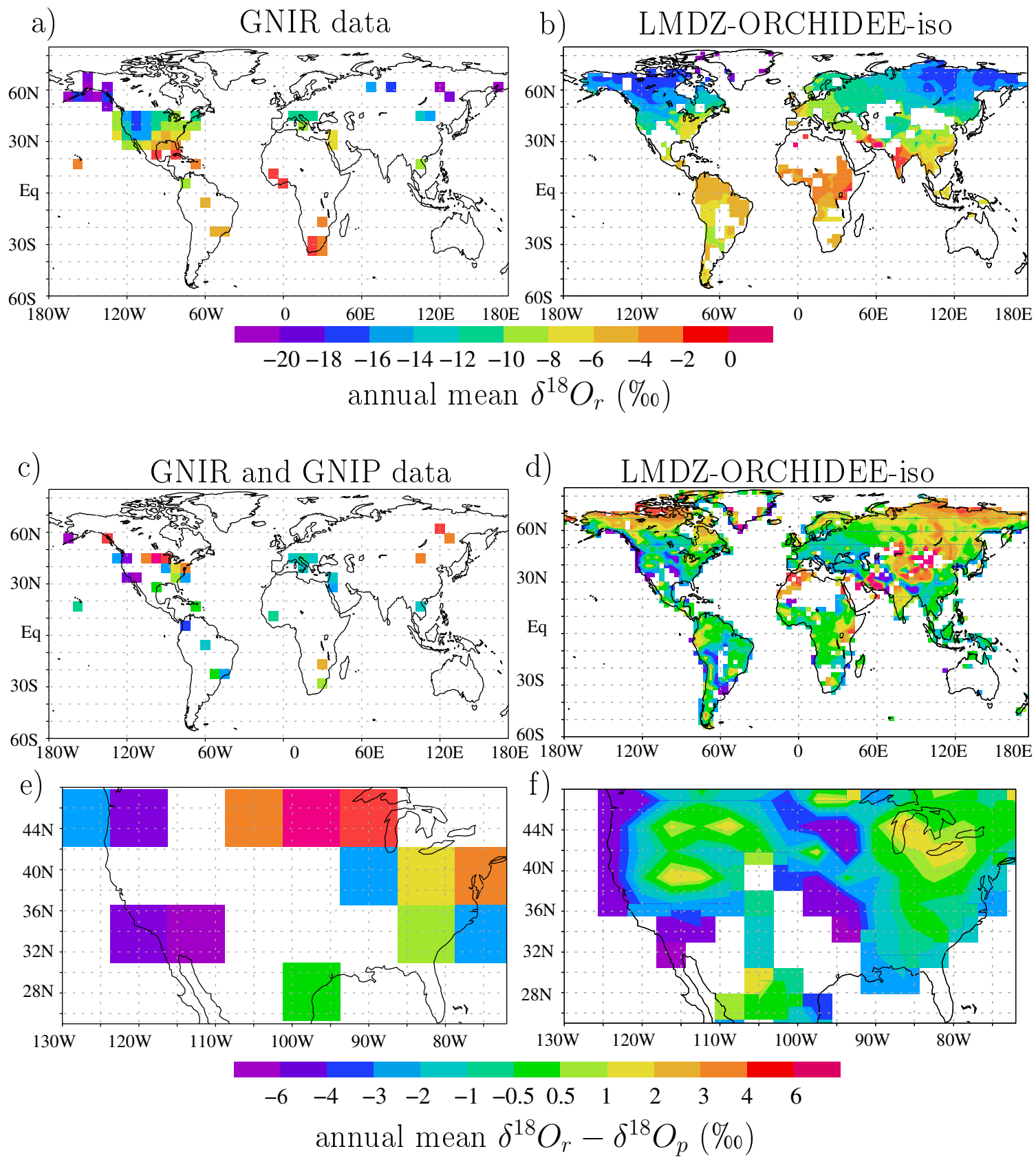

Figure E.12: Annual mean $\delta^{18} O$ in rivers $\left(\delta^{18} O_{\text {river }}\right)$ measured from the GNIR database (a) and simulated by LMDZ-ORCHIDEE for the control simulation (b). Annual mean $\delta^{18} O_{\text {river }}-\delta^{18} O_{p}$ observed from the GNIR and GNIP databases (c,e) and simulated by LMDZ-ORCHIDEE for the control simulation (d,f). On sub-plots $d$ and $f$ the United States, where the GNIR network is the densest, are enlarged for better readability. 

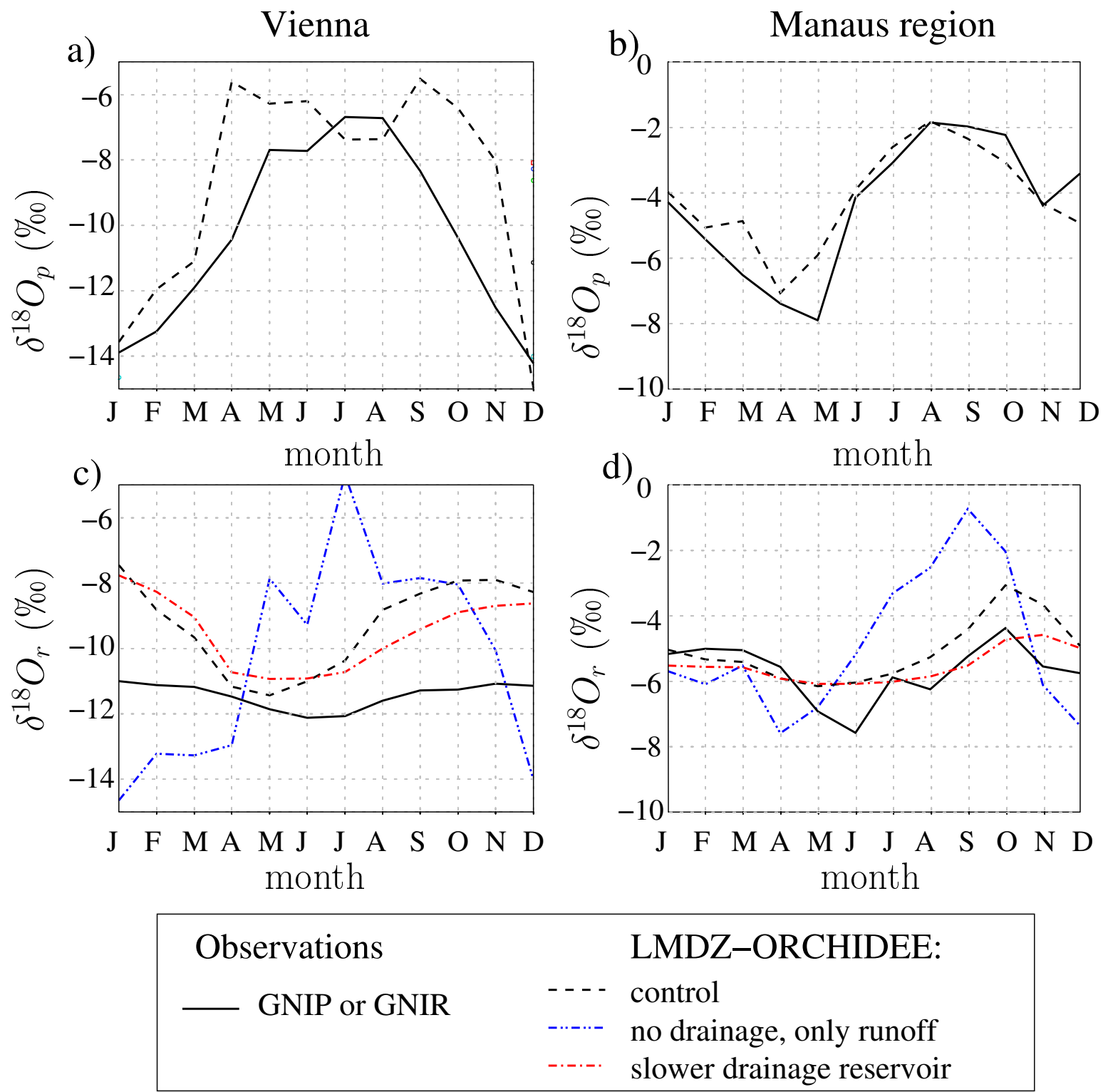

Figure E.13: Seasonal variations in $\delta^{18} O_{p}(\mathrm{a}, \mathrm{b})$ and $\delta^{18} O_{\text {river }}(\mathrm{c}, \mathrm{d})$ observed (solid black) and simulated for the control LMDZ-ORCHIDEE simulation (dashed black) for (a,c) the Danube river in Vienna and (b,d) the Amazon river in the Manaus region (average over the $8^{\circ} \mathrm{S}-3^{\circ} \mathrm{S}-56^{\circ} \mathrm{W} 63^{\circ} \mathrm{W}$ domain). Also shown are $\delta^{18} O_{\text {river }}$ for simulations where the total runoff is partitioned into surface runoff only without drainage (dash-dotted blue) and where we multiplied by two the time residence in the reservoir collecting drainage in the routing scheme (dash-dotted red). Beware that the y-scale is different on the two sites. The difference in the annual-mean values between the two sites reflect the difference in the annual-mean $\delta^{18} O_{p}$. 


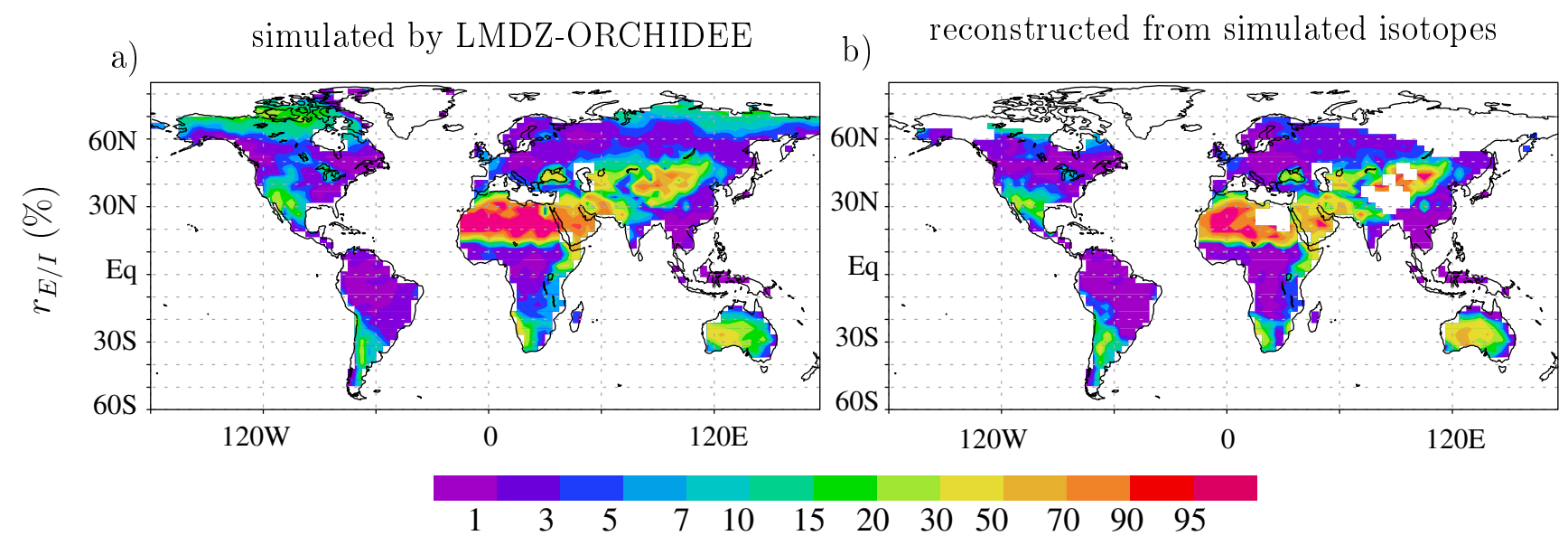

Figure E.14: a): annual mean $E / I$ (proportion of infiltrating water recycled back to the atmosphere as bare soil evaporation) simulated by LMDZ-ORCHIDEE for the control simulation. b) $E / I$ estimated from water isotopes measurements as described in section 3.5.1. We perform the estimations only on grid points where the denominators in the equation are different from 0 and where the soil water contents and the water fluxes whose compositions we need are strictly positive. Grid points where estimations cannot be performed are left white. 
a)

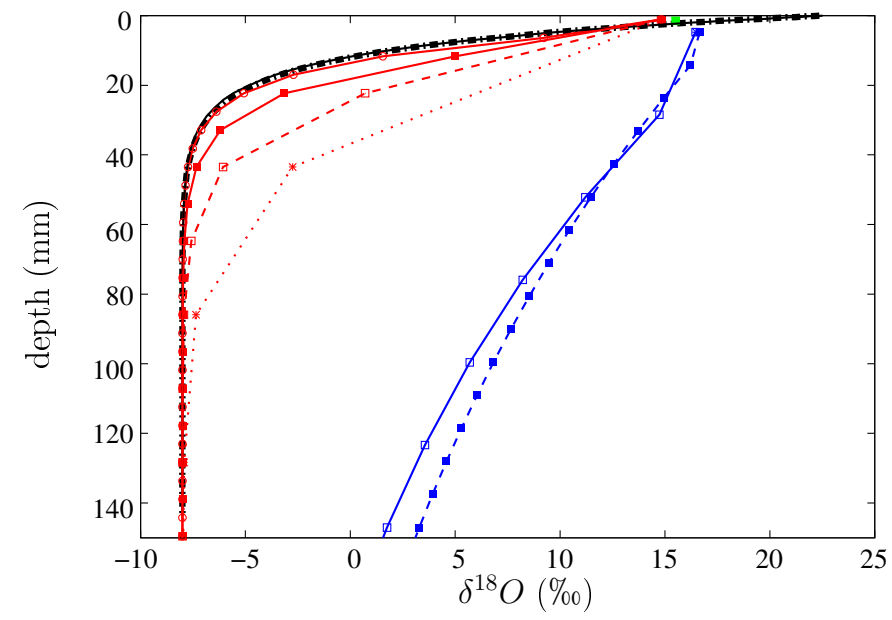

$$
\begin{aligned}
& -\begin{array}{l}
\text { MuSICA model } \\
\text { analytical solution }
\end{array} \\
& \text { ORCHIDEE simulations } \\
& \cdots \cdots \theta_{l} \cdot \tau=0.005, \text { resol }=40 \\
& -\because-\theta_{l} \cdot \tau=0.005, \text { resol }=20 \\
& --\theta_{l} \cdot \tau=0.005, \text { resol }=10 \\
& -\theta_{l} \cdot \tau=0.005, \text { resol }=5 \\
& --\theta_{l} \cdot \tau=0.1, \text { resol }=5 \\
& \rightarrow-\theta_{l} \cdot \tau=0.1, \text { resol }=2
\end{aligned}
$$

b) Test 1 of Braud et al 2005

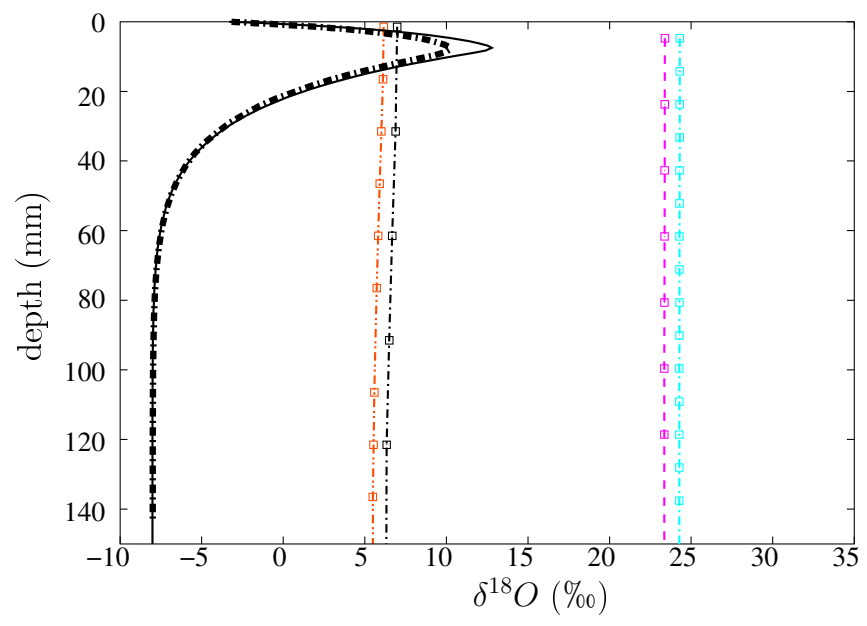

$$
\begin{aligned}
& -\cdots \text { MuSICA model } \\
& \text { ORCHIDEA simulations } \\
& -\because \cdots \theta_{l} \cdot \tau=0.01, \text { resol }=10 \\
& -\bullet \cdot-\theta_{l} \cdot \tau=0.01, \text { resol=20 } \\
& -\bullet \cdot-\theta_{l} \cdot \tau=0.1, \text { resol }=2 \\
& -\bullet-\theta_{l} \cdot \tau=0.1, \text { resol }=5
\end{aligned}
$$

Figure E.15: Vertical profile of soil water $\delta^{18} O$ in idealized cases described by [Braud et al., 2005]. a) The soil column evaporates at its top and is permanently refilled at the bottom by a water with $\delta^{18} O=-8 \%$. b) The soil column is evaporated progressively until its soil water content is only $20 \%$. See appendix C.2 for more details. Simulations using the soil profile module of the isotopic version of ORCHIDEE (colors) with different parameters and vertical resolution are compared with the more sophisticated MuSICA and SiSPAT models and with an analytical solution. For $\theta_{l} \cdot \tau=0.005$, the vertical resolution for ORCHIDEE is $0.15 \mathrm{~mm}$ for the first layer and $0.75 \mathrm{~mm}$ $\left(\right.$ resol=5), $1.5 \mathrm{~mm}\left(\right.$ resol=10), $3 \mathrm{~mm}(\mathrm{resol}=20)$ or $6 \mathrm{~mm}\left(\right.$ resol=40) for the other layers. For $\theta_{l} \cdot \tau=0.01$, the vertical resolution for ORCHIDEE is $0.21 \mathrm{~mm}$ for the first layer and $2.12 \mathrm{~mm}$ (resol=10) or $4.24 \mathrm{~mm}$ (resol=20) for the other layers. For $\theta_{l} \cdot \tau=0.1$, the vertical resolution for ORCHIDEE is $0.67 \mathrm{~mm}$ for the first layer and from $1.34 \mathrm{~mm}($ resol=2) to $3.35 \mathrm{~mm}($ resol=5) for the other layers. 


\begin{tabular}{|c|c|c|c|c|c|}
\hline Site name & Country & Location & Network & Years & Reference \\
\hline \hline Le Bray & France & $44.70^{\circ} \mathrm{N}$, & MIBA, & $2007-2008$ & [Wingate et al., 2009] \\
& & $00.77^{\circ} \mathrm{W}$ & Carbo-Euroe & & \\
\hline Yatir & Israel & $31.33^{\circ} \mathrm{N}$, & MIBA, & $2004-2005$ & [Raz-Yaseef et al., 2009, \\
& & $35.0^{\circ} \mathrm{E}$ & Carbo-Euroe & & Raz-Yaseef et al., 2012] \\
\hline Morgan- & United States & $39.32^{\circ} \mathrm{N}$, & MIBA-US & $2005-2006$ & [Schmid et al., 2000, \\
Monroe & & $86.42^{\circ} \mathrm{W}$ & & & Dragoni et al., 2011] \\
\hline Donaldson & United States & $29.8^{\circ} \mathrm{N}$, & MIBA-US & $2005-2006$ & [Gholz and Clark, 2002, \\
Forest & & $82.163^{\circ} \mathrm{W}$ & & & Zhang et al., 2010] \\
\hline Anchorage & United States & $61.2^{\circ} \mathrm{N}$, & MIBA-US & $2005-2006$ & - \\
& & $149.82^{\circ} \mathrm{W}$ & & & [Kurz-Besson et al., 2006] \\
\hline Mitra & Portugal & $38.54^{\circ} \mathrm{N}$, & Carbo-Euroe & $2001-2002$ & [Kratochvilová et al., 1989] \\
& & $8.00^{\circ} \mathrm{W}$ & & & [Voelker et al., 2014] \\
\hline Bily Kriz & Czech & $49.5^{\circ} \mathrm{N}$, & MIBA, & 2005 & [Knohl et al., 2003] \\
& Republic & $18.53^{\circ} \mathrm{E}$ & Carbo-Euroe & & \\
\hline Brloh & Czech & $49.80^{\circ} \mathrm{N}$, & MIBA & $2004-2010$ & \\
& Republic & $14.66^{\circ} \mathrm{E}$ & & & \\
\hline Hainich & Germany & $50.97^{\circ} \mathrm{N}$, & Carbo-Euroe & $2001-2002$ & \\
& & $13.57^{\circ} \mathrm{E}$ & & & \\
\hline Tharandt & Germany & $51.08^{\circ} \mathrm{N}$, & Carbo-Euroe & $2001-2002$ & \\
& & $10.47^{\circ} \mathrm{E}$ & & & \\
\hline
\end{tabular}

Table 1: Information on the 10 sites used in this study: geographical location, network the sites are part of, years during which the istopic measurements were made and are used in this study, reference.

\begin{tabular}{|c|c|c|c|c|c|}
\hline Site name & Biome & Dominant Species & $\begin{array}{c}\text { Annual-mean } \\
\text { temperature } \\
\left({ }^{\circ} \mathrm{C}\right)\end{array}$ & $\begin{array}{c}\text { Annual-mean } \\
\text { precipitation } \\
\text { (mm/year) }\end{array}$ & $\begin{array}{l}\text { Elevation } \\
\quad(\mathrm{m})\end{array}$ \\
\hline Le Bray & $\begin{array}{c}\text { Temporate coniferous } \\
\text { forest }\end{array}$ & Maritime pine & $\overline{12.0}$ & 1022 & $\overline{260}$ \\
\hline Yatir & semi-arid forest & Aleppo pine & 15.3 & 270 & 650 \\
\hline $\begin{array}{l}\text { Morgan- } \\
\text { Monroe }\end{array}$ & $\begin{array}{c}\text { Temperate deciduous } \\
\text { forest }\end{array}$ & Liriodendron tulipifera & 12.4 & 1094 & 275 \\
\hline $\begin{array}{c}\text { Donaldson } \\
\text { Forest }\end{array}$ & Tropical pine plantation & Pinus palustris & 21.7 & 1330 & 50 \\
\hline Anchorage & Boreal coniferous forest & Picea glauca & 2.3 & 408 & 35 \\
\hline Mitra & Mediteranean forest & $\begin{array}{c}\text { Sparse holm oak trees } \\
\text { with patches of cork } \\
\text { trees }\end{array}$ & 13.9 & 480 & 230 \\
\hline Bily Kriz & $\begin{array}{l}\text { Temperate coniferous } \\
\text { forest }\end{array}$ & Pine forest & 3.4 & 1024 & 936 \\
\hline Brloh & $\begin{array}{l}\text { Temperate deciduous } \\
\text { forest }\end{array}$ & Beech forest & 7.6 & 832 & 630 \\
\hline Hainich & $\begin{array}{l}\text { Temperate deciduous } \\
\text { forest }\end{array}$ & Fagus Sylvatica & 8.0 & 800 & 440 \\
\hline Tharandt & $\begin{array}{l}\text { Temperate deciduous } \\
\text { forest }\end{array}$ & Pine forest & 8.1 & 1000 & 380 \\
\hline
\end{tabular}

Table 2: Vegetation and climtological information on the 10 sites used in this study: biome, dominant species, annual-mean temperature and precipitation, elevation. 


\begin{tabular}{|c|c|c|c|c|}
\hline Site name & Prescribed vegetation in ORCHIDEE & $\begin{array}{l}\text { Meteoro- } \\
\text {-logical } \\
\text { forcing }\end{array}$ & $\begin{array}{c}\text { Isotopic } \\
\text { forcing for } \\
\text { precipitation } \\
\text { and vapor }\end{array}$ & $\begin{array}{c}\text { local, GNIP, USNIP or Carbo-Europe } \\
\text { stations used to calculate isotopic } \\
\text { forcing }\end{array}$ \\
\hline Le Bray & $\begin{array}{l}\text { 70\% temperate needleleaf evergreen } \\
(\mathrm{LAI}=0.4) \\
30 \% \mathrm{C} 3 \text { grass }(\mathrm{LAI}=0.4)\end{array}$ & obs & obs_iso & $\begin{array}{l}\text { Le Bray local data for both } \\
\text { precipitation and water vapor }\end{array}$ \\
\hline Yatir & $\begin{array}{l}100 \% \text { temperate needleleaf evergreen } \\
\qquad(\mathrm{LAI}=4)\end{array}$ & obs & obs_iso & $\begin{array}{c}\text { Rehovot for water vapor and Beit } \\
\text { Dagan GNIP station for precipitation }\end{array}$ \\
\hline $\begin{array}{l}\text { Morgan- } \\
\text { Monroe }\end{array}$ & $\begin{array}{l}100 \% \text { temperate broad-leaved } \\
\text { summergreen }(\mathrm{LAI}=4.5)\end{array}$ & obs_ERA & NIP_LMDZ & $\begin{array}{l}\text { USNIP_IN22, USNIP_KY03 } \\
\end{array}$ \\
\hline $\begin{array}{l}\text { Donaldson } \\
\text { Forest }\end{array}$ & $\begin{array}{l}100 \% \text { temperate needleleaf evergreen } \\
\qquad(\mathrm{LAI}=2.85)\end{array}$ & obs_ERA & NIP_LMDZ & USNIP_FL14, USNIP_FL99 \\
\hline Anchorage & $\begin{array}{c}40 \% \text { boreal needle-leaved evergreen } \\
(\mathrm{LAI}=4), 60 \% \text { boreal broad-leaved } \\
\text { summergreen }(\mathrm{LAI}=4.5)\end{array}$ & ERA & NIP_LMDZ & $\begin{array}{c}\text { Bethel, USNIP_SOGR_10, } \\
\text { USNIP_CA45 }\end{array}$ \\
\hline Mitra & $\begin{array}{l}50 \% \text { temperate broad-leaved evergreen } \\
(\mathrm{LAI}=2), 50 \% \mathrm{C} 3 \text { grass }(\mathrm{LAI}=0.4)\end{array}$ & obs_ERA & NIP_LMDZ & $\begin{array}{l}\text { Beja, Faro, Penhas, Mitra, } \\
\text { Portoallegre }\end{array}$ \\
\hline Bily Kriz & $\begin{array}{l}100 \% \text { temperate needleleaf evergreen } \\
\qquad(\mathrm{LAI}=7.5)\end{array}$ & obs_ERA & NIP_LMDZ & $\begin{array}{l}\text { Vienna, Podersdorf, Apetlon, } \\
\text { Liptovsky, Krakow }\end{array}$ \\
\hline Brloh & $\begin{array}{l}100 \% \text { temperate broad-leaved } \\
\text { summergreen }(\mathrm{LAI}=4.5)\end{array}$ & ERA & NIP_LMDZ & $\begin{array}{l}\text { Leipzig, Hohhohensaas, Regensburg, } \\
\text { Vienna, Petzenkirchen }\end{array}$ \\
\hline Hainich & $\begin{array}{c}80 \% \text { temperate broad-leaved } \\
\text { summergreen }(\mathrm{LAI}=4.5), 20 \% \text { C3 grass } \\
(\mathrm{LAI}=0.4)\end{array}$ & obs_ERA & NIP_LMDZ & $\begin{array}{c}\text { Leipzig, Hohhohensaas, Braunschweig, } \\
\text { BadSalzuflen, Wuerzburg, } \\
\text { Wasserkuppe }\end{array}$ \\
\hline Tharandt & $\begin{array}{c}80 \% \text { temperate needleleaf evergreen } \\
(\mathrm{LAI}=4), 20 \% \mathrm{C} 3 \text { grass }(\mathrm{LAI}=0.4)\end{array}$ & obs_ERA & NIP_LMDZ & $\begin{array}{c}\text { Leipzig, Berlin, Hohhohensaas, } \\
\text { Regensburg }\end{array}$ \\
\hline
\end{tabular}

Table 3: Information on the offline simulations performed on the 10 sites listed in table 1: meteorological forcing $(6$ hourly observations of temperature, humidity, winds, precipitation and radiative fluxes), isotopic forcing (monthly isotopic composition of the precipitation and near-surface water vapor), and prescribed vegetation type and LAI (leaf area index) properties. We give proportions (in \%) of the total vegetated area, excluding bare soil. For example, if a given vegetation type covers $100 \%$ of the vegetated area and the bare soil fraction is $30 \%$, then the vegetation type covers only $70 \%$ of the total area. Three kinds of meteorological forcing are possible: meteorological observations only (obs), meteorological observations filled with ERA-Interim for missing variables (obs_ERA) or ERA-Interim (ERA). Two kinds of isotopic forcing are possible: isotopic composition of precipitation and water vapor observed on the site (obs_iso), or interpolation between GNIP, USNIP or Carbo-Europe stations using the LMDZ atmospheric general circulation model. In the former case, the datasets used for prescribing the water vapor and precipitation isotopic composition forcing are mentionned. In the latter case, GNIP, USNIP or Carbo-Europe stations used to construct the interpolated precipitation isotopic composition forcing are listed. See section 3.2 and appendix D for more details. 


\begin{tabular}{|c|c|c|}
\hline Absolute or relative error & RMS absolute error on $r_{E / I}$ & $\begin{array}{c}\text { RMS relative error on } r_{E / I}, \\
\text { when } r_{E / I}>4 \%(37 \% \text { of total } \\
\text { land aread) }\end{array}$ \\
\hline soil profiles & $12 \%$ & $50 \%$ \\
\hline$\Delta T=1{ }^{\circ} C$ & $0.2 \%$ & $1 \%$ \\
\hline$\Delta r h=1 \%$ & $0.5 \%$ & $1 \%$ \\
\hline$\Delta \delta_{p}=1 \% 0$ & $3 \%$ & $35 \%$ \\
\hline$\Delta \delta_{v}=1 \% 0$ & $1 \%$ & $8 \%$ \\
\hline$\Delta \delta_{s}=1 \% 0$ & $5 \%$ & $49 \%$ \\
\hline$\Delta n=0.5$ & $14 \%$ & $52 \%$ \\
\hline
\end{tabular}

Table 4: Uncertainties in the estimation of $E / I$ related to measurement errors and assumptions necessary in the simple conceptual model (appendix E). Values give absolute (in ratio) and relative variations (in \%) in estimated $E / I$ when temperature $T$ is modified by $1^{\circ} \mathrm{C}$ (line 4 ), when relative humidity $r h$ is modified by $1 \%$ (line 5 ), when $\delta^{18} O_{v}, \delta^{18} O_{p}$ and $\delta^{18} O_{s}$ are modified by $1 \%$ (lines 6 to 9 ), when $n$ in the kinetic fractionation is varied from 0.5 to 1 (line 7 ), and when the soil $\delta^{18} O$ is not homogeneous vertically (line 10). The resulting variations in estimated $E / I$ are averaged over all land grid points where the estimation could be performed. 